GCR 06-899

\title{
Measuring ATP Impact: 2006 Report on Economic Progress
}

Prepared for

Economic Assessment Office

Advanced Technology Program

National Institute of Standards and Technology

Gaithersburg, MD 20899-4710

By

AKOYA

2325 East Carson Street

Pittsburgh, PA 15203-2109

Contract SB1341-06-8-0208

August 2006

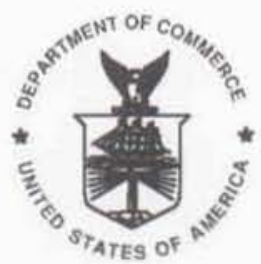

U.S. DEPARTMENT OF COMMERCE

Carlos M. Gutierrez, Secretary TECHNOLOGY ADMINISTRATION

Robert Cresanti, Under Secretary for Technology NATIONAL INSTITUTE OF STANDARDS AND TECHNOLOGY William Jeffrey, Director ADVANCED TECHNOLOGY PROGRAM Marc G. Stanley, Director 


\section{ATP Mission}

To accelerate the development of innovative technologies for broad national benefit through partnerships with the private sector.

\section{Mission Specifications}

- Add to the nation's scientific and technical knowledge base

- Foster expanded/accelerated technology development and commercialization by U.S. firms

- Promote collaborative R\&D

- Refine manufacturing processes

- Ensure appropriate small business participation

- Increase competitiveness of U.S. firms

- Generate broadly based benefits

\section{Operational Mechanisms} and Features

- Cooperative agreements with industry for industry-led, costshared research

- Focus on high-risk research to develop enabling technologies

- Competitive selection of projects using peer review and published criteria

- Sunset provisions for all funded projects

- Requirement that all projects have well-defined goals and identified pathways to technical and economic impacts

- Reporting requirements for project management

- Flexibility in the face of change as long as selection criteria still met

- Program evaluation

\section{The Advanced Technology Program (ATP)}

The Advanced Technology Program (ATP) of the National Institute of Standards and Technology (NIST) seeks to benefit the economy and the people of the United States by sharing the cost of research with industry to foster new, innovative technologies. ATP invests in risky, challenging technologies that create opportunities for world-class products, services, and industrial processes for the benefit not just of ATP participants, but of other companies and industries, and, ultimately, consumers and taxpayers. By reducing the early-stage research and development risks of individual companies, ATP enables industry to pursue promising technologies that would have been ignored otherwise or developed too slowly to compete in rapidly changing world markets.

\section{Contents}

A Message About This Report $\ldots \ldots \ldots \ldots \ldots \ldots \ldots \ldots \ldots \ldots$

Executive Summary $\ldots \ldots \ldots \ldots \ldots \ldots \ldots \ldots \ldots \ldots \ldots \ldots \ldots \ldots$

ATP Invests in America's Future . . . . . . . . . . . . . . . . . . . . 4

The Role of Evaluation at ATP $\ldots \ldots \ldots \ldots \ldots \ldots \ldots \ldots \ldots$

ATP Project Management ...........................

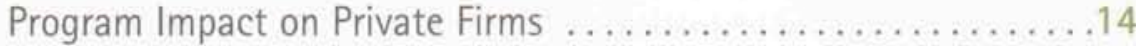

Collaboration in ATP Projects . .......................

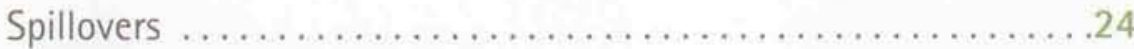

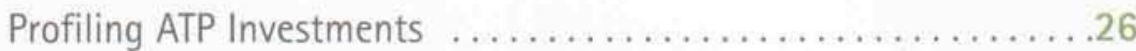

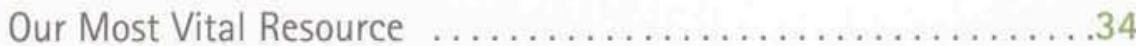

Appendix A: ATP Statistics . . . . . . . . . . . . . . . . 35

Appendix B: Significant Recent Studies . . . . . . . . . . . 42 


\section{A Message About This Report}

The Advanced Technology Program is a partnership between government and industry to conduct high-risk research with the goal of developing enabling technologies that promise significant commercial payoffs and widespread benefits to the U.S. economy. The rationale for these investments is that the benefits to the economy are large, yet because of the high-risk nature of the project, companies are unwilling and/or cannot find funding to proceed alone.

ATP's evaluation program uses multiple approaches to track the selection and progress of projects once funding is awarded. Our findings demonstrate that ATP is indeed meeting its mission. In addition, we seek to increase the understanding of underlying relationships between technological change and economic phenomena.

The Report on Economic Progress presents findings from our economic and policy studies and provides data about ATP-funded project outputs, outcomes, and impacts on the U.S. economy and society. For example, almost three-fourths of our recent awards go to small companies and about one-third of these companies are startups. Almost two-thirds of these startups have boards of scientific advisors that meet regularly and almost half of our startups have received equity investment after receiving an ATP award. Further, innovators will find that, to date, more than 1,400 patents have resulted from just 768 ATP projects.

This is the second and likely final Report on Economic Progress for ATP, as we officially phase down our program. With the desire to preserve ATP's legacy, we have updated the text, tables, and report summaries to provide a comprehensive reporting on ATP's progress and to share with you important findings from our studies. Further, ATP is participating in a Data Enclave at NORC/University of Chicago to allow researchers access to ATP's unique source of Innovation Survey data. Our reports will remain available at the U.S. National Technical Information Service (NTIS).

We hope that you will find our Report on Economic Progress useful, not only to learn about public-private partnerships such as the Advanced Technology Program, but also as a resource for understanding the innovation process in the United States. We welcome your comments.

Marc

Marc G. Stanley

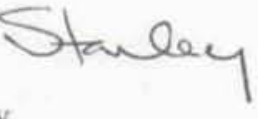

Director, Advanced Technology Program

marc.stanley@nist.gov

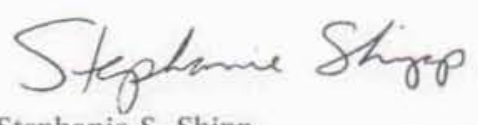

Stephanie S. Shipp

Director, Economic Assessment Office stephanie.shipp@nist.gov 


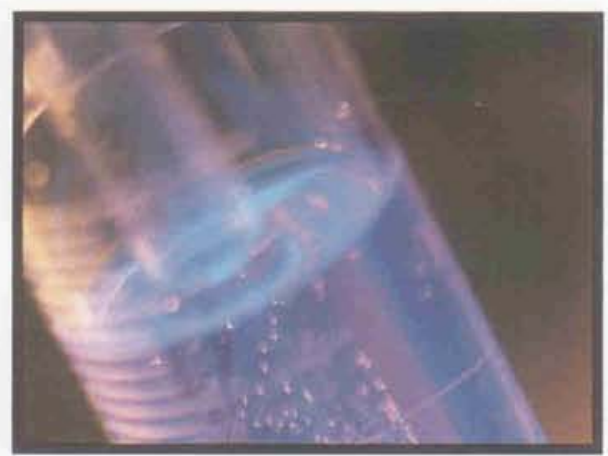

Executive Summary

Technological ingenuity and innovation propelled the United States into a position of world economic leadership in the late nineteenth century. The capacity to unite innovation and opportunity has sustained U.S. economic growth into the twenty-first century and enabled our nation to rebound successfully from fiscal crises throughout our history.

During the great stagflation of the 1970s, businesses struggled to maximize profits in the short term, and many companies refrained from conducting long-term research and development (R\&D). Other countries, including Japan, stepped up their investments in industrial R\&D. These nations focused on bringing research results to the marketplace, which led to dramatic increases in the ability of Japanese firms to compete with the United States. In response, the U.S. Congress charged the Department of Commerce with creating and overseeing the Advanced Technology Program (ATP) to stimulate innovation in the United States.

Housed in the National Institute of Standards and Technology, ATP's mission is to accelerate the development of innovative technologies for broad national benefit through partnerships with the private sector. ATP accomplishes this mission by providing cost-shared funding to industry for fledgling technologies that are high risk in nature, but which could lead to positive spillovers for other companies and industries, thereby boosting the U.S. economy and enhancing the quality of life of Americans.
Projects funded by ATP must meet the following selection criteria:

- Is the proposed technology highly innovative and high risk?

- Does the R\&D plan feature feasible means of overcoming the high technical risk?

- Is it likely that sufficient equity or debt financing will not be available and/or that the scope, scale, or timing to meet a window of opportunity make federal government investment appropriate?

- Will the technology provide broad-based economic benefits for the United States?

- Is there a clear commercial pathway to economic benefits?

Another way to look at the issue of broad public benefits is to consider the appropriability of the benefits of a technology. ATP seeks to fund R\&D where the resulting knowledge and technologies are not fully appropriable; that is, innovators cannot fully capture the financial returns to their investment. Instead, the benefits flow to other firms, industries, consumers, and the general public.

Through a competitive, merit-review process, ATP invests in projects that meet these criteria. Over 16 years, through 44 competitions and 6,924 submitted proposals to develop new technologies, ATP has made 768 awards which include 1,511 participants. Technology areas funded include manufacturing, information technology, biotechnology, electronics/ photonics, and advanced materials and chemistry, covering a broad range of research topics. Nearly $\$ 4.4$ billion has been invested in ATP-funded projects, half of which represents industry contributions. 
Since the inception of the program, ATP has performed rigorous and multifaceted evaluations to determine returns to the taxpayer. To assess whether the program is meeting its stated objectives, ATP's Economic Assessment Office (EA0) employs statistical analyses, case studies, surveys, benefit-cost analyses, and other methodological approaches to measure program effectiveness in terms of:

- Inputs (the funding and staff necessary to move the $R \& D$ effort forward)

- Outputs (project research results)

- Outcomes (products, processes, and services resulting from the innovation)

- Longer-term impacts (on industries, society, and the economy)

Key features of ATP's evaluation program include:

- The Business Reporting System, a unique online survey of participants, that gathers data on an annual basis on the business progress and indicators of future economic impact of funded projects.

- Status reports, which assess projects on a portfolio basis by rating completed projects three to five years out on a scale from zero to four stars, representing a range of performance from poor to outstanding. Rating criteria include solving challenging technical problems, producing patents or publications that could lead to further breakthroughs later on, making new technical knowledge available to others, accelerating the commercial use of new technologies, and assessing the future outlook for the project.

- Benefit-cost analyses, which identify, assess, and quantify the net private, public, and social benefits of ATP project outcomes.
- Economic and policy studies prepared by staff and external researchers that evaluate particular impacts of the program, including the effect of collaboration on the research productivity of participating organizations and the role of the program in the U.S. innovation system.

Returns for the American people, as measured from 14 projects in 5 benefit-cost studies, have exceeded $\$ 1.2$ billion in economic benefits. Benefits from these and other projects studied are projected to be much greater over the longer run, and far exceed ATP's cumulative investment to date of less than $\$ 2.3$ billion.

EAO surveys have revealed the existence of a "halo effect" for participating firms-the ATP award establishes or enhances their expected value in the eyes of potential investors. Such validation is especially important for small companies with little or no market presence and limited financial resources-the type of firm ATP has most frequently funded. From 1990 through 2006, 66 percent of all ATP award recipients were small businesses; a large percentage had fewer than 50 employees.

ATP stresses the importance of partnerships and collaborations in its projects. A recent analysis of data showed that 86 percent of participants had collaborated with others in research on their ATP projects, with 69 percent of these companies stating that ATP brought about the collaboration "to a large extent." Company applicants are encouraged to propose projects that feature collaborations with other businesses, with federal laboratories, and with universities. Nearly 70 percent of joint ventures and more than 50 percent of single-company projects involve universities either as formal participants or subcontractors, which offers access to eminent researchers and opens possibilities for further diffusion of knowledge created by the projects.

Several surveys confirm the fact that ATP involvement accelerates the development and commercialization of new technologies:

- Time to market was reduced by one year in 10 percent of projects; by two years in 22 percent of projects; and by three years in 26 percent of projects.

- Sixteen percent of funded projects would not have proceeded without ATP.

- In a control group of non-ATP winners, less than 40 percent had begun any aspect of their projects. ${ }^{1}$

Success of ATP-supported R\&D efforts can also be measured by:

- Increases in the number of patents granted-one study estimates an average increase of between 5 and 30 patents per firm per year of participation, attributable to ATP.

- The number of new products or processes - a study of the first 150 completed ATP projects shows that 203 new products or processes resulted from 91 of these projects.

- Changes in the size of participating companies-employment changes were profound for the small companies involved (45 companies at least doubled in size; 14 companies grew by more than 1,000 percent).

ATP's $\$ 2.3$ billion investment has yielded substantial and measurable innovations for American businesses, industries, and the consumers of today - and tomorrow.

Advanced Technology Program, Survey of Applicants 2002, NIST GCR 05-870, June 2005, Fact Sheet R3: What Hoppens to Nonfunded Projects? 


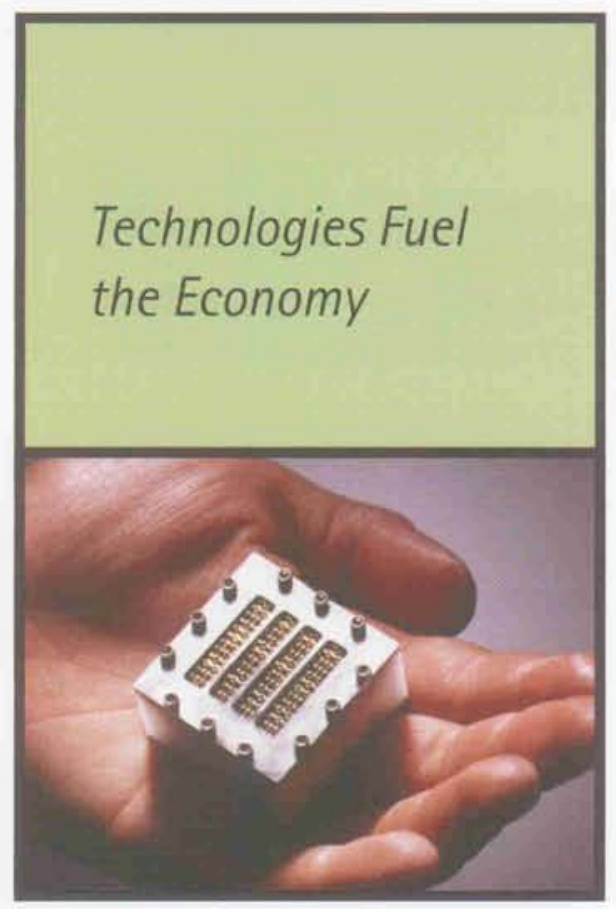

Figure 1. 768 ATP Awards by Technology Area Forty-four Competitions (1990-2006)

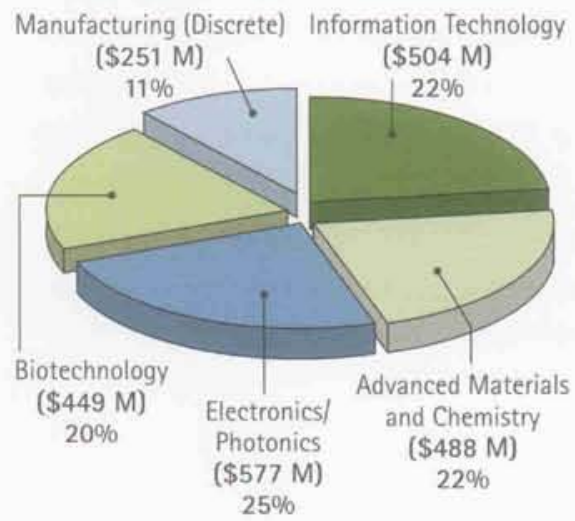

ATP Invests in America's Future

Modern economies rely on the development of new technologies for economic growth and prosperity. The United States emerged as a world economic leader in the late nineteenth century due to ingenuity, breakthrough ideas, and the creative application of new knowledge. Since that time, emerging technologies have continued to support and promote America's economic growth. But while research, invention, and the creation of knowledge define an opportunity, it takes economic incentives to translate the opportunity into economic benefits. The success of a new technology depends on an economic environment conducive to its development and commercialization.

Since our nation's birth, the capacity to unite technological innovation and economic opportunity has enabled the nation to rebound from economic crises and achieve sustained growth. Today, America's ongoing commitment to foster technology development will depend on an environment that promotes exploration into new ways to address existing problems and challenges.

\section{Investing in U.S. Technologies}

After decades of strong growth in U.S. productivity, the oil embargo of 1973-74 led to a crisis in economic competitiveness. This crisis continued through the 1980s, with disabling energy shortages and a combination of high unemployment and double-digit inflation, or "stagflation." The dollar strengthened from a tight money policy and high interest rates, creating a ballooning trade deficit that affected not only traditional sectors like manufacturing, but also research-intensive industriesincluding electronics, machine tools, and semiconductors. The ability of U.S. firms to turn invention into innovations declined in the face of more formidable competition while investment capital dried up for research and development (R\&D) into early-stage, high-risk technologies. This in turn heightened concerns about America's ability to compete economically with other world industrial powers.
Congress passed several pieces of legislation to address declining U.S. competitiveness. Through the Omnibus Trade and Competitiveness Act of 1988, Congress charged the National Institute of Standards and Technology, an agency within the U.S. Department of Commerce, with creating and overseeing the Advanced Technology Program. With this step, Congress sought to provide cost-shared funding to industry to accelerate the development and broad dissemination of enabling, high-risk technologies with the potential to boost the U.S. economy and enhance the quality of life of Americans.

\section{ATP at 16}

In 16 years, through 44 competitions and 6,924 proposals for new technologies, ATP has made 768 awards to a total of 1,511 participants. ${ }^{2}$ Projects with ATP involvement have totaled almost $\$ 4.4$ billion, with just under $\$ 2.3$ billion invested by ATP and another $\$ 2.1$ billion by the commercial sector. Figure 1 shows the distribution of ATP funding by technology area. To date, more than 1,400 patents have resulted from ATP projects.

As shown in Figure 2, the returns to the American people realized to date, as measured by in-depth benefit-cost studies of 14 projects, have exceeded $\$ 1.2$ billion. In addition to the realized benefits, studies of these and an additional 9 projects estimate another $\$ 6.7$ billion in potential net economic benefits.

\section{The Need for a Federal Role} According to a 2002 study of the state of early-stage, high-risk funding for technology R\&D in the United States, monies for such research remain limitedjust as they were upon ATP's launch in 1990. Study coauthors Lewis M. Branscomb and Philip E. Auerswald report that the factors limiting the availability of R\&D funding are several:

- Entrepreneurs see a lack of funding for projects "that no longer count as basic research but are not yet far enough along to form the basis for a business plan." 
- "Markets, technologies, and their interrelation are becoming increasingly complex, further complicating the challenge of converting inventions into innovations."

- "...Even the large corporations with the largest R\&D budgets have difficulty putting together all the elements required for in-house development and commercialization of science-based technologies."

- "Venture capitalists are not in the R\&D business. Rather, they are in the financial business...to earn maximum returns for their investors. ${ }^{3}$

A further assessment of research data by Branscomb and Auerswald in 2004 examined corporate early-stage R\&D investment decisions and the forces driving them. The new interview data from a sampling of 31 corporations reveal increasing pressure on these investments based on the sophistication of new technologies, the need to demonstrate financial value from the investment, and the maturity of the industry involved. In response, firms are exhibiting "a growing reliance on acquisitions, alliances, and outsourcing to obtain access to earlier stage technologies. ${ }^{-4}$

These studies reflect a critical need for a federal role in funding. "National investment into the conversion of inventions into radically new goods and services," conclude the authors of Between Invention and Innovation, "...significantly affects long-term economic growth by converting the nation's portfolio of science and engineering knowledge into innovations generating new markets and industries."

Figure 2. Total Net Economic Benefits to Date (Realized and Prospective) of 23 Projects in 11 Studies.

\begin{tabular}{lccr}
\hline Study Topic (\# of projects) & Realized Benefits & Prospective Benefits & \multicolumn{1}{c}{ Total } \\
Component Based Software (8) & $\$ 840.0 \mathrm{M}$ & - & $\$ 840.0 \mathrm{M}$ \\
DNA Chip (2) & $216.8 \mathrm{M}$ & - & $216.8 \mathrm{M}$ \\
2mm Auto Body Consortium (1) & $185.6 \mathrm{M}$ & \multicolumn{1}{c}{$142.5 \mathrm{M}$} & $185.6 \mathrm{M}$ \\
Digital Video (1) & $23.4 \mathrm{M}$ & $319.6 \mathrm{M}$ & $165.9 \mathrm{M}$ \\
X-Ray Optics (2) & $7.4 \mathrm{M}$ & $3,000.0 \mathrm{M}$ & $327.0 \mathrm{M}$ \\
Digital Data Storage (2) & -- & $1,410.0 \mathrm{M}$ & $3,000.0 \mathrm{M}$ \\
Composites (2) & -- & $1,150.0 \mathrm{M}$ & $1,410.0 \mathrm{M}$ \\
Flow-control Machining (1) & -- & $450.0 \mathrm{M}$ & $1,150.0 \mathrm{M}$ \\
Refrigeration (1) & - & $219.0 \mathrm{M}$ & $450.0 \mathrm{M}$ \\
Digital Mammography (1) & -- & $39.6 \mathrm{M}$ & $219.0 \mathrm{M}$ \\
Green Technologies (2) & $\$ 1,273.2 \mathrm{M}$ & $\$ 6,730.7 \mathrm{M}$ & $39.6 \mathrm{M}$ \\
TOTAL & & & $\$ 8,003.9 \mathrm{M}$ \\
\hline
\end{tabular}

\section{ATP as a Difference Maker- Addressing the Counterfactual} What difference did ATP make in the lives of fledgling technologies? In addition to accelerating technology development, ATP's involvement can provide a "stamp of approval" that attracts capital investment from other sources as well as opens the door to additional technical help. It can also broaden the scope of research and foster collaboration.

In measuring this counterfactual impact, all companies proposing new technologies to ATP were surveyed in 2002. Survey results indicate that without ATP support, many projects were not executed as originally proposed. As shown in Figure 3, survey data collected 18 months after the close of the 2002 competition reveal that 39 percent of nonawarded projects had no activity, and about 45 percent had less activity than proposed. Only 16 percent were pursuing research at or above the level of effort described in their proposals (which indicates ATP funding may not have been needed, and therefore was not awarded). ${ }^{6}$

\footnotetext{
As of September 2003. Subcontracting organizations are excluded but are equal in number to formal participants.

Lewis M. Branscomb and Philip E. Auerswaid, Between invention and Innovation: An Analysis of Funding for Early-Stoge Technology Development. NIST GCR 02-841, November 2002, pp. 3-11.

4 Philip E. Auerswald and Lewis M. Branscomb. Understanding Private-Sector Decision Making for Early-Stage Technology Development: A 'Between Invention and Innovation' Project Report, NIST GCR 02-841A, September 2005.

5 Branscomb and Auerswald, Between Invention and innovation, p. 11.

5 Advanced Technology Program, Survey of Applicants 2002, NIST GCR 05-870, June 2005, Fact Sheet R3: What Happens to
} Nonfunded Projects?

\section{Who Participates in the Program?}

ATP provides competitively awarded funding to companies that wish to pursue innovative technologies. In response to an announced competition, companies propose R\&D projects to the program. These proposals are then evaluated for technical and economic merit through a rigorous review process that includes strict criteria for companies that wish to participate. A variety of factors are considered before ATP makes its final choices for a given year, and invests in technologies that are high risk but also may be high payoff for many industries in many applications. 
Figure 3. Current Status of Nonfunded Projects (Year 2002 ATP Competition)

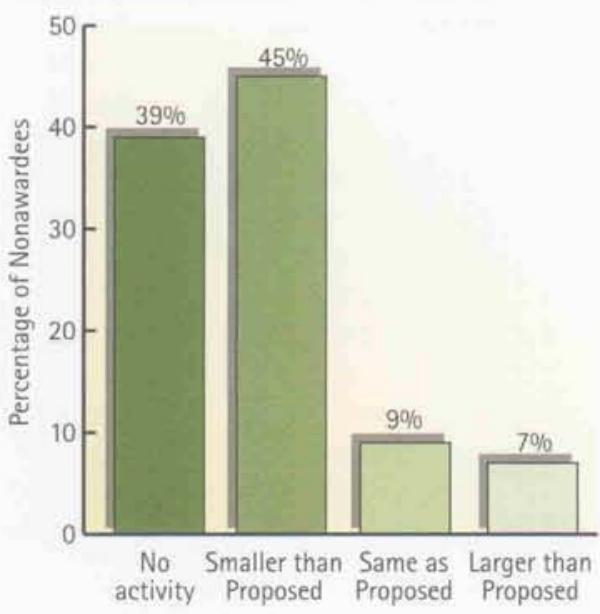

Current Scale of Effort, Relative to Project as Originally Proposed to ATP

Figure 4. Technical Risk-Proposed ATP Projects and Typical Company R\&D Projects

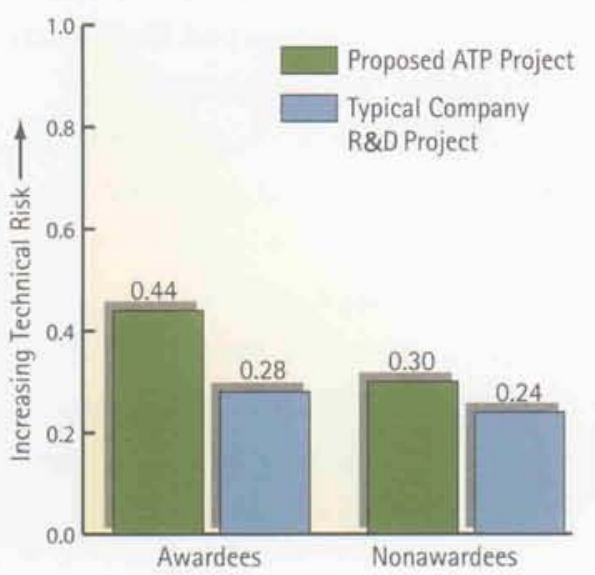

The survey also shows that ATP attracts and funds R\&D projects with higher technical risk and longer time horizons than "typical" R\&D efforts at applicant companies. "Technical risk" means extremely difficult technical challenges that make success uncertain.

As shown in Figure 4, ATP awardees report a greater contrast between their proposed and typical R\&D projects, as compared to nonawardees. Awardees estimate that the probability of not fully achieving technical goals in the ATP-proposed project is 0.44 , while only 0.30 for nonawardees. Figure 4 also shows that both ATP awardees and nonawardees report a higher level of risk for projects proposed to ATP versus their typical R\&D projects. Appropriately, awardees report significantly higher technical risk levels than nonawardees. In addition, the expected time it takes to see the impact of first revenue is longer for proposed ATP projects; about half ( $49 \%)$ expect revenue in four years or more, while two-thirds of nonawardees expect revenue before that time frame.

ATP funding has enabled companies in a variety of industries to pursue promising technologies that would otherwise have been ignored, developed more slowly, or pursued on a smaller scale.
Statistics from 2006 indicate that 85 percent of project participants believed they were significantly ahead in their R\&D cycle as a result of ATP funding. Of these, 37 percent believed they would not have pursued the R\&D at all without the ATP award; 59 percent believed they were one to three years ahead as a result of ATP funding; 4 percent believed they were more than three years ahead. The ideas and technologies developed from these research projects have sparked prosperity through innovation and improved the lives of Americans in a variety of ways.

In an economy where money invested in technology is measured in billions and even trillions of dollars, ATP's relatively modest allocations for research (\$155 million to 78 companies, including 11 joint ventures in the 2004 competitions) make returns to date all the more significant. Just some of ATP's current portfolio of investments are expected to return $\$ 8$ billion to the American people against the program's $\$ 2.3$ billion investment. Each success strengthens participating companies while also delivering such economic benefits as quality-of-life improvements, consumer savings, productivity gains, and additions to Treasury receipts through taxes. Some innovations even spur whole new industries.

Figure 5. Distribution of Terminated Projects by Reason for Termination

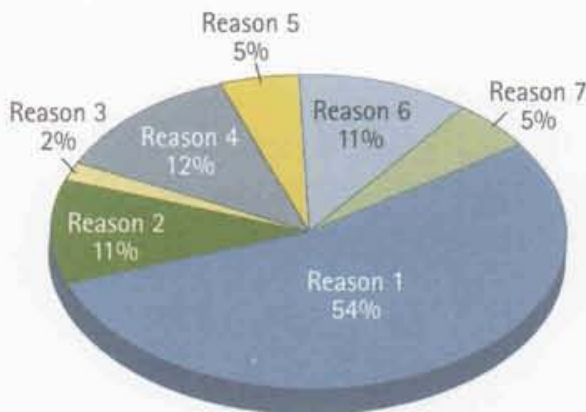

Statistics based on 768 projects, including 84 terminated projects
1 - Company or joint venture (JV) member(s) requested project be stopped due to change in strategic goals, structure, markets, or other factors

2 - Financial distress

$\square 3$ - JV members could not reach agreement

$\square 4$ - Lack of technical progress

$\square 5$ - Early success

$\square 6$ - ATP stopped project due to changes in scope, membership, performance, or other factors causing the project to no longer meet ATP criteria

7 - Cancelled before project start 


\section{Dealing with Failed Projects}

Not all ATP projects succeed; if ATP is meeting its mandate of funding high-risk research, failure must be expected from a percentage of funded projects. These "failures" include projects that never get off the ground, are terminated before completion, or show no or few outputs. In practice, however, most projects achieve something, whether it is patents, papers, collaborative relationships, or products - or knowledge about how to refine the program itself.

Eleven percent of all ATP projects funded over the program's life were terminated after the award announcement and before completion. ${ }^{7}$ Figure 5 reflects the 84 projects terminated by ATP, and the rationale for termination. Other poor performers are identified by ATP's rating system of 0 to hrsks (see page 26). Using these ratings,

ATP Applications, Awards, and Participants by State Forty-four Competitions (1990-2004)

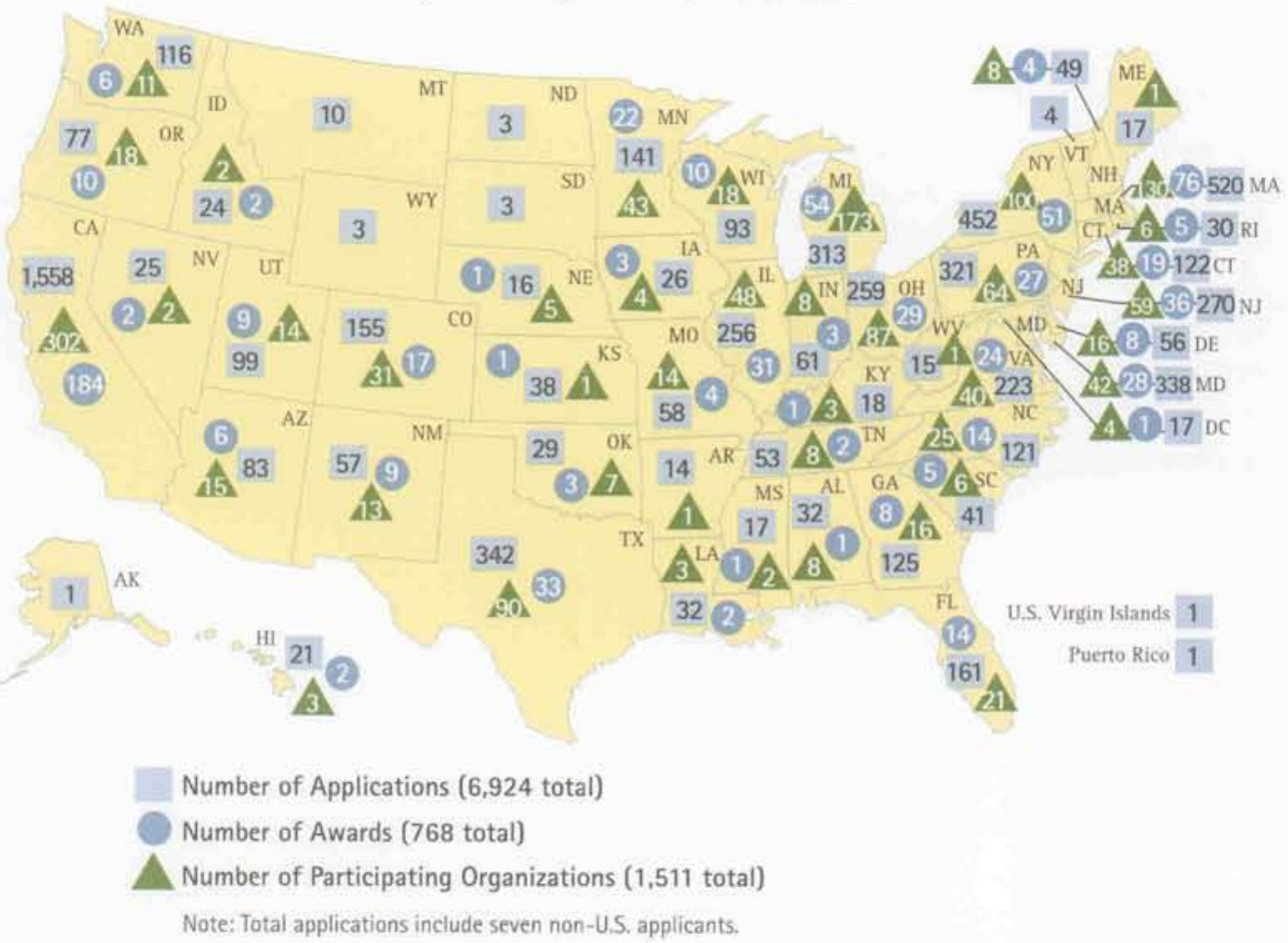

7 Performance of 150 Completed ATP Projects, Stotus Report 4, 2006. about 30 percent of the first 150 completed ATP projects were considered to be poor performers. Such rigorous standards help to assure that projects are progressing and helping to meet program goals - even if a few never make it out of the gate, and others don't reach the finish line.

\section{ATP Is a National Program}

ATP does not take geographic location into consideration when making its project selections. Rather, ATP seeks to increase awareness across the nation of the program's opportunities for small, medium, and large businesses as well as other types of organizations. To date, ATP has received applications from organizations based in every state, and has provided funding to participating organizations located in 40 states and the District of Columbia-as shown below.

\section{Positioning for Success}

Through contractors and sponsored workshops, ATP provides both prospective applicants and awarded companies with a variety of resources designed to enhance the likelihood of a successful project. These resources include:

- The online ATP PowerTips interactive web site (www.atppowertips.org), offering insights for entrepreneurs via audio clips in 10 categories plus the link, Making Money With Your Technology: A Guide to Commercial Success.

- The Art of Telling Your Story: Tips \& Insights for Putting Your Best Foot Forward with Investors and Corporate Partners by Rick King (http://www.atp.nist.gov/eao/gcr02$831 /$ contents.htm), an easy-to-read, 41page NIST guide to presentation tips and techniques for companies seeking investors.

- Commercialization and Business Planning Guide for the Post-Award Period, (http://www.atp.nist.gov/eao/gcr99779/contents.htm) a 265-page NIST text and workbook designed to increase the likelihood of commercialization success by companies that receive funding through the program.

- ATP-sponsored workshops (http://www.larta. org/ on such topics as how firms should present themselves in order to maximize their opportunities for obtaining venturecapital funding.

- Achieving Exports and Value-Added Partnerships with Japan: Considerations for U.S. High Tech Companies by Gerald Hane, a study of U.S. emerging technology companies that have successfully entered markets in Japan, and their strategies for success. ${ }^{8}$

- Gerald Hane, Achieving Exports and Volue-Added Partnerships with Japan: Considerations for U.S. High Tech Companies, 2006. 


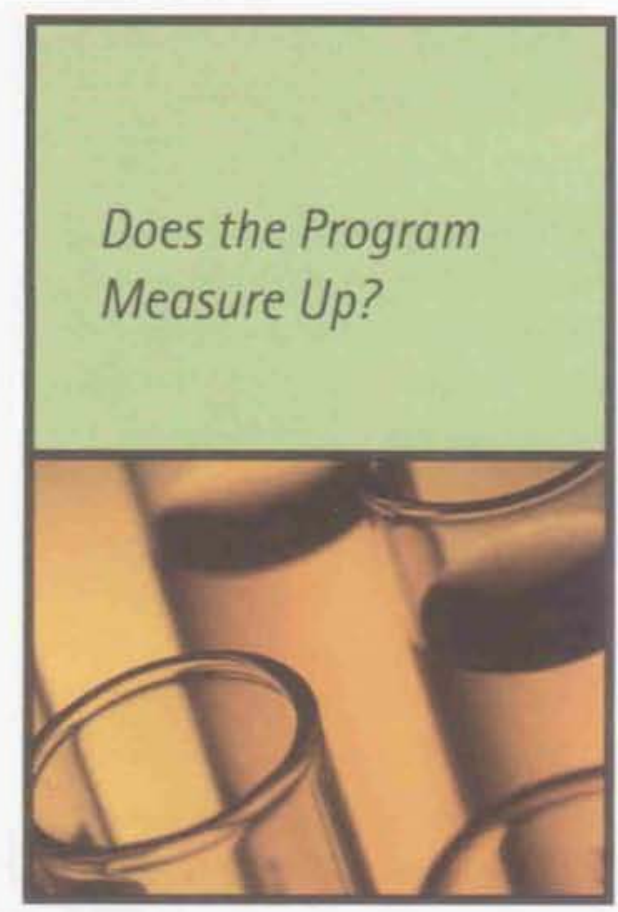

\section{The Role of Evaluation at ATP}

The nature of the Advanced Technology Program-combining federal tax dollars with private sector ingenuity and cost sharing to develop new technologies and refine manufacturing processes-demands that such a program be built on a foundation of evaluation. At any time, ATP must be prepared to show how the program benefits the U.S. economy. An effective measurement system for ATP must be sophisticated enough to answer a crucial question for Congress, the Office of Management and Budget, the General Accounting Office, and the American people: -What does America gain by imvesting in high-risk technologies that industry would not fund on its own?

The ATP Economic Assessment Office (EA0) uses a battery of analytical tools to measure program effectiveness, including statistical analyses, case studies, surveys, stories, and more. These metrics address the design, conceptualization, implementation, and impacts of the program. They can look at selected features, or focus on measurement of certain outputs or outcomes expected based on the program's mission. They can be rigorous in the sense of searching for the most comprehensive and systematic set of causal linkages between and among variables, employing carefully constructed and sifted data. Or they can just be general and descriptive, offering a defensible answer to a particular question, given constraints on time, budget, and access to data.
ATP also attempts to measure the program's counterfactual impact-evaluating what would not have happened in the absence of ATP funding. What differences did the program funding make in scope of research, collaborations, attraction of additional capital, and acceleration of technology development. ATP benchmarks by scanning industries, patents, papers, and commercialization rates of companies that received ATP funding versus companies or industries that have not been funded through the program.

Figure 6 on page 10 depicts the progress of an idea from proposal through dispersal of knowledge and commercialization of a technology. It also shows the measures employed in the short, mid, and long term to compile a 3-D snapshot of the project and its impact. As shown, technologies that attract ATP investment tend to deliver a rather flat return for the developer(s), but a more significant return to the nation through absorption and use of the innovation by other firms and by society as a whole. 


\section{Short- and Long-term Measurement}

How are benefits measured? The ATP

evaluation program involves four categories

of measurements, including:

- Program inputs derived from

Congressional appropriations and industry cost-share to provide budgets for making awards, convening staff to carry out the research, and providing for equipment, facilities, and other direct costs.

- Principal outputs, including the funded projects, collaborative relationships formed as a result of the program, plus publications, patents, models and algorithms, and prototype products and processes.

- Principal outcomes, including sales of new and improved products, processes, and related services; productivity effects on firms; changes in firm size and industry size; changes in the inclination of firms and other organizations to collaborate; the spread of resulting knowledge through publications, presentations, patents, and other means; and the adoption of the funded innovations - and various adaptationsby the market.

- Longer-term impacts related to the broad societal goal that drove the program's creation, including increased GDP, employment gains, improved international competitiveness of U.S. industry, and quality-of-life improvements to the nation's health, safety, and environment. Impacts may also include an effect on the nation's capacity to innovate.
Evaluation objectives include tracking progress of funded projects; estimating benefits and costs of projects and of the program overall; identifying the more difficult-to-measure effects, such as adaptations of the knowledge by others; relating findings back to the program's mission; and applying tests of success. Additional objectives include disseminating evaluation results and feeding them back to program administrators (to improve the program) and to policy makers (to inform them and meet reporting requirements).

Not all projects progress at the same rate. Recent results from ATP's Business Reporting System (BRS) looked at the rate of development of innovative technologies by industrial sector. This study found that information technologies and electronics enter the market quickly, with commercialization soon after the ATP funding period. Manufacturing and materials/chemical projects tend to commercialize at a slower rate because they typically involve new process technologies in mature industries. Because of regulatory requirements for many health care applications, biotechnologies also enter the market at a slower rate, and major applications often can be implemented more than five years after ATP funding ends. ${ }^{9}$

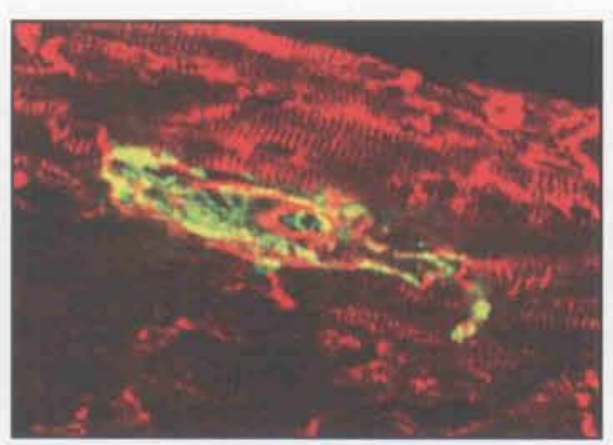

ATP funding helped Osiris Therapeutics, Inc., of Baltimore to research the regeneration of damaged heart tissue using adult stem cells derived from bone marrow. In this image from animal testing, human stem cells are seen in an adult mouse heart 60 days after implantation. Osiris worked with researchers at Johns Hopkins University, the University of Florida, and Emory University on the project. Almost half of ATP awards include a university researcher among the principals, which speeds the dissemination of new technologies. 
Figure 6. Timeline: What EAO Measures and When

In the EAO timeline, economic impacts are depicted on the vertical scale and time on the horizontal scale.

A Conceptual Benefits curve starts above zero at the time of competition announcement, implying that there will be benefits from the technology project planning, and from the formation of collaborations stimulated by the announcement. The curve then splits at about mid-project. The lower curve, Benefits to Awardees, shows returns to the project innovators increasing over time as they commercialize or license their technology. This curve remains relatively flat, however, due to such factors as appropriability, or the degree that firms are able to protect the profitability of their inventions (see page 25 for more on appropriability). The upper curve, Total Economic Benefits, shows returns to the economy at large increasing as the technology diffuses to wider use and generates spillovers. The Total Economic Benefits curve veers more steeply upward from the Benefits to Awardees curve as the project nears completion, signifying an expectation of increasing spillover effects over time.

Sources: Ruegg, Assessment of the ATP, 1999, p. 19; Cohen and Walsh, R\&D Spillovers, Appropriability and R\&D Intensity, 2000.

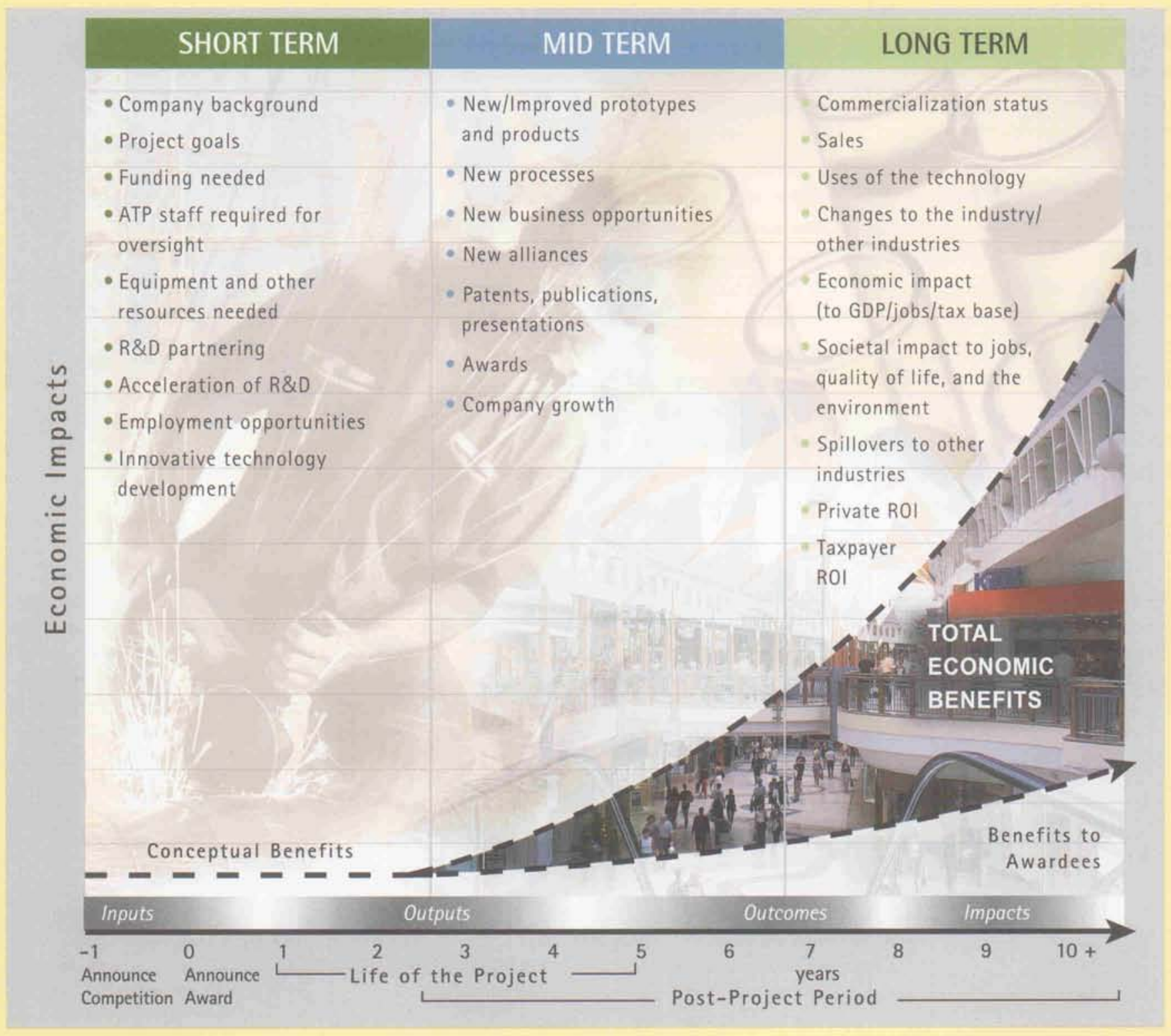




\section{How Does ATP Measure?}

Programs such as ATP use a variety of evaluation methods to "measure against mission." These methods can range from early surveys used to generate immediate information to detailed case studies, statistical analyses, tracking of knowledge created and disseminated through patents and citation of patents, and informed judgments. Table 1 shows the full range of evaluation methods available to ATP. Figure 7 shows the actual use of these methods by ATP since its inception in 1990 .

Figure 7. Intensity of ATP's Use of Evaluation Methods

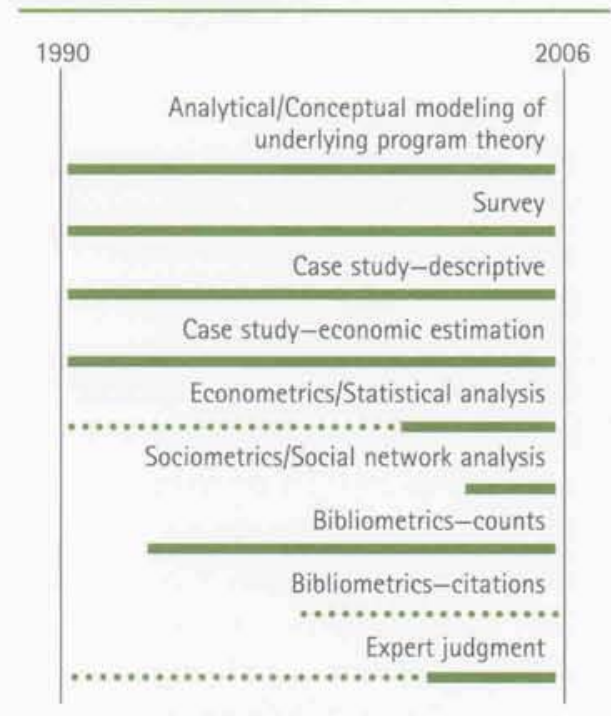

Since 1990, ATP has employed a growing number of evaluation methods to gauge the success of the program mission in accelerating U.S, technology development and increasing research partnerships.
Table 1. Overview of Evaluation Methods*

\begin{tabular}{|c|c|c|}
\hline Method & Brief description & Example of use \\
\hline Analytical/Conceptual modeling & $\begin{array}{l}\text { Investigating underlying } \\
\text { concepts and developing models } \\
\text { to better understand a program, } \\
\text { project, or phenomenon }\end{array}$ & $\begin{array}{l}\text { To describe conceptually the } \\
\text { paths through which spillover } \\
\text { effects may occur }\end{array}$ \\
\hline Survey & $\begin{array}{l}\text { Asking multiple parties a uniform } \\
\text { set of questions for statistical } \\
\text { analysis }\end{array}$ & $\begin{array}{l}\text { To find out how many companies } \\
\text { have licensed their newly } \\
\text { developed technology to others }\end{array}$ \\
\hline Case study-descriptive & $\begin{array}{l}\text { Investigating in depth a } \\
\text { program, project, technology, } \\
\text { or facility }\end{array}$ & $\begin{array}{l}\text { To recount how a particular joint } \\
\text { venture was formed, how the } \\
\text { collaboration worked, and } \\
\text { reasons for success-or lack } \\
\text { thereof }\end{array}$ \\
\hline Case study-economic estimation & $\begin{array}{l}\text { Adding quantification of } \\
\text { economic effects to a descriptive } \\
\text { case study, using, for example, } \\
\text { benefit-cost analysis }\end{array}$ & $\begin{array}{l}\text { To estimate whether, and by how } \\
\text { much, benefits of a project } \\
\text { exceed its cost }\end{array}$ \\
\hline $\begin{array}{l}\text { Econometric and statistical } \\
\text { analysis }\end{array}$ & $\begin{array}{l}\text { Using statistics, mathematical } \\
\text { economics, and econometrics to } \\
\text { analyze links between economic } \\
\text { and social phenomena, and to } \\
\text { forecase economic effects }\end{array}$ & $\begin{array}{l}\text { To determine how public funding } \\
\text { affects private funding of } \\
\text { research }\end{array}$ \\
\hline $\begin{array}{l}\text { Sociometric and social network } \\
\text { analysis }\end{array}$ & $\begin{array}{l}\text { Identifying and studying the } \\
\text { structure of relationships to } \\
\text { increase the understanding of } \\
\text { social/organizational behavior } \\
\text { and related economic outcomes }\end{array}$ & $\begin{array}{l}\text { To learn how projects can be } \\
\text { structured so that the diffusion } \\
\text { of resulting knowledge can be } \\
\text { increased }\end{array}$ \\
\hline Bibliometrics-counts & $\begin{array}{l}\text { Tracking the quantity of research } \\
\text { outputs }\end{array}$ & $\begin{array}{l}\text { To find how many publications } \\
\text { per research dollar a program } \\
\text { generated }\end{array}$ \\
\hline Bibliometrics-citations & $\begin{array}{l}\text { Assessing the frequency with } \\
\text { which others cite publications or } \\
\text { patents and noting who is doing } \\
\text { the citing }\end{array}$ & $\begin{array}{l}\text { To learn the extent and pattern } \\
\text { of dissemination of a project's } \\
\text { publications and patents }\end{array}$ \\
\hline Bibliometrics-content analysis & $\begin{array}{l}\text { Pulling information from text } \\
\text { using co-word analysis, database } \\
\text { tomography, and textual data } \\
\text { mining, as well as visualization } \\
\text { techniques }\end{array}$ & $\begin{array}{l}\text { To identify a project's } \\
\text { contribution, and its timing } \\
\text { relative to the evolution of a } \\
\text { technology }\end{array}$ \\
\hline Historical tracing & $\begin{array}{l}\text { Tracing forward from research to } \\
\text { a future outcome, or backward } \\
\text { from an outcome to contributing } \\
\text { developments }\end{array}$ & $\begin{array}{l}\text { To identify linkages between a } \\
\text { public research project and } \\
\text { significant later occurrences }\end{array}$ \\
\hline Expert judgment & $\begin{array}{l}\text { Using informed judgments to } \\
\text { make assessments }\end{array}$ & $\begin{array}{l}\text { To hypothesize the most likely } \\
\text { first use of a new technology }\end{array}$ \\
\hline
\end{tabular}

- Rosalie Ruegg and Irwin Feller, A Toolkit for Evaluating Public R\&D Investment Models, Methods, and Findings from ATP's First Decode, NIST GCR 03-857, July 2003, pp. 30-31. 


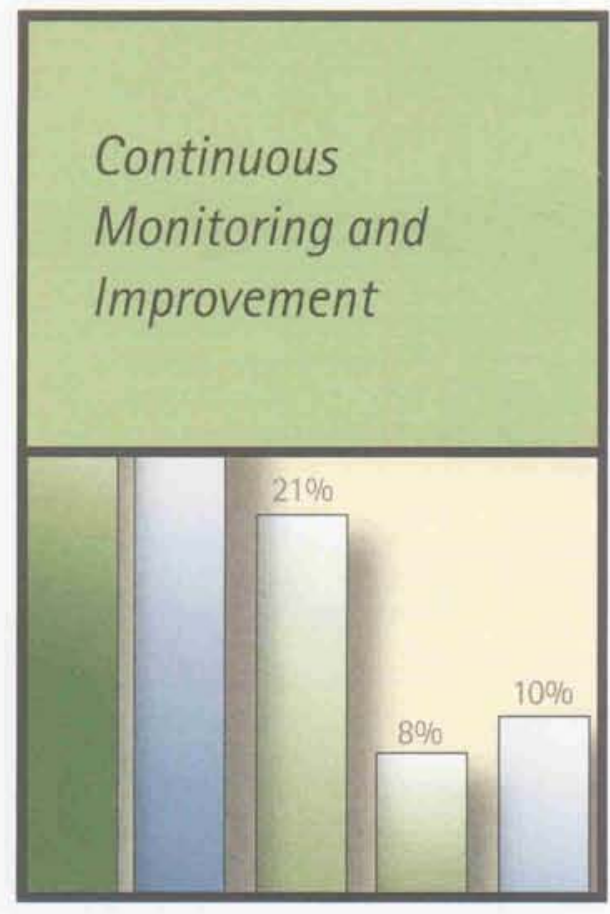

\section{ATP Project Management}

The management process for projects funded by ATP is designed to assure that the R\&D effort remains faithful to the original proposal (which satisfied the program's strict selection criteria), and to the cooperative agreement governing the award. Figure 8 defines the roles and responsibilities of the ATP project management team. Project management monitors the technological and business progress made in the projects through each project milestone. These include:

- Defining, qualitatively and quantitatively, what it means to overcome technical barriers.

- Integrating the efforts of various project tasks.

- Advancing the state of the technology.

- Describing a project's achievements.

- Providing a foundation for reporting project activities and accomplishments.

These milestones are used by the program in a number of ways. They help ATP to encapsulate the scope and merit of the project versus its original goals. They also help to define critical project decision points, and clarify alternative pathways that can optimize success.

Within the project oversight process, and because of the nature of innovative, highrisk research, ATP expects changes to occur. In fact, the program is accepting of changes that will strengthen the project and enhance the prospects for success-as long as those changes work in the context of the selection criteria, terms and conditions of the award, budget, commercialization plan, and other important factors.

\section{Business Reporting}

Since 1993 EAO has used its Business Reporting System (BRS) to gather data from companies, universities, and laboratories participating in ATP-funded projects. In 1999 EA0 switched to the web and began collecting survey data via secure Internet connection. Figure 9 summarizes the system's five surveys that track ATP projects over time. The BRS helps to create an ever more concise picture of the company, the project, and the impacts of the technology under development.

The five BRS surveys are:

1. A baseline report completed before the project begins to identify a company and establish the goals of the project.

2. Quarterly reports to provide an update of developments in the project.

3. Anniversary reports to detail the status of the project in terms of collaboration, new applications of the technology, publications and presentations, and company financial data.

4. Closeout reports to identify remaining barriers to commercialization, set fiveyear business goals for the technology, and identify expected spillovers.

5. Post-project reports at two, four, and six years following the completion of the project to document actual progress in commercializing the technology and impacts of the innovation to the company and society.

Over time, BRS survey results form the basis for a database of companies, proposed technologies, business impacts, and spillover benefits for industries and the nation. 


\section{ATP Competitions}

ATP concentrates on those technologies that offer significant, broad-based benefits to the nation's economy-technologies that likely would not be developed without program support because they are judged too risky. Often they are path-breaking approaches. The subjects of ATP research projects are proposed by industry, and competitions are open to proposals from any area of technology.

Of all the proposals received by ATP, about 11 percent result in awards because each potential research project must meet a list of strict criteria to qualify for funding. Each innovative technology must have the potential for broad benefits to the nation in jobs, economic growth, and better quality of life. Specifically, the program looks for proposals with strong technological and economic merits. As explained in the

ATP Proposal Preparation Kit:

- The proposal must convince expert reviewers that the project involves a high level of technical merit.

- Successful proposals must effectively balance high technical risk with evidence of scientific and/or engineering feasibility for overcoming that risk.

- The technical plan must explain how the technical objectives will be reached, addressing all the anticipated problems and describing how these problems will be handled.

- Submitters must explain the business opportunity and identify future users of the technology, as well as describe its national economic significance, additional societal benefits, and how it improves upon existing technology.

- In establishing the need for ATP funding, efforts made to obtain funding from other sources must be described, along with the results of those efforts.
- To characterize the pathway to economic benefits, the experience and structure of the firm must be documented, as well as what products will result from the technology, how those products will be commercialized, and how the technology will be broadly diffused. ${ }^{10}$

Proposals are evaluated in peer-reviewed competitions against the above criteria. Reviewers are experts in such fields as biotechnology, photonics, chemistry, manufacturing, information technology, or materials, and sit on one of several technology-specific boards. All reviewers are screened by ATP for conflicts of interest and sign nondisclosure agreements.

Each proposal receives appropriate, technically competent reviews even if it involves a broad, multi-disciplinary mix of technologies. When proposals are deemed to meet all criteria, ATP uses cooperative agreements to enter into cost-sharing arrangements with recipients rather than awarding an outright grant. Awarded funds can be applied only to research costs approved by the board.

Figure 9. Summary of ATP Business Reporting System

\begin{tabular}{|c|c|c|c|c|c|}
\hline & \multicolumn{5}{|c|}{ Survey Type } \\
\hline$\square=$ Web $\quad=$ Phone & Baseline & Quarterly & Annual & Closeout & Post project \\
\hline $\begin{array}{l}\text { Business Plans } \\
\text { - Identification of planned applications } \\
\text { - Strategies for commercialization, protection } \\
\text { of intellectual property, and dissemination of } \\
\text { non-proprietary information }\end{array}$ & $\square$ & $\square$ & & & \\
\hline Significant business developments & & & & & \\
\hline $\begin{array}{l}\text { Update of business plan and progress } \\
\text { - Products, processes, and licensing activity }\end{array}$ & & & $\square$ & & \\
\hline Collaboration experiences & & & $\square$ & $\square$ & \\
\hline Attraction of new funding & & & $\square$ & $\square$ & \\
\hline New intellectual property & & & $\square$ & $\square$ & \\
\hline Technology diffusion & & & $\square$ & $\square$ & \\
\hline Company financial data & & & $\square$ & $\square$ & 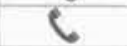 \\
\hline Next 5 years-technical and business goals & & & & $\square$ & \\
\hline Effects outside your organization & & & & $\square$ & \\
\hline
\end{tabular}

Figure 8. ATP Project Management (PM) Team Roles

Project Manager

- Provides general oversight and PM functions

- Ensures that the project is executed in accordance with the proposal and award

- Recommends appropriate actions to the NIST Grants Officer

- Reviews technical reports and progress against milestones

- Assists in research and evaluation of ATP projects

Business Specialist

- Reviews business and commercialization issues

- Follows the diffusion strategy of results beyond the commercialization path

- Assists in research and evaluation of ATP projects

NIST Grants/Cooperative Agreement Specialist

- Performs cooperative agreement administration (Grants Officer)
- Issues final prior approval for changes 
Enhancing the

Competitiveness of U.S. Companies

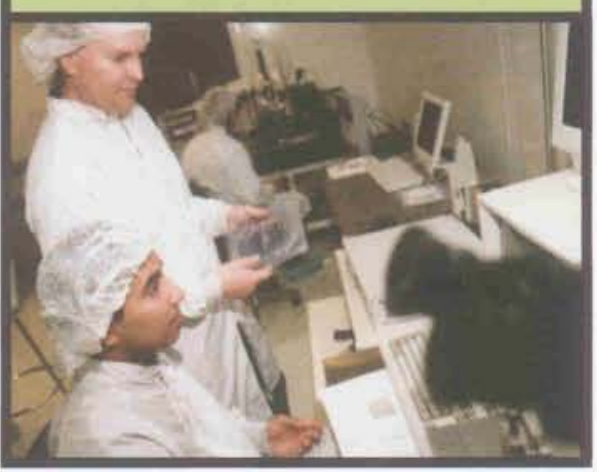

\section{Program Impact on Private Firms}

Private firms play a central role in ATP operations. The program seeks to attract these firms as partners, and relies on them for their:

- Specialized market knowledge.

- Profit orientation.

- Entrepreneurial ability.

At the same time, ATP seeks to create the conditions necessary to maximize the chances of project success. Recently, EAO compiled 19 studies that looked at the factors leading firms to seek funding from ATP for the development of new technologies - and how the program and its processes affected these firms. Table 2 lists these studies by author, with column headings indicating the six major sub-themes covered in the research."

\section{ATP Support Addresses the Financing Gap}

Private firms face important barriers to innovation because of the great amount of time it takes to make progress in the research lab and commercialize in the marketplace. In 1999 ATP commissioned a study by Lewis M. Branscomb (principal investigator) and others to look at the decision-making process for the funding of early-stage, high-risk technology R\&D projects inside firms and with outside investors. The goal was to better identify projects not undertaken or pursued less vigorously by industry that would meet ATP criteria of having broad-based technical benefits and commercial success. ATP bridges what the study refers to as this "...serious gap...the 'Valley of Death' in R\&D."12

Table 2. Studies Showing the Impacts of ATP on Private Firms (an extension of the Table in Ruegg and Feller, 2003)

\begin{tabular}{|c|c|c|c|c|c|c|c|}
\hline Author & $\begin{array}{c}\text { Year of } \\
\text { publication }\end{array}$ & $\begin{array}{l}\text { Financing } \\
\text { gap and } \\
\text { investment } \\
\text { choices }\end{array}$ & Halo effect & Acceleration & $\begin{array}{c}\text { Firm } \\
\text { productivity }\end{array}$ & $\begin{array}{c}\text { Small firm } \\
\text { participation }\end{array}$ & $\begin{array}{l}\text { Commericalization, } \\
\text { company growth, } \\
\text { and private retums }\end{array}$ \\
\hline Pelsoci (Delta Research) & 2007 & & & $\checkmark$ & & & $\checkmark$ \\
\hline O'Connor et al (RTI). & 2006 & & & $\checkmark$ & & & $\checkmark$ \\
\hline Dyer et al. & 2006 & & & & $\checkmark$ & $\checkmark$ & $\checkmark$ \\
\hline Watkins et al. & 2006 & $\checkmark$ & & & $\checkmark$ & $\checkmark$ & $\checkmark$ \\
\hline Petrick et al. & 2006 & & & $\checkmark$ & $\checkmark$ & & $\checkmark$ \\
\hline Fogarty et al. & 2006 & & & & $\checkmark$ & & 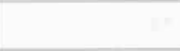 \\
\hline Nail et al. & 2006 & & & & $\checkmark$ & & \\
\hline ATP Status Report 3 & 2006 & & & & & & \\
\hline Pelsoci (Delta Research) & 2005 & & & $\checkmark$ & $\checkmark$ & & $\checkmark$ \\
\hline Auerswald et al. & 2005 & $\checkmark$ & & & & & \\
\hline Brodd & 2005 & $\checkmark$ & & & $\checkmark$ & & \\
\hline Nail et al. & 2005 & $\checkmark$ & & & $\checkmark$ & & $\checkmark$ \\
\hline White et al. & 2004 & & & $\checkmark$ & & & $\checkmark$ \\
\hline Polenske et al. & 2004 & & & $\checkmark$ & $\checkmark$ & & $\checkmark$ \\
\hline Brown et al. & 2003 & & & & & & \\
\hline Pelsoci (Delta Research) & 2003 & & & $\checkmark$ & $\checkmark$ & & $\checkmark$ \\
\hline Popkin & 2003 & & & & $\checkmark$ & & \\
\hline Zucker et al. & 2002 & & & & $\checkmark$ & & \\
\hline White et al (RTI). & 2002 & & & $\checkmark$ & & $\checkmark$ & $\checkmark$ \\
\hline
\end{tabular}

11. Rosalie Ruegg and Irwin Feller, A Toolkit for Evaluating Public R\&D Investment Models, Methods, and Findings from ATP's First Decade, NIST GCR 03-857, July 2003, pp. 295-365. This table is an extension of a similar table in the Toolkit.

12 Branscomb et al., Managing Technical Risk: Understanding Private-Sector Decision Making on Early-Stage, Technology-Based Projects, NIST GCR 00-787, 2000, p.2. 
In this desolate place between invention and innovation, the risk of failure may be too high to attract venture capital. In addition, the value to the individual company may not be high enough to warrant the investment, and the company may lack the infrastructure necessary to take it to fruition.

A 2005 report by Harvard School of Public Policy interviewed 38 senior executives and investors from 31 corporations across 8 industry sectors and 8 venture capital firms to examine trends in management of corporate R\&D and how new market realities are affecting the ways corporations manage and support early-stage technology development. Among these emerging corporate strategies is an increasing formalization of portfolio management approaches to corporate $\mathrm{R} \& \mathrm{D}$ and a growing reliance on acquisitions, alliances, and contracting out to obtain access to exploit earlier-stage technologies, especially where intemal barriers are blocking progress. Case studies suggest that government funding is effective, even essential, in helping larger firms pursue in-core radical innovations (via alliances) that bring economic and social benefits that would otherwise be lost. ${ }^{13}$

ATP helps to bridge the Valley of Death by providing participating companies with:

- Cost-shared funding.

- Partnership opportunities with other companies, federal laboratories, and universities.
- Peer-reviewed evaluations of technical and business plans.

- Control of intellectual property rights.

- ATP project monitoring activities and reporting regulations.

- The "halo effect" in attracting funding that results from the prestige of winning an ATP award.

Table 3 illustrates the impact of ATP involvement on the goals of three ATP projects. As can be seen, goals established with ATP funding were far more ambitious than those without ATP funding.

\section{The Halo Effect}

From the first survey of ATP effectiveness, firms participating in the program have recognized the validity of a "halo effect"the fact that an ATP award enhances the respect paid to such a firm. ATP's second major survey, covering the first three competitions, replaced the term "halo effect" with "increased credibility." This survey concluded that 90 percent of participants benefited moderately or greatly from enhanced credibility because of the award. ${ }^{14}$

A study of BRS survey data in 2006 revealed that 94 percent of participating firms perceived that they had increased credibility due to the ATP award. An earlier study stated that, "The 'halo effect' may be...of particular benefit to ATP-funded small businesses, which have little if any market presence and typically very limited financial resources at the time of the ATP award." ${ }^{15}$

Table 3. The Impact of ATP Funding on Company Goals for Three Different Technologies

\begin{tabular}{|lll|}
\hline Status at project start & Goal without ATP funding & Goal with ATP funding \\
\hline 1 gene per day sequenced & 5 genes per day sequenced & 100 genes per day sequenced \\
$\$ 500$ cost per medical test & $\$ 500$ cost per medical test & $\$ 50$ cost per medical test \\
3.9 gigabytes data storage & 4.7 gigabytes data storage & 60 gigabytes data storage \\
\hline Sourte: Powell and Lellock, Development, Commercialization, and Diffusion of Enabling Technologies: Progress Report, p. 11. \\
\hline
\end{tabular}

\footnotetext{
13 Philip E. Auerswald and Lewis M. Branscomb, Understanding Privote-Sector Decision Moking for Early-Stage Tectınology Development: A 'Between Invention and Innovotion' Project Report, NIST GCR 02-841A. September 2005 ,

14 Silber and Associates, Survey of Advanced Technology Progrom 1990-1992 Awardees: Company Opinion About the AIP ond its Early Effects, 1996, pp. 41-43.

11. Jeanne W. Powell and Karen Lellock, Development, Commercialization, and Diffusion of Enobling Technologies: Progress Report, ATP, 2000, p. 31.
} 
Figure 10. Levels of Analysis for Measuring Additionality

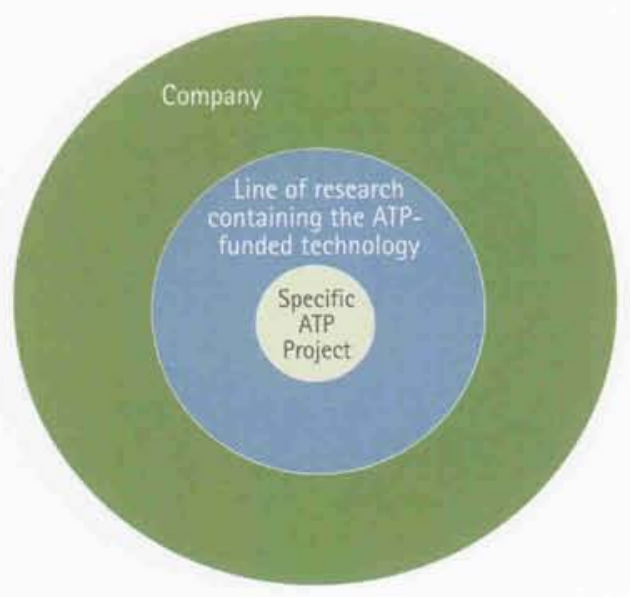

Another study compared winners and non-winners, and found evidence that ATP encourages pursuit of new technical areas outside the scope of participating firms past R\&D activities. This study found that 95 percent of all proposals represented a new R\&D direction for the industry or technology field. Almost two-thirds of ATP applicants say their project proposal fostered new company partnerships. In effect, ATP cost sharing enabled firms to initiate high-risk projects in new technical areas. ${ }^{16}$

\section{ATP Funding Additionality}

The ATP selection criteria and process were designed to expand research in areas where a "market failure" resulted in low levels of $R \& D$ from society's perspective. Examples of these market failures include gaps or wedges between the return to a company from investing in R\&D and the return to society at large, information asymmetries regarding the technical and commercial potential of an R\&D project, and knowledge spillovers that prohibit private companies from appropriating significant benefits from their R\&D efforts. The justification of public expenditures in these areas therefore requires that the funding of $R \& D$ projects be in areas not otherwise profitable and therefore not pursued by private actors. This requires the funding agency to be able to separate "marginal projects" (projects that would not be undertaken in the absence of government subsidy) from "inframarginal projects" (generally highreturn projects that would have been undertaken with or without government subsidy).

Additions were made to ATP's Business Reporting System (BRS) to determine the additionality of government funding of private R\&D. These new data collected from 272 companies on active projects since 2004 enable ATP to begin to answer the following questions:

- Is ATP funding research projects that would not likely be pursued in the absence of ATP support?
- Does ATP funding act as a catalyst or magnet attracting additional research expenditures ("crowd in") or does it merely replace existing R\&D efforts ("crowd out")?

The BRS was designed to address these questions at various levels.

ATP funds specific R\&D projects. These projects usually fit into a broader line of research for a company. For larger companies, this line of research may be only one of several lines of research in the entire company R\&D portfolio. (See Figure 10.) Companies were asked questions about R\&D activity in all three areas (project level, line-of-research level, and company level).

In order to address the efficacy of ATP in funding marginal projects, companies were asked to what extent they would be pursuing the ATP project if funding had not been received. Fifty-four percent of companies indicated they would not be pursuing any part of the ATP project without program support. The remaining indicated that they would be pursuing only a portion of the proposed ATP project.

ATP was also interested in examining if ATP funding "crowds in" or "crowds out" internal company funding to the ATP line of research. Companies were asked to report actual R\&D expenditures for the ATP line of research to help answer the question, "What happens to R\&D expenditures for the line of research after the injection of ATP dollars?"

- If R\&D expenditures increase by less than the amount of the ATP funding, then ATP is crowding out private $R \& D$.

- If R\&D expenditures increase by exactly the amount of the ATP funding, then ATP has a neutral impact on private R\&D.

- If R\&D expenditures increase by more than the ATP funding, then ATP crowds in additional private $R \& D$. 
The data show that ATP crowded in R\&D for 90 percent of the companies. The ATP selection process may well be acting as an independent referee and signaling to companies the technical and commercial merit of the ATP research. This quality signal could result in companies shifting resources to this validated line of research.

\section{Increasing Productivity Within Firms}

Tracking changes in the number of patents secured by ATP participants helps to measure increases in productivity due to ATP. One study looking at changes in the number of patents secured by ATP firms estimated an increase in patenting that averaged between 5 and 30 patents per firm per year of participation, attributable to ATP. ${ }^{17}$

Another study also used patent data to measure productivity increases among ATP participants. The authors compared ATP participants with a control group and found that taking part in ATP joint ventures increased patenting in the targeted technology areas above those levels established prior to participating in the project. The rate of increase in productivity due to an ATP project, as measured by patents, was 8 percent per year. Productivity was found to be highest among consortia with members expert in the same area of technology. ${ }^{18}$

\section{Participation of Small Firms}

ATP's mission specifications include the line, "Ensure appropriate small-business participation." Since this is the case, ATP's self-evaluations address the following questions:

- To what extent do ATP proposals reflect small-business involvement in the application process?

- Do ATP awards reflect small-business participation among awarded projects?
Table 4. Estimates of Economic Value of a One-Year Reduction in Applied Research Cycle Time, in Order of Decreasing Value (\$5 Million to $\$ 6$ Million Median Value)

\begin{tabular}{|c|c|c|}
\hline Size of firm & $\begin{array}{l}\text { Economic value to getting } \\
\text { to market one year sooner }\end{array}$ & $\begin{array}{l}\text { Nature of the } \\
\text { economic value }\end{array}$ \\
\hline \multicolumn{3}{|c|}{ Medium/Large ........ S100s of millions to billions .................... Sales revenue } \\
\hline Medium/Large & \$1 billion. & Sales revenue \\
\hline Medium/Large & $\$ 100-200$ million ......... & Sales revenue \\
\hline Small ......... & $. \$ 15-250$ million to ultimatel & Sales revenue \\
\hline \multicolumn{3}{|c|}{ Small ............... \$10-100 million ........................... Sales revenue } \\
\hline \multicolumn{3}{|c|}{ Small ...............\$10-30 million .............................. Sales revenue } \\
\hline \multicolumn{3}{|c|}{ Medium/Large .......\$15 million ............................ Sales revenue } \\
\hline \multicolumn{3}{|c|}{ Small ............... \$5-6 million (median value) $\ldots \ldots \ldots \ldots \ldots \ldots . . . \ldots$ Sales revenue } \\
\hline \multicolumn{3}{|c|}{ Medium $/$ Large $\ldots \ldots \ldots . \$ 5.2$ million $\ldots . \ldots \ldots \ldots \ldots \ldots \ldots \ldots \ldots \ldots . \ldots \ldots$ Capital cost savings } \\
\hline \multicolumn{3}{|c|}{ Small ...............\$2-5 million ............................ Sales revenue } \\
\hline \multicolumn{3}{|c|}{ Small .................Millions of dollars .......................... Sales revenue } \\
\hline \multicolumn{3}{|c|}{ Small ................Millions of dollars .......................... Sales revenue } \\
\hline \multicolumn{3}{|c|}{ Small ............... Millions of dollars ........................... Sales revenue } \\
\hline \multicolumn{3}{|c|}{ Medium/Large ....... \$2 million ............................ Sales revenue } \\
\hline \multicolumn{3}{|c|}{ Small .............. $\$ 1-2.25$ million ........................... Sales revenue and cost savings } \\
\hline
\end{tabular}

Table 5. ATP Effeets That Helped Interviewees to Reduce Qycle Time

\begin{tabular}{|lcc|}
\hline ATP effects that reduced cycle time & $\begin{array}{c}\text { Frequency } \\
\text { of mention }\end{array}$ & Percent \\
\hline ATP's required project planning and management & 15 & 25.86 \\
Achievement of critical mass of resources with ATP funding & 12 & 20.69 \\
Attraction of additional financial support through ATP "halo effect" & 12 & 20.69 \\
Greater project stability through focus an technical problem & 12 & 20.69 \\
ATP's emphasis on collaboration & 7 & 12.07 \\
\hline Total & 58 & 100.00 \\
\hline Source: Laidlaw & & \\
\hline
\end{tabular}

\footnotetext{
35. ATP, Survey of Applicants 2002, NIST GCR-05-876, June 2005.

" Michael R. Darby, Lynne G. Zucker, and Andrew Wang, Program Design and Firm Success in the Advanced Technology Program: Project Structure and Innovation Outcomes, NISTIR 6943, 2002, p. 10.

II" Mariko Sakakibara and Lee Branstetter, Measuring the Impoct of ATP-Funded Research Consortia on Research Productivity of Participating Firms: A Framework Using Both U.S. and Jopanese Data, NIST GCR 02-830, 2002, p. vi.
} 
Figure 11. Number of Employees Among Year 2000/2002/2004 ATP Applicants

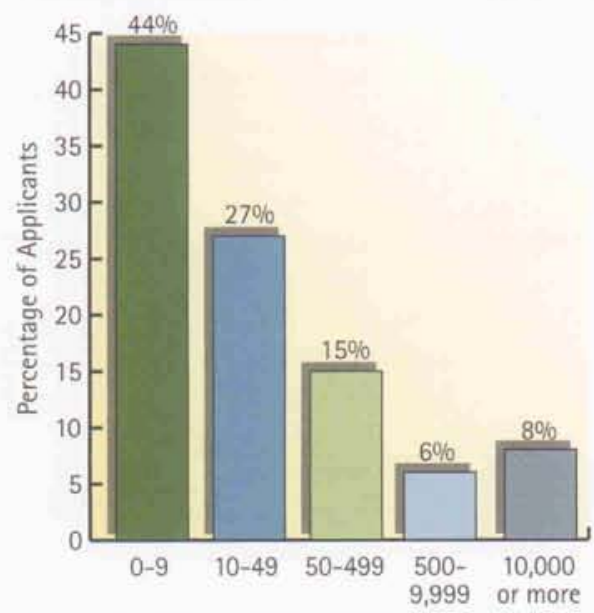

Figure 12. ATP Awards to 620 Small-Firm Participants by Size-Class: 1993-2004

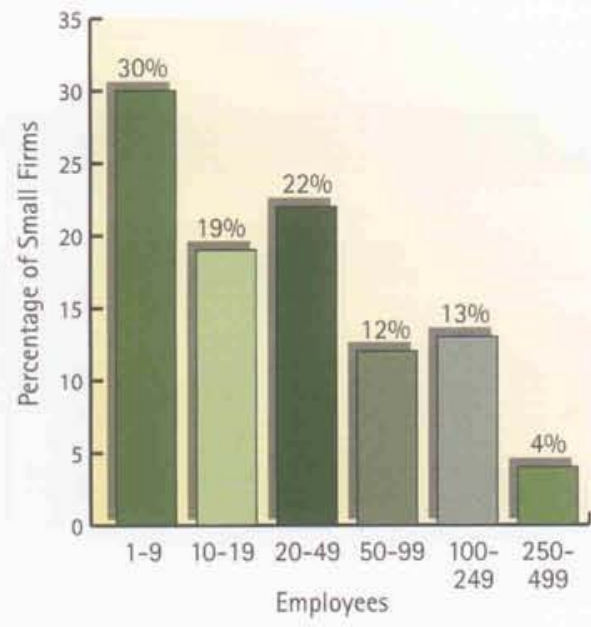

Figure 13. Type of Participation of 620 Small Firms, Funded by ATP, by Size-Class: 1993-2004

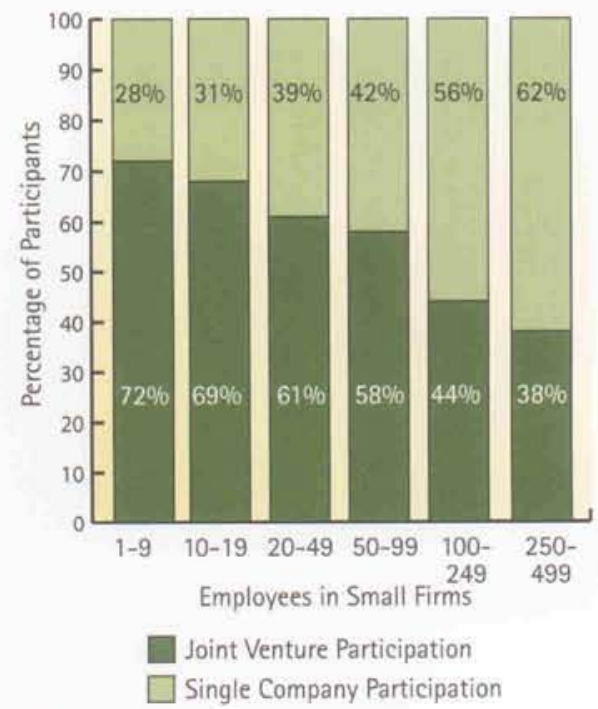

- How do small businesses participate?

- What are the characteristics of start-up companies participating in ATP projects?

Figure 11 suggests that ATP is sufficiently attracting small businesses into the application process. Eighty-six percent of all companies in proposals from the 2000 , 2002, and 2004 competitions were small businesses (fewer than 500 employees). Small-business participation is also evident among awarded ATP projects. Approximately two-thirds $(66 \%)$ of all ATP awards have been to projects led by a small company. More than three-fourths of ATP projects include small-business participation (as project leads, joint venture partners, or subcontractors).

While a small company is defined as having fewer than 500 employees, more than two-thirds $(71 \%)$ of small companies participating in ATP projects have fewer than 50 employees. (See Figure 12.)

The relative size of the small company impacts the likelihood of being involved in a single-company project or participating in a joint venture. Smaller companies are more likely to be involved in singlecompany projects. (See Figure 13.)

ATP surveys were redesigned to encourage a deeper look at small company participation, including the role of start-up companies in ATP projects. There were 272 companies participating in active projects since 2004. Of these 272 companies, 74 percent had fewer than 500 employees. From this universe of small companies, more that one-third (35\%) were start-up companies. Several survey items shed light on the characteristics of start-up companies in ATP projects. Some of the findings include:

- 59 percent of ATP start-ups have a board of scientific advisors and about two-thirds of those boards meet at least monthly.
- Start-up companies have greater shares of their R\&D budgets devoted to basic and applied research (and less to product development).

- About one-half (48 percent) of ATP start-ups have received equity investment after receiving the ATP award.

- Start-up companies are as likely to generate commercial and technical outcomes as non-start-up companies.

\section{Impact on Private Companies}

As they make progress toward commercialization, innovating firms that participate in a project cost shared by ATP may experience growth, higher sales, and increases in capitalized value, revenue, and return on investment. Figure 14 shows the employment change at 75 small companies receiving a single-company award from ATP. ${ }^{19}$ Collaborators and licensees close to such firms are also positioned to make early commercial progress.

The activities of awardees and their collaborators and licensees constitute ATP's "direct path to impact." A study of the first 150 completed ATP projects shows that 91 of these projects yielded a total of 203 new products or processes. Employment changes were profound for the small companies involved -45 companies at least doubled in size; 14 companies grew by more than 1000 percent. Table 7 looks at the progress of the first 150 projects in reaching the commercialization of new technologies and Table 8 provides examples of products and processes realized from the first 150 completed ATP projects. ${ }^{20}$

A recent study looked at the potential impact of optics technologies for use in diverse industrial applications. The resulting miniature capillary arrays have application for process control metrology for petroleum refineries and distribution systems and
19 Performance of 150 Completed ATP Projects, Status Report Number 4, NIST SP 950-4, 2006. 
process control metrology for semiconductor fabrication. Prior to ATP funding, capillary optics technology was a laboratory curiosity. In 1991, ATP funded a new company X-Ray Optical Systems, Inc., (XOS) to address underlying modeling, materials, and manufacturing issues impeding commercial development. The project targeted two major obstacles to commercial use, bending of thousands of miniature glass tubes in a uniform manner to form precisely engineered arcs, and discovering which materials could withstand intense $\mathrm{x}$-ray beam irradiation. While $\mathrm{X}$-rays provide intense penetrating power for precise materials analysis and industrial process control, X-rays until recently could not be easily focused or collimated. ATP-funded capillary optics technology overcomes this problem and offers practical solutions for a wide range of industrial applications. Based on this study, quantified economic benefits include at least $\$ 23,000$ in annual operating cost savings per optic, used in laboratory materials analysis, over $\$ 123,000$ annual energy savings from each in-line sensor engine employing $\mathrm{X}$-Ray optics in petroleum refineries (beginning in 2004), and over $\$ 70,000$ annual energy savings from each in-line sensor engine employing $\mathrm{X}$-Ray optics in petroleum distribution systems (beginning in 2005). The benefits to the nation are expected to far exceed the ATP investment. The net present value (\$2004) is \$184 million (of which $\$ 7.4$ million has been realized to date) or $\$ 75$ in returns for each dollar invested by ATP in the technology. 21

Such returns to companies-versus industries and the economy as a wholeare brought about because of the strict. criteria used by ATP in choosing technologies with the potential for broad impact.
Figure 14. Employment Change at 75 Small Companies Receiving a Single-Company Award

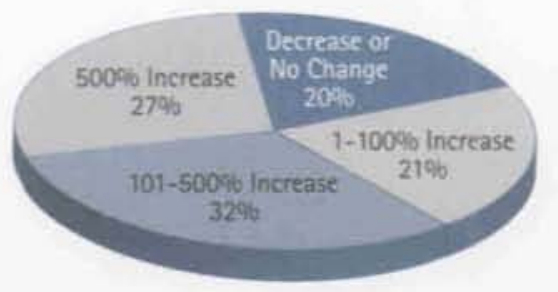

Source: Advanced Technology Program, Performance of 150 Completed ATP Projects, Status Report 4, 2006.

\section{Table 7. Progress of Participating Companies in Commercializing New Technologies}

\begin{tabular}{|lcc|}
\hline Nature of commercialization progress & $\begin{array}{c}\text { Number of } \\
\text { projects }\end{array}$ & $\begin{array}{c}\text { Number of } \\
\text { products/process }\end{array}$ \\
\hline Product/Process on the market & 91 & 203 \\
First product/process expected soon & 18 & 23 \\
On the market with additional product/process expected soon & 17 & 63 \\
On the market or expected soon & 109 & 245 \\
\hline
\end{tabular}

Source: Advanced Technology Program, Performance of 150 Compieted ATP Projects, Status Report 4, 2006.

Table 8. Examples of Products and Processes from the First 150 Completed ATP. Projects

\begin{tabular}{|c|c|c|}
\hline Award name & Technology developed & $\begin{array}{l}\text { Product or process commercialized } \\
\text { or near commercialization }\end{array}$ \\
\hline $\begin{array}{l}\text { Third Wave } \\
\text { Technologies, Ine. }\end{array}$ & $\begin{array}{l}\text { DNA sequencing process to reduce time } \\
\text { and cost of genetic analysis/diagnosis }\end{array}$ & $\begin{array}{l}\text { Cleavase Fragment Length Polymorphism, } \\
\text { and Invader" Technology }\end{array}$ \\
\hline SciComp, Inc & $\begin{array}{l}\text { Component software synthesis for } \\
\text { creating mathematical models in } \\
\text { scientific computing }\end{array}$ & $\begin{array}{l}\text { Scifinance: an automated system for } \\
\text { pricing complex derivative securities }\end{array}$ \\
\hline $\begin{array}{l}\text { SDL, Ine (now JDS } \\
\text { Uniphase Corp.) }\end{array}$ & $\begin{array}{l}\text { Monolithic process to produce } \\
\text { multiwavelength arrays of individually } \\
\text { selectable laser diodes }\end{array}$ & $\begin{array}{l}\text { Laser products for several markets, } \\
\text { including high-speed color reprographics, } \\
\text { optical data storage, displays, medical } \\
\text { therapy, and telecommunications }\end{array}$ \\
\hline
\end{tabular}

27 Thomas M. Pelsoci, Photonics Technologies: Applications in Petroleum Refining, Building Controls. Emergency Medicine, and Industrial Materials Analysis, NIST GCR 05-879. 


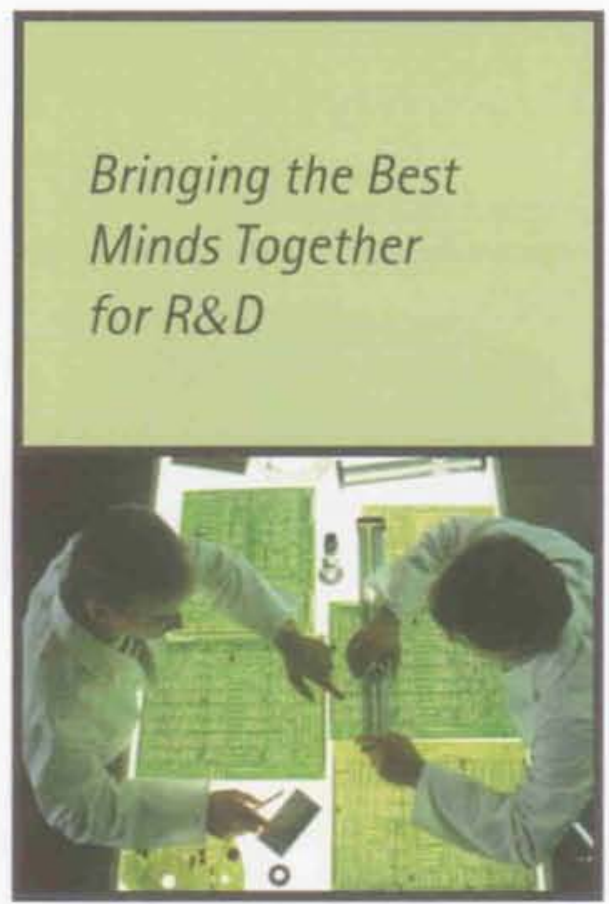

\section{Collaboration in ATP Projects}

ATP's statute includes a mandate to "aid industry-led United States joint research and development ventures." Various studies by the ATP Economic Assessment Office and others have looked at joint ventures in terms of their stability, the factors that help them succeed, their benefits and costs, and the role of universities. A 1995 study of eariy ATP projects found that the average joint venture had six members, and that 43 percent of joint venture members -forged subcontracting relationships with an average of five additional companies. ${ }^{-22}$

More recently, an analysis of BRS data from 424 participants in 199 ATP projects provides further evidence that collaborative activities are extensive. Among singlecompany applicants and joint ventures, 86 percent of respondents had collaborated with others on projects, with 69 percent of these companies stating that ATP brought about the collaboration "to a great extent." The same study noted that many strategic alliances-with producers, suppliers, customers, distributors, and licensing partners - had been formed primarily to commercialize ATP-funded technologies. ${ }^{23}$

Another study of firms that won-or failed to win-ATP awards determined that the program successfully encouraged applicants to propose projects featuring collaboration, frequently with entirely new partners. While 79 percent of 1998 applicants included other organizations in their proposals to ATP, 59 percent of award winners sought first-time partnerships, while only 42 percent of non-winners sought first-time partnerships. These numbers support the idea that the selection process at ATP encouraged new partnerships by favoring the selection of proposals that included new partnership opportunities. ${ }^{24}$

Table 9 summarizes the incidence of collaboration as tracked in a number of surveys throughout the life of ATP. Similar findings resulted from the Survey of Applicants 2002, which studied companies submitting proposals to ATP in the 2002 competition.

Table 9. Summary of Study Findings on Frequency of Collaboration

\begin{tabular}{|llll|}
\hline $\begin{array}{l}\text { Percent } \\
\text { collaborating }\end{array}$ & Sample & When surveyed & Source \\
\hline $46 \%$ of participants & $\begin{array}{l}26 \text { participants in } \\
1990 \text { competition }\end{array}$ & $1992-1993$ & Solomon Associates survey \\
\hline $\begin{array}{l}52 \% \text { of single- } \\
\text { company awardees }\end{array}$ & $\begin{array}{l}125 \text { participants in three } \\
\text { competitions 1990-1992 }\end{array}$ & 1995 & Silber \& Associates survey \\
\hline $79 \%$ of applicants & $\begin{array}{l}395 \text { applicants in 1998 } \\
\text { competition }\end{array}$ & 1999 & Feldman and Kelley survey \\
\hline $86 \%$ of participants & $\begin{array}{l}424 \text { participants in } 199 \\
\text { projects, 1993-1997 }\end{array}$ & 1998 & Powell and Lellock \\
\hline $\begin{array}{l}\text { 87\% of completed } \\
\text { projects }\end{array}$ & $\begin{array}{l}150 \text { first completed } \\
\text { projects }\end{array}$ & $1997 / 2003 / 2006$ & ATP \\
\hline $85-90 \%$ of applicants & $\begin{array}{l}891 \text { applicants in 2002 } \\
\text { competition }\end{array}$ & 2006 & ATP/Westat \\
\hline
\end{tabular}

\footnotetext{
22 Silbet and Associates, Survey of Advanced Technology Program 1990-1992 Awurdees: Company Opinion About the AIP and its Early Effects, AIP, 1996.

21 Powell and Lellock, Development, Commerciolization, and Diffusian of Enobling Technologies: Progress Report, 2000, p. 19.

24 Feldman and Kelley, Winning on Aword from the Advanced Technology Program: Pursuing Rso Strategies in the Public Interest and Benefiting from a Halo Effect, NiSTR 657, 2000, pp. 19-20.
} 


\section{University Involvement}

In its first decade of operation, ATP came to recognize the importance of universities as collaborators in projects. Universities involved in R\&D efforts provide major benefits to the participants and their research: Companies working with universities gain access to eminent researchers, while universities collaborating with private firms in an ATP project acquire needed additional funding and, often, insights into industry problems that hone their research efforts. Table 10 shows the prominent role played by universities in the first 150 completed ATP projects.

Nearly 70 percent of joint ventures and more than 50 percent of single-company projects involve universities; one study found that as of 2006,55 percent of all ATP projects included universities as joint venture members or subcontractors. ${ }^{25}$ As reflected in Figure 15, 73 percent of firms included in the Survey of Applicants 2002 considered university involvement to be a factor in proposals to ATP. It was "somewhat" or "very critical" to 42 percent of those surveyed.
A 2002 study queried 47 ATP participants about universities as research partners (collaborators or subcontractors). Results from such a small sampling couldn't provide accurate measures, but showed important trends:

- Projects involving universities usually took on more ambitious research.

- Respondents working with a university participant were more likely to report difficulty in acquiring and assimilating knowledge needed for progress toward the project's goal.

- University participants were more likely to act as ombudsmen or referees in the process.

- Projects involving universities tended to end in success, but took longer to complete-perhaps because of the more ambitious nature of the research. ${ }^{26}$

The Branscomb study also found that universities played a vital role in ATP research projects. Said the study, "Universities represent a vital source of new technical ideas for firms of all sizes. The ferment of industrial relationships pervades even the most elite academic institutions. ${ }^{-27}$
Figure 15. How Critical Was University Involvement to Proposed ATP Project? From Survey of Appficonts 2002

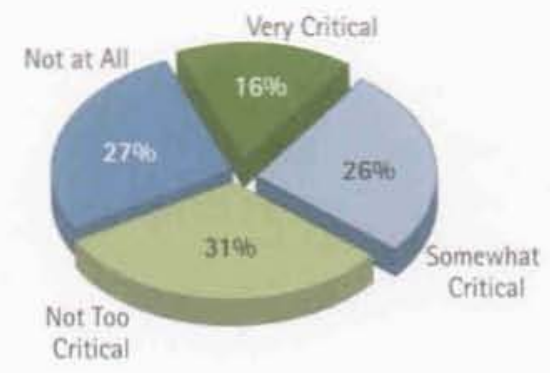

Table 10. Collaborative Activity of the First 150 Completed Projects

\begin{tabular}{|lc|}
\hline Type of collaboration & Percent \\
\hline Collaborating on R\&D with other companies or non-university organizations & 61 \\
\hline Close R\&D ties with universities & 49 \\
\hline $\begin{array}{l}\text { Collaborating on R\&D with other companies or non-university organizations } \\
\text { OR close R\&D ties with universities }\end{array}$ & 75 \\
\hline $\begin{array}{l}\text { Collaborating on commercialization with other organizations } \\
\text { Collaborating in one or more of the above ways }\end{array}$ & 46 \\
\hline Source: Advanced Technology Program, Ferformance of 150 Completed AIP Projects. Stotus Report 4.2006. \\
\hline
\end{tabular}

\footnotetext{
25 From ATP Business Reporting System data.

it Bronwyn H. Hall, Albert N. Link, and John T. Scott, Universities os Reseorch Partners, NIST GCR 02-829, 2002, pp. vi-vii.

27 Branscomb et al. Managing Technical Risk, p. 6.
} 


\section{There Is No 'Lone Ranger'}

It doesn't happen alone. Innovation-from initial idea through end use by industry and the American people-involves companies of all sizes working with universities, non-profits, federal labs, and other independent researchers. As shown below, ATP fosters collaborative efforts early in the process to enhance the likelihood of success. All participants bring unique capabilities; working together allows them to leverage strengths across organizations. When larger and smaller firms collaborate, they realize powerful synergies. Larger firms can gain access to promising new technologies, while their smaller partners can benefit from big-company expertise in product commercialization and marketing.

More than one-quarter (28 percent) of ATP projects are formal joint ventures, and ATP has studied the factors that influence the success of R\&D joint ventures in achieving technical and commercialization objectives. ${ }^{28}$ On average, these joint ventures include 4.2 partners and 6.6 total organizations, including subcontractors. Nearly 70 percent of joint ventures involve universities and 80 percent include a small company.

Although 71 percent of ATP-funded projects are led by a single company, 4 out of 5 of these projects include other organizations. Single-company projects usually include two additional organizations at one time or another. More than 75 percent of all singlecompany projects involve a small company; more than half include a university as a subcontractor.

\section{Changes in Collaborative Relationships}

Because ATP projects typically unfold over a number of years, changes in the makeup of a joint venture can take place. One survey found that 59 percent of projects were carried out without changes in the group of collaborating organizations. The same survey found that for " 23 percent of the projects, at least one participating company was changed to a different company, and [for] 18 percent, at least one participant, along with that company's piece of the project, was dropped altogether." 29

Such changes in collaborative arrangements are important because they raise an issue for ATP project managers: At what point does a change in project makeup or goals no longer comply with the original criteria by which the project was selected for an ATP award? ${ }^{30}$ By analyzing changes within projects, project managers can better understand this issue. It therefore represents a valid component of evaluation.
Determining Collaborative Success In 2006, the ATP Economic Assessment Office published a study of ATP-funded joint ventures that had been surveyed in 2003. This study investigates the relative importance of a set of joint venture design factors (e.g., joint venture structure characteristics such as number of partners and type of partners, and firm-level attributes such as prior experience with joint ventures and existing R\&D capabilities) and joint venture management factors (e.g., frequency of communication among partners, effectiveness of governance arrangements). This study of 397 firms involved in 142 R\&D joint ventures finds that "joint venture success" is a firm-level phenomenon; the variance found within a joint venture in terms of firm-specific performance outcomes is great enough that one individual firm's assessment of joint venture success cannot be used as a proxy for a partner's joint venture success. The results indicate that more ambitious projects have better outcomes and joint venture leader companies have better outcomes. Frequent communication and the establishment of effective governance arrangements are important factors in determining success. ${ }^{31}$

New Ties and Company Relationships: Single Company versus Joint Venture Applicants (From Survey of Applicants 2002)

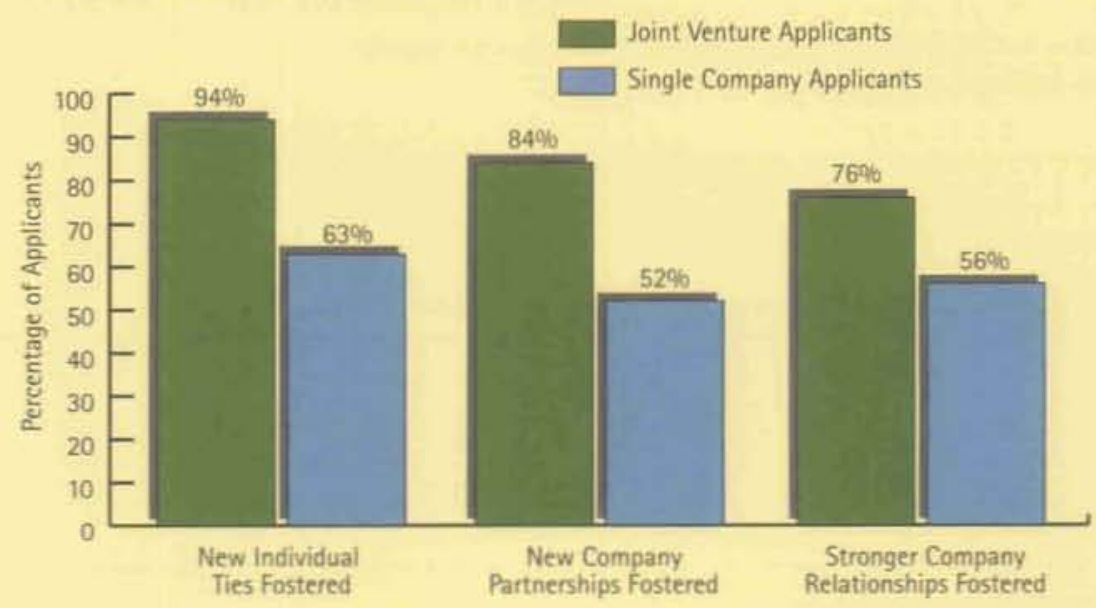

Jeffrey H. Dyer et al, Determinants of Sucess in RS.D Alliances, NistiR 7323, August 2006. 


\section{Benefits and Costs of Collaboration}

A 2003 survey of ATP-funded joint ventures that received funding between 1991 and 2001 found that the most important motivation for a joint venture to form was an opportunity to benefit from the complementary R\&D expertise of their partners (see Table 11). In fact, most ATP joint ventures would not have formed without an AIP award. The majority of respondents reported that the joint venture undertook research that represented a new direction for both the company and the industry. ATP-funded joint ventures are more ambitious than other research in their industry and more technically challenging than typical company projects. These joint venture projects have higher technical risk and longer time horizons for realizing revenues or cost savings than typical projects at their companies.
About one-third of all joint venture participants reported that their AIP projects are based on university research with more than half of the largest joint venture participants (in terms of number of partners) reporting that their research is based on university research. An ATP award fosters collaboration and trust among joint venture partners, and ensures stability of company funding for the project. The joint venture partners reported that the exchange of technical know-how was critical in achieving research success.

Table 11. Motivations for Collaborations

\begin{tabular}{|c|c|}
\hline Benefits from collaboration & $\begin{array}{l}\text { Percent indicating "important" } \\
\text { reason for forming joint venture }\end{array}$ \\
\hline Benefit from complementary R\&D expertise & $83 \%$ \\
\hline Pool resources with other firms & $72 \%$ \\
\hline Address a technical problem that is common to the industry & $72 \%$ \\
\hline Gain knowiedge and learn from other firms & $66 \%$ \\
\hline Access commercialization capabilities of other firms & $42 \%$ \\
\hline \multicolumn{2}{|c|}{$\begin{array}{l}\text { Source: Jennifer O'Brien. Andrew Wang, Stephanie Shipp, Kathleen MeTigue, Findings from the Advanced Technology } \\
\text { Program's Survey of Joint Ventures, NIST GCR 06-889. }\end{array}$} \\
\hline \multicolumn{2}{|c|}{ Note: The response categories 'extremely important' and 'very important' are combined for this table. } \\
\hline
\end{tabular}

\footnotetext{
23 Silber and Associates, p. 33.

30 Responding to project changes requires balancing the need for flexibility to allow firms to make changes needed for project viability, with the need to adhere to AIP's legislated mandate to fund high-risk research to develop technologies with potential for generating broad-based benefits. To protect the public trust, AIP decides on a case-by-case basis, after reviewing changes in project makeup, whether to approve or disapprove the changes.

In Jeffrey Dyer et al, The Determinants of Success in RSD Alliances, NISHR 7323, August 2006.
} 


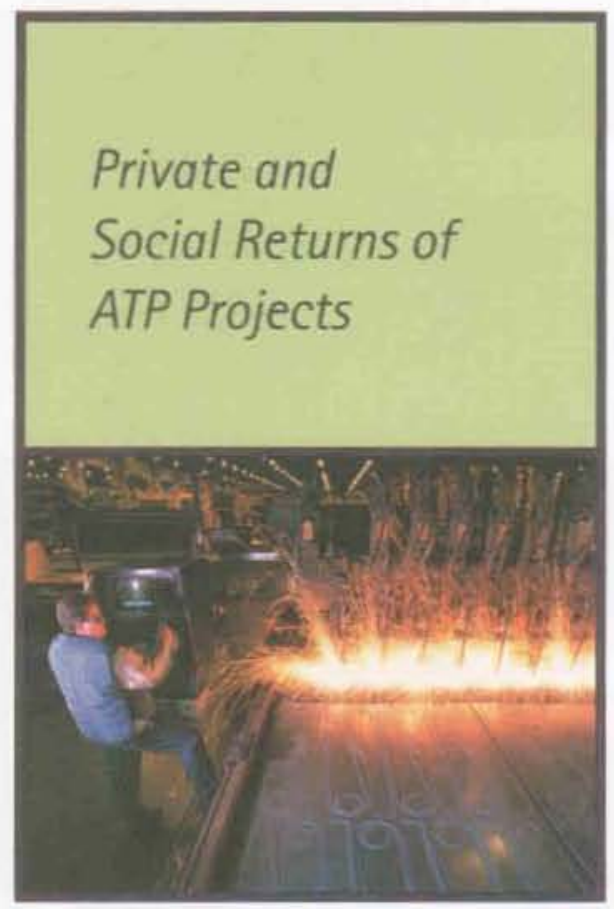

\section{Spillovers}

ATP delivers technology impacts and achieves broad-based benefits to society via two pathways:

1. An indirect route by which knowledge, leading to private and social returns, is diffused through publications, presentations, patents, and other means of knowledge communication.

2. A direct roufe by which award recipients and their collaborators accelerate development and commercialization of technologies, resulting in private and social returns, and also in spilloversproducts and processes that benefit other companies, other industries, and the American people.

Impact in the form of spillovers can take many forms. ${ }^{32}$ For example, a look at products resulting from ATP projects yields the following:

- More than 8 out of 10 products reduce their customers' cost of production.

- On average, products have more than 250 customers.

- Half of companies with products have customers outside their own industry.

- Depending on the technology area, 10-18 percent of commercial applications involve licensing outside their own industry,

- Products resulting from ATP technologies are finding their way into a host of both upstream and downstream products.

Because these spillovers get at the heart of ATP's mission, the ATP Economic

Assessment Office has devoted considerable effort to measuring them. Proof of large spillovers supports the wisdom of a public investment in high-risk, high-impact technologies. A number of studies have looked at two important types of spillovers that benefit the nation: knowledge spillovers and market spillovers.

\section{Estimating Knowledge Spillovers}

Data revealed by both the ATP Business Reporting System and the Status Report of Completed Projects strongly indicate that as a portfolio, ATP-funded projects are generating outputs with the potential to lead to both knowledge and market spillovers. ${ }^{33}$ These outputs inciude publications, patents, patent citations, collaborative linkages, and products and processes - all of which can lead to spillovers.

A 2002 survey of ATP applicants found that ATP is selecting projects likely to generate large knowledge spillover effects. ATP encourages R\&D collaborations among companies and with other organizations to promote infrastructural change across an industry and to address technology challenges that are larger than one company could address alone. Evidence from this survey shows that ATP successfully fostered new directions and partnerships-nearly all ATP applicants report that their proposed project represented a new R\&D direction for their industry or technology field:

- 68 percent of ATP applicants say their proposed project fostered new individual ties.

- 57 percent of ATP applicants say their proposed project fostered stronger company relationships.

- 60 percent of ATP applicants say their proposed project fostered stronger company relationships.

\footnotetext{
32 John Nail and Hayden Brawn, ldentifying Technology Flows and Spillovers Through NAICS Coding of ATP Project Purticipants, NuSTIR 7280, April 2006; and ATP fact Sheet: Customers Across Many Industries Enjoy Significant Benefits.

33 Poweil and Leilock, Development, Commercialization, and Diffusion of Enabling Technologies: Progress Report, 2000; and Advanced Technology Program, Performance of 750 Completed ATP Projects, Status Report, 2006.
} 
Another study from the same time frame, by Cohen and Walsh, focused directly on the measurement of knowledge spillovers. This study linked spillovers to appropriability economic factors limiting a company's ability to capture profits from its own innovation-and the strategies they use to secure those profits. Results showed that information flowing inside an industry help the R\&D efforts of individual firms. The finding is consistent with the core propositions that led to ATP's establishment and its key design features. In particular, by selecting generic technologies applicable to many firms both upstream and downstream, and by supporting specific joint ventures, ATP can foster the generation of knowledge spillovers, and thus increase the productivity of a firm's R\&D. ${ }^{34}$

Other studies provide additional evidence of the potential of projects for large knowledge spillovers. Figure 16 displays the distribution of the first 150 completed projects by the number of patents filed-including those granted and not yet granted.

\section{Estimating Market Spillovers}

Several ATP-funded evaluations have sought to estimate the magnitude of market spillovers related to ATP projects. An early study by Research Triangle Institute (RTI) measured market spillovers for a portfolio of seven ATP-funded products in tissue engineering, focusing on the gap between estimated social and private returns. The market spillovers - the gap between social and private returns - are seen to be large due to estimates of the value of changes in quality-adjusted life years for patients from the new and improved medical treatments developed, in addition to treatment cost differences. RTI concludes that the private sector might under-invest in high-risk R\&D due to the fact that "the social returns far outweigh the returns to the companies developing, commercializing, and producing these high-risk projects." This in turn indicates the importance of ATP in pursuit of such technologies to offset the lack of private investment. ${ }^{35}$
Figure 16. Distribution of Projects by Number of Patents Filed

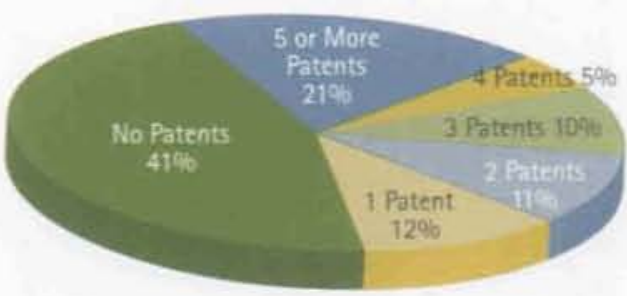

Source: Performance of 150 Compieted ATP Projects, Status Report Number 4 ,

\footnotetext{
${ }^{34}$ Wesley N. Cohen and John P. Walsh, RSD Spillovers, Appropriability and R\&D Intensity: A Survey Based Approoch, ATP, 2000.

Is Sheila A. Martin et al., A Framework for Estimating the National Economic Benefits of ATP Funding of Medical Technologies, NiST GCR 97-737, 1998
} 


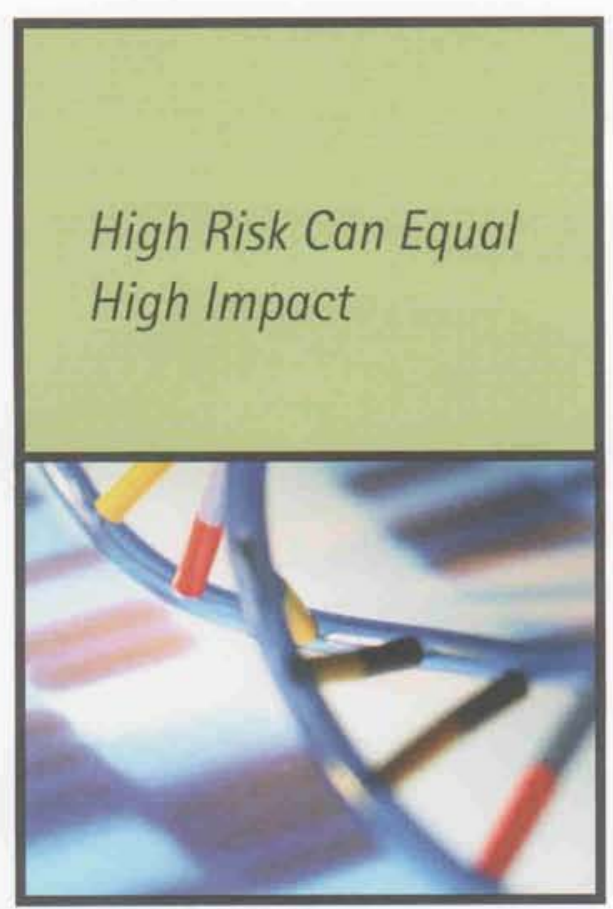

\section{Profiling ATP Investments}

The Advanced Technology Program supports innovation by providing awards and resources to organizations that tackle long-term, high-risk research problems. For the program, the term "high-risk technology research" accepts a wide range of results, from outstanding success to outright failure. Some very high performers solve challenging and significant technical problems, make new technical knowledge available to others, and accelerate its commercial use. Many more participants reach levels of solid performance; they may be strong technically while achieving little or only some follow-on effort toward commercialization. Another group fails to show sustained direct progress toward commercialization, although their research may produce patents or publications and lead to other breakthroughs later on.

ATP rates projects on a scale from 0 to 4 stars, with 0 or \& representing poor overall performance, tris signaling moderate performance, isitit strong performance, and thets $x$ outstanding performance. Figure 17 shows the overall performance of the first 150 completed ATP projects.

\section{Returns on Investment}

ATP has been funding long-term research for over a decade and a half and provided nearly $\$ 2.3$ billion to innovators for 768 high-risk research projects from 1990 through 2006. Industry matched this funding with $\$ 2.1$ billion in cost sharing. In return, as previously noted, 23 projects from the program's portfolio yielded over $\$ 1.2$ billion in realized economic benefits to the nation, with additional prospective benefits valued at $\$ 6.7$ billion. Participating companies, national laboratories, and academia have researched an array of breakthrough technologies to improve U.S. industrial processes, energy reliability, product durability, and products and services-as well as the quality of life of Americans.

In the field of health care alone, several ATP-sponsored technologies have resulted in significant breakthroughs in patient care, including:

- Stem cell replication technology (strity) developed by Aastrom Biosciences, Inc., of Ann Arbor, Michigan, estimated to produce $\$ 47$ million in cost savings, attributable to ATP, by reducing the time and effort associated with collecting stem cells for use in bone marrow transplants. ${ }^{36}$

Figure 17. Star Performance Rating of Completed Projects

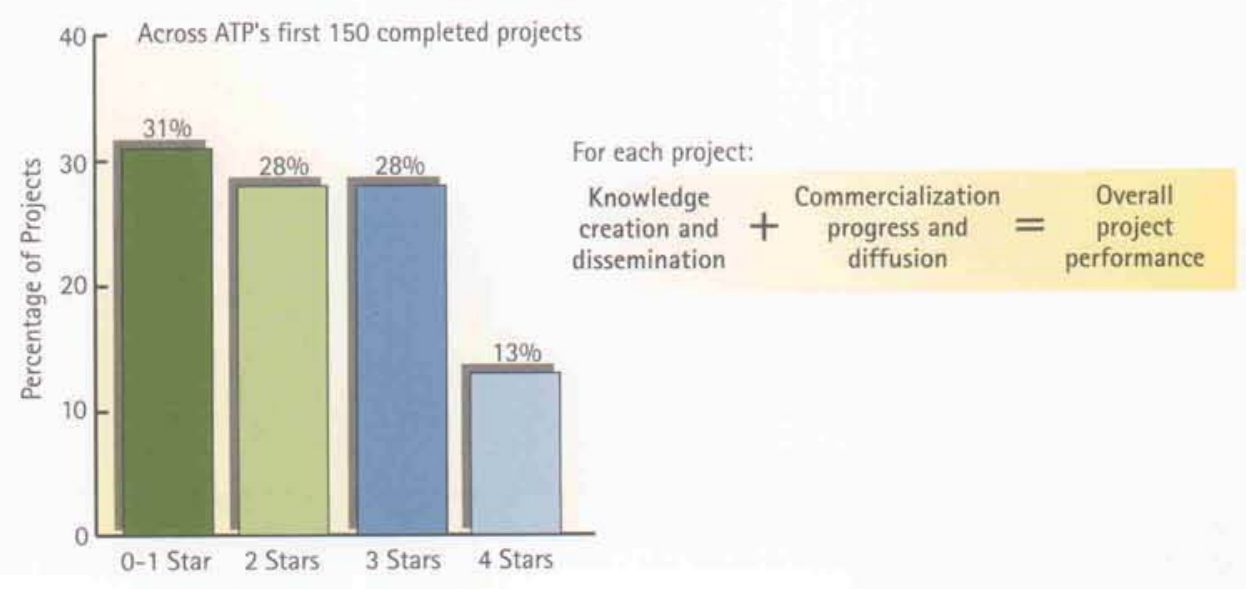


- A new generation of digital

mammography and digital radiology

technology developed by GE Global

Research of Schenectady, New York; this

breakthrough provides more accurate

detection methodologies at lower cost

and has a net present value of \$219-

339 million (2002 dollars) in costs

savings to health care facilities and

patients, with a benefit-to-cost ratio of

the ATP investment of $125: 1$ to $193: 1{ }^{37}$

- High-energy imaging technology

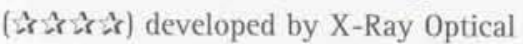

Systems, Inc., of Albany, New York, that reflects X-rays and neutrons through thousands of tiny, curved glass tubes; 7 patents have resulted, along with use by NASA and the National Institutes of Health, a major 1996 photonics award, company growth from 1 to 22 employees, and recognition in $R \& D$ Magazine. ${ }^{38}$

- Surgical repair of cartilage and tendons using highly pure, manufactured

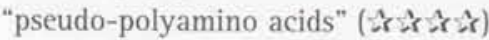
developed by Integra LifeSciences Corporation of Plainsboro, New Jersey; this polymer replaces screws, plates, pins, wedges, and nails in bone fracture repair at a savings of $\$ 98$ million in the avoidance of second surgeries; the technology received a 1997 patent and has been recognized through a major award, numerous presentations, 15 publications, and licensing to commercial partners. ${ }^{39}$

\section{A Technology Sample}

As shown in this section, ATP's many assessment tools reveal the impact of each completed and ongoing project. Results from selected projects follow.

Photonics Technologies: Applications in Petroleum Refining, Building Controls, Emergency Medicine, and Industrial Materials Analysis ${ }^{40}$

Photonics is a class of enabling infrastructure technologies that promises broad economic benefits by bringing together technical advances from optics and electronics to develop high-performance manufacturing processes, ultra-high-sensitivity metrologies, and new products. Recognizing the potential for broad-based economic impact from reversing these tendencies, ATP funded more than 120 photonics projects from the time of its inception in the early 1990 s.

Public benefits, excluding benefits to the innovating firm, will be realized by:

- Health care institutions and by industrial and commercial users of new photonics technologies.

- Consumers of improved medical services, industrial products, and commercial services.

- Society-at-large, enjoying reduced environmental emissions and other benefits.

X-Ray Optical Systems of Albany, NY, used ATP cost-share to develop high-transmission efficiency optics using tiny capillary glass tubes to guide and focus $\mathrm{X}$-rays. The project led to fully commercial optical products used as performance-enhancing components in industrial materials analysis, as well as optical components in industrial process sensors to detect trace-level contaminants in petroleum refining and distribution.

Public benefits to industry users and the general public from this ATP cost-shared project were quantified on the basis of conservatively estimated unit sales estimates of up to 300 performance-enhancing X-ray optics and process sensors each year.
"Progress in freezing and cooling in

the 20th Century often was

measured by new, man-made refrigerants. Now industry is rediscovering natural solutions."

-Food Engineering Magazine

November 1, 2003

Public returns on ATP's investment

(retrospective and prospective) over the period from 1994-2014 indicate net present values of

\$184-\$233 million and \$75-\$94 of benefits for every dollar invested. Retro-spective benefit analysis alone, over the 1994-2003 period, indicates a realized net present value of $\$ 7.4$ million and realized benefit-to-cost ratio of $\$ 4$ of public benefits for every dollar invested by ATP. These economic performance metrics reflect cost savings from the use of $\mathrm{X}$-ray optics in industrial materials analysis, as well as energy savings and corresponding cost savings at U.S. petroleum refineries and distribution systems.

Ion Optics, Inc. of Waltham, MA, used ATP cost-share to develop photonic crystal sensors that could be tuned to accurately, reliably, and inexpensively measure $\mathrm{CO}_{2}$ levels (the first target gas for which this technology is commercially viable) in the expired breath of emergency room patients and in commercial office buildings. Commercial production of photonic crystal $\mathrm{CO}_{2}$ sensors is targeted for 2006 with annual sales expected to ramp up to 400,000 units for emergency medicine applications and to 290,000 units for commercial building controls applications over the next 10 years.

Medical use of photonic crystal $\mathrm{CO}_{2}$ sensors is expected to result in more than 112,000 prevented in-ambulance deaths of trauma victims and critically ill patients on their way to U.S. emergency rooms over the 2006-2015 period. In addition, cost savings from avoided medical treatments, as well as energy savings (and associated cost savings) from commercial building control systems are projected to result in net present values of $\$ 201-\$ 245$ million and \$244-\$298 of benefits for every dollar invested.

\footnotetext{
37 Thomas M. Pelsoci, Low-Cost Manufacturing Technology for Amorphous Silicon Detector Panels: Applications in Digital Mammogrophy and Radiography, NIST GCR 03-844, February 2003.

38 ATP "Gem": X-Ray Optical Systems, Inc.

39 ATP "Gem": Integra LifeSciences Corporation.

${ }^{40}$ Thomas M. Pelsoci, Photonics Technologies: Applications in Petroleum Refining, Building Controls, Emergency Medicine, and Industrial Materials Analysis, NIST GCR 05-879.
} 


\section{What Is a Societal Benefit?}

In creating ATP, Congress believed that for the federal government to support commercially relevant technology development, the resulting breakthroughs would need to benefit more than one company, and more than one industry, with the ultimate beneficiaries being the American economy and the American people. This pollination of technologies across sectors would inevitably yield rewards for society as a whole, as companies prosper, the economy strengthens, jobs are created, and new technologies reduce costs and enhance quality of life. From the technologies sampled on these pages to many others now in development, Americans are reaping the benefits of breakthroughs sponsored by ATP every day, in literally thousands of ways.
"It was at a stage where it was for too risky to get venture capital."

- David Wallace, Research Director, MicroFab Technologies, Inc.

\section{ATP and Homeland Security}

In its history, ATP has made 141 investments to technologies that touch on the area of U.S, homeland security. The total investment in these AIP projects has been $\$ 669$ million\$364 million by ATP and another \$305 million by industry. About $\$ 145.2$ million, or 40 percent, was devoted to critical physical infrastructure projects, and $\$ 135.4$ million, or 37 percent, in research related to chemical, biological, or radiological/nuclear exposure. In the aftermath of the September 11, 2001 attacks on New York City and Washington, D.C. ATP is helping to enhance the nation's ability to respond to and even prevent terrorism. For example:

- GE Global Research of Schenectady, New York, has developed digital imaging technology of unprecedented detail and clarity using amorphous silicon panels to detect heart disease and breast cancer. The same technology could also be used to assure the structural integrity of aircraft and as a means of airport customs and cargo inspection.

- Genex Technologies, Inc, of Kensington, Maryland, is developing revolutionary facial recognition technology that integrates hardware and software and uses true 3D imaging for face enrollment, identification, and verification at airports, border crossings, and sensitive facilities.

- Quantum Signal, LLC, of Ann Arbor, Michigan, is developing 90-percent accurate biometric authentication through face or voice recognition for occupant sensing in vehicles, passenger screening at airports, and automated verification in telecommunications applications.

\section{Materials}

Composite Utility Poles (1995) At th A Ebert Composites Corp., Chula Vista, Califonia. and Strongwell Corp., Bristol, Virginia

Truditional apright utility poles and touers have disadvantages. Metal towers are difficult to transport, require teams of installers, and must be ireated turice a year for comrosion. Wood poles require anti-decay treatments with chemicals that can leach into local water supplies.

Ebert Composites Corporation proposed to use composite materials to madically improve the design, manufacture, and cost of utility towers and poles. The company believed that composites would be price competitive with steel and wood, more durable, fower maintenance, and conducive to production in minutes rather than the hours necessary to manufacture a steel pole. Ebert did not, however, have access to the resources needed for the intensive research that would result in such a product. Today, four years after completion of the ATP project, industries from oil to defense are interested in the technology, as are state DOTs.

Investment: $\$ 1.03$ million by ATP; $\$ 303,000$ by the participants

Project achievements:

- All technical goals met

- A 97-percent reduction in manufacturing time for electric utility towers as well as cost savings and higher quality due to the development of innovative equipment

- Commercialization of composite structures for electric power poles and lattice towers

- Two patents for "high shear strength pultrusion"

Spillovers:

- The 1999 Charles Pankow Award from the Civil Engineering Research Foundation

- Publication in a Society of Manufacturing Engineers journal (1999)

- Presentation of a paper at the Composite Manufacturing and Offshore Operations conference (2000)

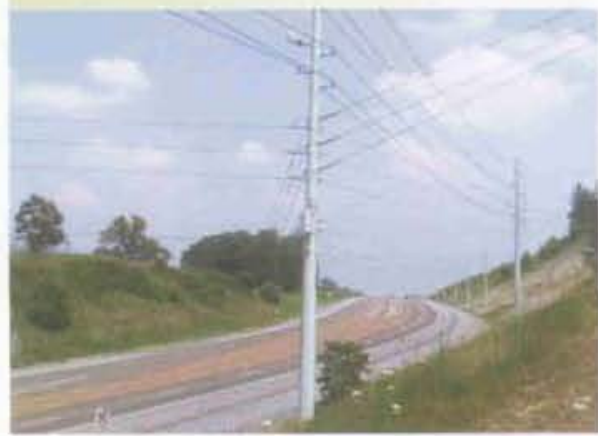




\section{IT and Electronics Breakthroughs}

In the past decade, the areas of information technology (IT) and electronics have received increasing attention from ATP. The program strives for measurable productivity changes and accelerated technology development in electronics, electrical, photonics, memory storage, systems language and integration, displays for computers and televisions, and many other areas in IT and electronics. Important breakthroughs include:

- Collaborative Planning, Forecasting, and Replenishment (CPFR') technology $(\hat{x} \not \hat{x})$ developed by Benchmarking Partners of Cambridge, Massachusetts, that uses the Internet for supply chain coordination, reducing costs for consumers and making the industrial and retail sectors more competitive in global markets. One food manufacturer saw a 17-percent increase in sales and an 18-percent decrease in inventory; a women's clothing manufacturer experienced a 45-percent increase in sales and a 23-percent decrease in inventory. ${ }^{41}$

- New technology for health care legacy systems $(\boldsymbol{r} \dot{x} \boldsymbol{x})$ that make it possible to integrate systems throughout the health care industry. With 15-percent funding from ATP and 85 percent from $3 \mathrm{M}$, the technology became the foundation for the Department of Defense Military Health System and is used in 150 health care facilities in the U.S. ${ }^{42}$

- Speech recognition software ( $\vec{r} \boldsymbol{k} \boldsymbol{r} \boldsymbol{r}$ ) developed by Kurzweil Applied Intelligence, Inc., of Waltham, Massachusetts, that helps computer novices and the severely disabled to communicate by saying phrases in a natural language, touching a computer screen with a pen or mouse, or typing: 100,000 clients and 4 patents resulted, although the future of the technology was uncertain. ${ }^{43}$

\section{Computer and Television Hardware}

Dramatically Better Video Displays

(1994) ar trt Displaytech, Inc,

Longmont, Colorado

With the explosion in multi-media teclmologies-from large-screen TVs to videophones and personal digital assistants (PDAs)-high-resolution displays have been highly sought after, but inhibited by the constraints of liquid crystal display (LCD) technology and the enormous costs of research.

In the quest for better displays, researchers tumed to a new technology-the ferroetectric liquid crystal (FLC). Displaytech, a 20employee small business, sought to mass produce FLC display chips using "dummy" silicon wafers.

Investment: $\$ 1.79$ million from ATP:

$\$ 1.5$ million from Displaytech

Project achievements:

- Production capacity increased from one chip at a time in 1994 to a capacity of 100,000 chips a month by 2000

- 3 patents related to liquid-crystal displays

- Employment up from 20 employees to 150

- Technical barriers overcome to achieve a 600-percent increase in final image quality, a 100-percent increase in product liferime, and a decrease in per-unit costs from $\$ 6,000$ to $\$ 160$

Spillovers:

- Joint ventures and partnerships formed with Hewlett Packard, Miyota, Motorola, Samsung, JVC, Concord, and Densitron Technology

- Network of worldwide licensees of Displaytech technology

- New FLC chip applied to flat-pand HDTVs. graphics arrays produced by Hewlett Packard, and displays produced by JVC. Samsung, and Minolta
High-Quality Color Displays for Televisions (1996) stret th

ColorLink, Ine, Boulder, Colorado

For years, color televisions and computer monitors relied on color pirels composed of three monochrome pirels, each assigned a primary color (red, green, or blue). Haurever. new types of electranics, from digital video cameras to PDAs, web phones, and flatsereen TVs, require higher resolutions than the pirel can accommodate.

Colorlink's new model for high-resolution display and imaging relies on a highefficiency, tunable filter to encode color images in a rapidly changing sequence instead of traditional pixilated, slow-moving color switches. However, the development curve was too long to attract venture capital. An ATP award allowed Colorlink to partner with Polaroid Corporation, Kent State University of $\mathrm{Ohio}$, and others to develop color management solutions for liquid crystal on silicon (LCOS) technology in High Definition televisions, dispiay monitors, and other eiectronic devices. LCOS technology is now being used with color separation and recombination modules from Colorlink (pictured below) found in a new generation of JVC High Definition large-screen televisions.

Investment: $\$ 1.79$ million by AIP: $\$ 340,000$ by Colorlink

Project achievements:

- 8 patents associated with imaging and display

- Cost and size of projection displays decreased

- Display resolution and brightness improved

Spillovers:

- Entered into partnerships with Thomson RCA. Arisawa Manufacturing, and original equipment manufacturers

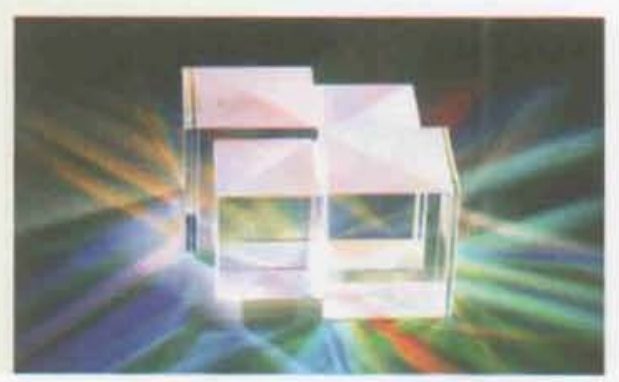

\footnotetext{
4 AIP Statcs Report 94-04-0046, December 2001.

a ATP Status Report 94-04-0027, December 2001.

43 ATP Status Report 93-01-0101, June 2002.
} 
Components for Easily Assembled Software Systems ${ }^{44}$ ATP ComponentBased Software Development (CBSD) Focused Program (1994-2000)

Historically, about 85 percent of all large software systems used in business have been customized applications with code written for a specific firm. Very little code is reused.

These systems are critical to the operation of large firms, expensive to develop and maintain, and sometimes unreliable.

The use of components-independent pieces of software that interact with other components in a well-defined manner to accomplish a specific task-could facilitate the development of "off the shelr" large applications that are lower cost, and easier to maintain and upgrade.

Investment: $\$ 42.06$ million for 24 projects; $\$ 55$ million by private firms

Economic impact:

- Technology valued at $\$ 840$ million (in year 2000 dollars) based on 8 of the most successful projects

- An internal rate of return of 80 percent

- A benefit-to-cost ratio of 10.5:1

- Total producer surplus of $\$ 538$ million (in year 2000 dollars)

- Total consumer surplus of $\$ 1.13$ billion (in year 2000 dollars)

Industry benefits:

- Reduced costs of developing and maintaining software systems

- Increased reliability of software

- Greater synergies across portions of software code and applications

- Two-thirds of the projects achieved their technical objectives

- Three of the projects generated enough returns to cover the entire cost of the focused program

Spillovers:

- Validation of the CBSD concept in the eyes of investors

- Premium pricing of products due to higher quality resulting from ATP involvement

- Internal credibility for participating firms, leading to more available R\&D funds and expanded scope of the project

\section{Information Storage}

Magnetic Recording Technology with Global Impact $(1991)^{45} \vec{t} \boldsymbol{t} \vec{k}$ Information Storage Industry Consortium [formerly National Storage Industry Consortium (NSIC)]

In 1991, magnetoresistive (MR) head information technology moved disk storage forward-but it still couldn't keep pace with rapidly increasing storage needs caused by the memory-hogging nature of graphics and video images as software evolved.

NSIC proposed to vastly improve the potential for MR head technology, with the five-year goal of achieving 10 gigabytes of memory per square inch. It was a level of R\&D that no company could afford to explore alone. The consortium received ATP funding on the condition that the magnetic recording industry as a whole be permitted to use the resulting series of innovations in product development.

Investment: $\$ 5.46$ million by ATP:

$\$ 5.98$ million by NSIC

Project achievements:

- Giant magnetoresistive (GMR) heads developed during the project can record nearly 100 times more information per square inch of recording medium than other heads commercially available

- Read-and-write heads created so precisely that errors occurred once in every $10^{14}$ bits

- Hundreds of researchers coordinated across the U.S. in 8 companies and 7 universities

Spillovers:

- By 2000 , after only 3 years, 100 percent of PCs made in the U.S. used GMR-head technology

- U.S. share of the global market increased from 62 percent to 70 percent in this time period

\section{DNA Diagnostics}

Genetic Anaylsis Lab on a Chip $(1994)^{46}$ tr frats it Orchid Biosciences (formerly Molecular Tool, Inc.)

Genetic analysis, the study of DNA to determine identity or disease, was cumbersome and expensive in 1994. Performing 1,000 generic tests to uniquely identify one human sample lor to test for disease) required at least two lab technicians, a 20-by 15-foot laboratory, several machines fo perform rote tasks, and 12 hours, at a total cost of $\$ 100,000$ or more.

Molecular Tool (later purchased by Orchid) successfully developed a patented prototype single nucleotide polymorphism (SNP) analysis tool that shrunk the testing operation from an entire lab to a 1 -square-inch chip. The new technology has been used for disease detection and treatment, as well as forensics, including identification of remains at the site of the World Trade Center in New York City after conventional methods failed.

Investment: $\$ 1.94$ million by ATP; $\$ 684,000$ by Molecular Tool

Project achievements:

- Reduced testing time by 75 percent from 4 weeks to 1 week

- Reduced total analysis cost by 70 percent

- 5 patents granted

Spillovers and commercial accomplishments:

- 22 publications in professional journals

- Genotyping tool technology sold to Beckman Coulter, with SNP technologyuse licensed by Orchid

- Growth in Orchid's genetic analysis service sales, from \$1 million in 2000 to over $\$ 62$ million in 2004

4. William 1. White and Michael P. Gallaghet, Benefits and Costs of AIP investments in Component-Based Software, NIST GCR 02-834, November 2002.

43 ATP Status Report 91-01-0016, December 2001.

45 ATP Status Report 94-05-0034, August 2004 
Investments to Keep Americo Energized

More than ever before, Americans rely on a steady supply of energy to power our lives. Consider the cost to the nation of the August 14, 2003 blackout, when overloaded power systems in the Northeastern U.S. failed. In all, eight U.S. states were affected, with an estimated cost to the economy of $\$ 30$ billion.

ATP is supporting the nation's energy security through investments in breakthrough technologies for fuel cells, solar cells, and batteries. ATP was one of the first large government programs to fund distributed generation technologies, such as fuel cells, that can power residences and businesses and provide improved backup power for telecommunications.

The innovative technologies fostered by AIP will make sources of distributed, off-grid power ever more compact, secure, reliable, and affordable.
Key energy projects currently under way include:

- Plug Power LC of Latham, New York, which experienced a workforce increase by 2003 from 50 to 300 with its breakthrough in a proton-exchange membrane fuel cell; this cell has improved carbon monoxide tolerance by 100 -fold, enabling clean, low-cost fuel cell performance for homes and businesses.

- Materials and Systems Research, Inc., of Salt Lake City, Utah, developer of high-performing, solid-oxide fuel cell technology-using natural gas or other combustible vapors-for emergency and remote power generation.

- Evergreen Solar, Inc, of Waltham, Massachusetts, creators of wide, ultra-thin, silicon ribbons that yield more than twice as many solar cells per pound of silicon as con-ventional methods, lowering the cost of solar power.
- PowerStor Corporation of Dublin, California, developers of a new supercapacitor that can deliver pulses of energy to portable or fixed electronic devises using carbon aerogels for high performance.

- MTI Microfuel Cells, Inc, of Albany, New York, which is developing a micro fuel cell that may provide power 5 to 10 times longer than the lithium ion batteries now used in cell phones, laptops, and PDAs.

- Ovonic Battery Co, of Troy, Michigan, which is developing magnesium-hydride alloys capable of storing 7-percent hydrogen in fuel-cell-powered electric vehicles, a level that far exceeds the capability of metal hydride technologies now in use.

These and other technologies will help future generations of Americans to enjoy uninterrupted power for a higher quality of life, enhanced security, and a more stable U.S. economy.

\section{The Case of Lithium-ion (Li-ion) Batteries ${ }^{47}$}

The market for Li-ion systems has grown from minimal production in 1992 to more than $\$ 3$ billion in 2003. Li-ion batteries power the telephones, music players, digital cameras, and notebook computers of the digital revolution. Production of $\mathrm{Li}$-ion cells originally centered in Japan, but new manufacturers with significant production capability have now appeared in China and Korea.

The U.S. primary battery industry is strong, due to low-cost, highly automated production and a strong marketing and distribution network. U.S. researchers once stood at the leading edge of Li-ion battery technologies, but chose not to compete with stronger players in East Asia, where home-country advantages permit the acceptance of lower profit margins than those seen in the U.S. primary battery market.
It is commonly believed that labor costs represent a major factor in determining where to manufacture these products. Production of Li-ion batteries consists of both unit-cell production (which can be automated to a high degree) and battery pack assembly (which is most cost-effective as a manual process). Automated unit cell production offsets the advantage of locating production in East Asia. However, establishing an automated production facility requires a minimum investment of about $\$ 120$ million.

Additionally, approaches to sales and marketing of rechargeable batteries differ from those of primary batteries. The rechargeable-battery market has a customer base composed of large, high-technologybased electronics companies located primarily in Japan that are both producers and users of rechargeable batteries. American companies are better able to compete in small-scale, high-quality, high-profit-margin niche rechargeable battery markets, such as those with medical, military, or space applications.

Despite having no large-volume producers of Li-ion batteries, the United States remains the major source for new concepts in battery, fuel cell, and display technologies. The United States is an incubator for new technologies relating to the electronics industry, while Asian and European companies develop the manufacturing expertise. The future could see a tendency for technological development to follow manufacturing to East Asia as a natural consequence of development of manufacturing expertise within Asian companies.

47 Ralph 1. Brodd, Foctors Affecting U.S. Production Decisions: Why ore There No Volume Lithium-lon Battery Manufacturers in 


\section{ATP in Manufacturing}

Since its start in 1990, ATP has emphasized innovation in industrial processes. Two of ATP's central themes have been advances in manufacturing technology and leaps in process-related capabilities.

Approximately 11 percent of ATP's support through matching funds has been awarded to projects intended to catalyze the development of leap-frog technologies for material forming and removal, welding and assembly, manufacturing system integration and measurement, and other processes and products relevant to discrete-parts manufacturing. Including projects in the categories of "advanced materials and chemistry" and "electronics and photonics"-areas with a heavy manufacturing emphasis or relevanceATP's investment in manufacturing accounts for nearly 60 percent of the $\$ 2$ billion awarded by the program between 1990 and July 2003.

"Unlike every other revolutionary product, this one won't change the world.

- Cargill Dow's togline for environmentally friendly PLA
Below are a few examples of manufacturing technologies either proven to be successful or with the potential to greatly improve aspects of U.S. industry:

- Polylactide (PLA), a corn-derived dextrose polymer developed by Cargill Dow for biodegradable packaging and clothing fibers resulted in the opening of a Blair, Nebraska, plant in 2002, 100 new jobs, greenhouse gas emissions in manufacturing reduced by 15-60 percent, and the production of 140 million metric tons of PLA per year. ${ }^{48}$

- Precision measurement for the automotive and bearing industries $(t \boldsymbol{x} \boldsymbol{x} \boldsymbol{t})$ created by Corning Tropel (formerly Tropel Corporation) of Fairport, New York, that uses diffractive optics and laser technology to measure even complex shapes, dramatically increasing accuracy while removing production bottlenecks and lowering consumer costs; five patents resulted as well as numerous papers and presentations. ${ }^{49}$

- Structural reaction injection molding

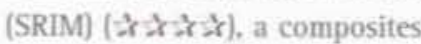
manufacturing process developed by the Automotive Composites Consortium, has enabled the production of large automotive parts traditionally made of steel. The parts are stronger, lighter in weight, and do not rust or corrode, resulting in better fuel efficiency and longer-lasting parts. The SRIM process has been used for part production for numerous domestic automobiles, aircraft, and marine craft, as well as the production of fire helmet shells that are 15 percent lighter and have greater impact resistance. ${ }^{50}$

\footnotetext{
4i Samuel Fromartz, Newbiz: in "Green" Contoiner, Corn Reploces Petroleum, Forbes.com from Reuters News Service, November 6, 2003.

4. ATP Status Report 95-01-0022, September 2001.

10 ATP Status Report 94-02-0027, June 2004.

5i ATP Status Report 91-01-017a, December 2001.
}

\section{Manufacturing}

Lightweight, Recyclable Car Parts $(1991)^{51}$ tr k s $x$ Ford Motor Company Scientific Research Laboratory and General Electric R\&D

The morement to consene eneryy and recyele in the late 1980 s created a need for new composites to achieve weight reductions in automobile mamufacturing-composites that could then be recycled at the end of a car's usefiul life. Hourever, the thermoset polymers then used in car parts could not be heated or necycled.

A consortium of seven organizations approached ATP to pursue promising technology involving cyclic thermoplastics, which offered many attractive properties in manufacturing, including the fact that they could be recycled simply by reheating the material. However, this was unproven technology and a dramatic shift away from accepted thermoset polymers.

Investment: 5.29 million by ATP; $\$ 5.74$ million by the consortium

Project achievements:

- 16 patents related to cyclic thermoplastics

- Substantial data collected regarding mold flow and filling

- Successful research partnership between Ford, GE, PPG, American Lisitritz, Rensselaer Polytechnic institute, the University of Tulsa, and the Environmental Research Institute of Michigan

- Met the manufacturing cost target of approximately $\$ 1$ per pound for automotive components and other parts fbut did not achieve the goal of translating key properties from laboratory beaker reactions to materials made under simulated production conditions)

Spillovers:

- Composite molding process now used by Ford Motor Company

- Portfolio of patents sold to Cyclics* Corporation of Rensselaer, New York, in 1999

- Cyclics Corp., undertaking development projects for direct customers in structural composites and related technology areas

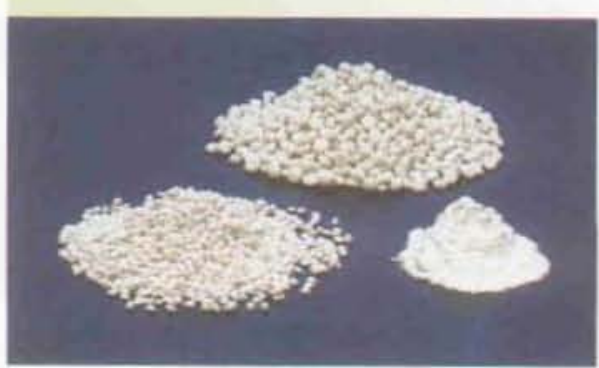




\section{Manufacturing}

Nanotechnology Works Cross-industry (1991) $^{52}$ k $k$ k $k+k$ Nanophase Technologies Corporation (NTC), Romeoville, Illinois

The advent of nanotechnology-the ability to manipulate matter at the atomic or molecular level-offered the opportunity to rearite the future by helping to fight disease and pollution and aid in manufacturing. However, the production of nanosized materials a billionth of a meter in length was cumbersome and expensive.

NTC proposed new technology to synthesize and process nanocrystalline ceramies that would be less prone to molecular breakdowns, then apply this nanotechnology to other materials and uses. With ATP funding, NTC created a gas-phase condensation (GPC) process as a foundation for research and development.

Investment: $\$ 944,000$ by ATP; $\$ 3$ million by NTC

Project achievements:

- 25,000-fold increase achieved in capacity to produce nanoscale materials along with a 20,000 -fold reduction in costs

- Growth in NTC from 2 to 61 employees

- 3 patents received related to nanomaterials production, with 28 more patents licensed or pending in the U.S., Europe, and Japan

Spillovers:

- NTC customer base now 20 companies worldwide

- Technology now being applied in a variety of industrial applications, including automobile coatings, carpet fibers, cosmetics, sunscreen, and high-opacity inks

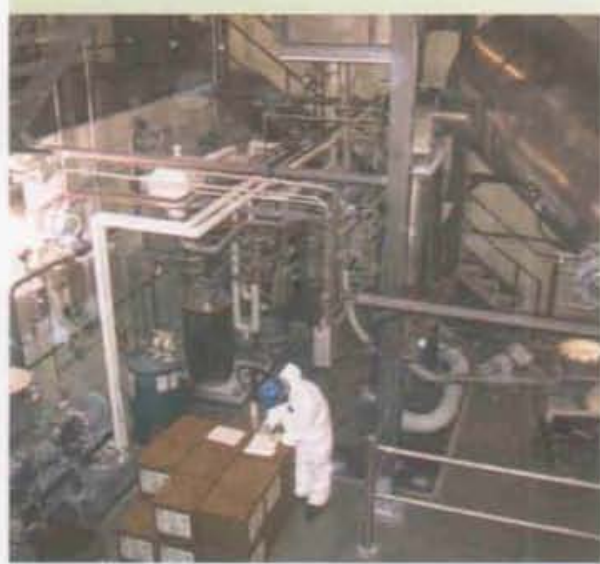

12 AIP Status Report 91-01-0041, December 2001.
Soldering with Ink-Jet Technology

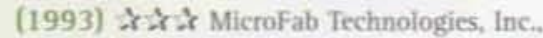
Plano, Texas

Continuing advances in electronics have led to new levels of miniaturization and corresponding needs for new ways to solder leads to circuit board contacts. Existing methods had been complex, expensive, and time consuming.

MicroFab proposed to use existing ink-jet printing technology to affix semiconductor chips to circuit boards at high temperatures via molten metal solder drops. Skepticism about the technology was high inside the industry, making venture capital unavailable. Investment: $\$ 1.63$ million by ATP; $\$ 695,000$ by Microfab

Project achievements:

- Successful prototype that dispenses 40micton to 120-micron spheres of molten solders onto high-density electronic components at up to $220^{\circ} \mathrm{C}$, on demand, at rates up to 2,000 per second

- 5 patents received for solder-related microdroplet technologies

- Partners included Motorola, Delco, Texas Instruments, Kodak, and AMP

- Company grew from 18 to 30 employees

Spillovers:

- Several papers published and presentations given

- Funding received from the Defense Advanced Research Projects Agency to test the technology at up to $325^{\circ} \mathrm{C}$ (with partial success)

- Technologies licensed to MPM, a division of the Cookson Group. PLC, for use in solder balls

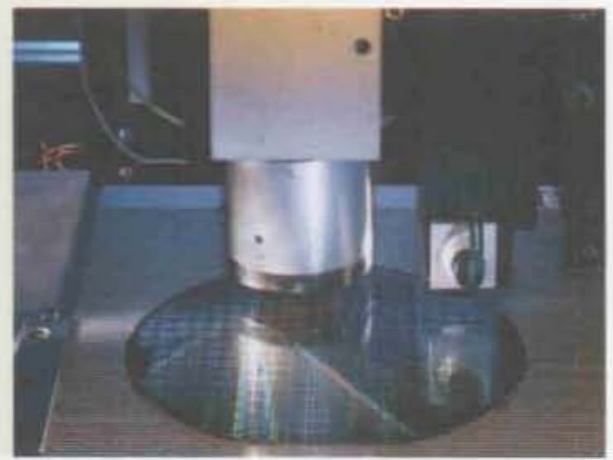

\section{Photonics}

Light Distribution Technology (1993) trkx ‘ Physical Optics Corporation (POC), Torrance, Califormia

Products in many industries-laptop computers, televisions. flashlights, cockpit and car dashboands, and ATM displays-rely on light diffusers composed of frosted glass or plastic to disperse light as needed. However, these have been notoriousty intefficient because they can only scatter light rather than direct it.

Physical Optics Corp., used ATP funding to pursue holographic technology that would increase the brightness of any traditional light source and enhance the contrast of optical images. The result would be screens and filters that "sculpt" beams of light by distributing the light in a desired direction. avoiding "hot spots" for any light source.

Investment: $\$ 850,000$ by ATP; $\$ 870,000$ by Physical Optics Corporation

Project achievements:

- New holographic systems technology for recording diffusers with desired scattering distributions

- Coating and processing techniques for deep-surface structures substantially improved

- Fabrication techniques for high-resolution diffusion masters refined

- High-resolution screens developed in a variety of sizes, shapes, and properties for a range of applications

- Projection screens with intense and directed light beams; transmission screens greatly enhance a previously dull image

- 3 patents related to illuminated displays

Spillovers:

- Several publications and seminars

- Alliances with original equipment manufacturers

- Licensing agreements with specific application providers

- Interest from Ford Motor and other large automotive companies 


\section{Our Most Vital Resource}

In 2005, the National Academy of Sciences, an elite body of scholars who provide science, technology, and health policy advice under congressional charter, noted that that U.S. capacity for innovation "has made this country a world leader for decades, allowing Americans to benefit from a high standard of living and national security. ${ }^{-55}$ But having great ideas is only half the battle. Innovators need to be able to take the next step. "...Truth be told," said Boston Globe columnist Robert Weisman in January 2004, "ideas are plentiful. For businesses, the hard part is choosing the right ones, turning them into products or services, and bringing them to the marketplace before their competitors do. That's the job of the Advanced Technology Program, to help these innovators pursue their ideas and turn them into possibilities.

ATP has compiled a measurable record of success in heiping private firms across the nation turn breakthrough ideas into highpayoff innovations and build future capacity to innovate by:

- Pursuing the development of high-risk, enabling technologies.

- Requiring well-thought-out technical and business plans up front.

- Involving the right combination of companies, universities, and non-profit independent research organizations as partners in R\&D projects.

- Monitoring their progress throughout the life of the project and measuring their outputs, outcomes, and impacts.
What are the next big ideas that will become breakthrough technologies? Right now, ATP participants are working on applications of nanotechnology to medicine and manufacturing, applications of information technology to virtual reality learning environments, the use of practical, affordable fuel cells for the home and automobile, a high-speed metal sorter to revolutionize recycling, exciting medical research into antibodies and drug delivery systems, and dozens of other R\&D efforts that could make the United States more competitive, spur the economy, and help future generations of Americans lead longer, healthier, and higher-quality lives.

Sif National Academy of Sciences, Committee on Prospering in the Global Econormy of the 21st Century. An Agenda for American Science and Technology. Rising Above the Gothering Starm: Energizing and Employing Americo for a Brighter Economic Future, 2006

3t Robert Weisman, "Finding New Ideas is Eas\}, Choosing Right Ones Isn't" Boston Globe, January 18, 2004. 


\section{Appendix A}

\section{ATP Statistics}

The ATP Economic Assessment Office measures the success of the Advanced Technology Program through a variety of evaluation studies aided by leading experts. All the recent studies described in this appendix can be found at www.atp.nist.gov/eao/eao_pubs.htm.

\begin{tabular}{l|c}
\hline \multicolumn{2}{|l}{ 1. Historical Statistics } \\
\hline \multicolumn{2}{|c|}{$1990-2004^{\prime}$} \\
\hline Number of Proposals Received & 6,924 \\
Number of Participants in Submitted Proposals & 10,227 \\
Total AIP Funding Request & $\$ 14,708 \mathrm{M}$ \\
Total Industry Cost Share & $\$ 14,142 \mathrm{M}$ \\
\hline Number of Awards & 768 \\
Single Applicants & 550 \\
Joint Ventures & 218 \\
Number of Participants in Awarded Projects & 1,511 \\
\hline Total ATP Funds Committed & $\$ 2,269 \mathrm{M}$ \\
Total Industry Cost Sharing & $\$ 2,102 \mathrm{M}$ \\
\hline Award Size for Projects (range) & $\$ 434 \mathrm{~K}-\$ 31 \mathrm{M}$ \\
Award Size for Single Applicant Projects (rangel & $\$ 434 \mathrm{~K}-\$ 2 \mathrm{M}$ \\
Award Size for Joint Venture Projects (range) & $\$ 600 \mathrm{~K}-\$ 31 \mathrm{M}$ \\
\hline Percent of Projects that Collaborate & 85 \\
Percent of Acceleration & 87 \\
Percent of Projects Commercializing & 45 \\
\hline Total Number of Publications & 1,701 \\
Total Number of Patents Filed & 1,418 \\
\hline
\end{tabular}

\begin{tabular}{|c|c|c|c|c|c|c|c|c|c|c|c|c|c|c|c|c|}
\hline \multicolumn{17}{|c|}{ 2. ATP Awards Funding (by project type and lead size) } \\
\hline Funding (\$Millions) & TOTALS ${ }^{+}$ & 2004 & 2003 & 2002 & 2001 & 2000 & 1999 & 1998 & 1997 & 1996 & 1995 & 1994 & 1993 & 1992 & 1991 & 1990 \\
\hline Total Funding & 2.269 & 155 & 154 & 156 & 164 & 144 & 110 & 235 & 162 & 19 & 414 & 309 & 60 & 48 & 93 & 46 \\
\hline Small" & 1,202 & 111 & 107 & 116 & 121 & 96 & 70 & 112 & 101 & 10 & 99 & 143 & 35 & 19 & 39 & 23 \\
\hline Medium & 320 & 12 & 18 & 18 & 15 & 12 & 9 & 44 & 10 & 3 & 118 & 45 & 9 & 5 & 2 & 0 \\
\hline Large"* & 447 & 29 & 18 & 22 & 4 & 36 & 20 & 68 & 37 & 6 & 93 & 69 & 13 & 15 & 13 & 4 \\
\hline Other" & 300 & 3 & 11 & 0 & 24 & 0 & 11 & 11 & 14 & 0 & 104 & 52 & 3 & 9 & 39 & 19 \\
\hline Single Applicant & 1,001 & 93 & 105 & 97 & 85 & 74 & 49 & 92 & 87 & 10 & 110 & 93 & 41 & 29 & 28 & 8 \\
\hline Small & 796 & 83 & 101 & 89 & 81 & 66 & 42 & 78 & 71 & 10 & 62 & 46 & 24 & 19 & 20 & 4 \\
\hline Medium & 102 & 4 & 2 & 0 & 3 & 2 & 4 & 11 & 8 & 0 & 28 & 26 & 7 & 5 & 2 & 0 \\
\hline Large & 100 & 6 & 2 & 8 & 1 & 6 & 3 & 3 & 8 & 0 & 20 & 21 & 10 & 5 & 3 & 4 \\
\hline Other & 3 & 0 & 0 & 0 & 0 & 0 & 0 & 0 & 0 & 0 & 0 & 0 & 0 & 0 & 3 & 0 \\
\hline Joint Venture Lead & 1,268 & 62 & 49 & 59 & 79 & 70 & 61 & 143 & 75 & 9 & 304 & 216 & 19 & 19 & 65 & 38 \\
\hline Small & 406 & 28 & 6 & 27 & 40 & 30 & 28 & 34 & 30 & 0 & 37 & 97 & 11 & 0 & 19 & 19 \\
\hline Medium & 218 & 8 & 16 & 18 & 12 & 10 & 5 & 33 & 2 & 3 & 90 & 19 & 2 & 0 & 0 & 0 \\
\hline Large & 347 & 23 & 16 & 14 & 3 & 30 & 17 & 65 & 29 & 6 & 73 & 48 & 3 & 10 & 10 & 0 \\
\hline Other & 297 & 3 & 11 & 0 & 24 & 0 & 11 & 11 & 14 & 0 & 104 & 52 & 3 & 9 & 36 & 19 \\
\hline \multicolumn{17}{|c|}{ Percent of Distribution ${ }^{H+}$} \\
\hline Total Funding & 100 & 100 & 100 & 100 & 100 & 100 & 100 & 100 & 100 & 100 & 100 & 100 & 100 & 100 & 100 & 100 \\
\hline Small & 53 & 72 & 69 & 74 & 74 & 67 & 64 & 48 & 62 & 53 & 24 & 46 & 58 & 40 & 42 & 50 \\
\hline Medium & 14 & 8 & 12 & 12 & 9 & 8 & 8 & 19 & 6 & 16 & 29 & 15 & 15 & 10 & 2 & 0 \\
\hline Large & 20 & 19 & 12 & 14 & 2 & 25 & 18 & 29 & 23 & 32 & 22 & 22 & 22 & 31 & 14 & 9 \\
\hline Other & 13 & 2 & 7 & 0 & 15 & 0 & 10 & 5 & 9 & 0 & 25 & 17 & 5 & 19 & 42 & 41 \\
\hline Single Applicant & 44 & 60 & 68 & 62 & 52 & 51 & 45 & 39 & 54 & 53 & 27 & 30 & 68 & 60 & 30 & 17 \\
\hline Small & 80 & 89 & 96 & 92 & 95 & 89 & 86 & 85 & 82 & 100 & 56 & 49 & 59 & 66 & $\pi$ & 50 \\
\hline Medium & 10 & 4 & 2 & 0 & 4 & 3 & 8 & 12 & 9 & 0 & 25 & 28 & 17 & 17 & 7 & 0 \\
\hline Large & 10 & 6 & 2 & 8 & 1 & 8 & 6 & 3 & 9 & 0 & 18 & 23 & 24 & 17 & 11 & 50 \\
\hline Other & 0 & 0 & 0 & 0 & 0 & 0 & 0 & 0 & 0 & 0 & 0 & 0 & 0 & 0 & 11 & 0 \\
\hline Joint Venture Lead & 56 & 40 & 32 & 38 & 48 & 49 & 55 & 61 & 46 & 47 & 73 & 70 & 32 & 40 & 70 & 83 \\
\hline Small & 32 & 45 & 12 & 46 & 51 & 43 & 46 & 24 & 40 & 0 & 12 & 45 & 58 & 0 & 29 & 50 \\
\hline Medium & 17 & 13 & 33 & 31 & 15 & 14 & 8 & 23 & 3 & 33 & 30 & 9 & 11 & 0 & 0 & 0 \\
\hline Large & 27 & 37 & 33 & 24 & 4 & 43 & 28 & 45 & 39 & 67 & 24 & 22 & 16 & 53 & 15 & 0 \\
\hline Other & 23 & 5 & 22 & 0 & 30 & 0 & 18 & 8 & 19 & 0 & 34 & 24 & 16 & 47 & 55 & 50 \\
\hline \multicolumn{17}{|c|}{ 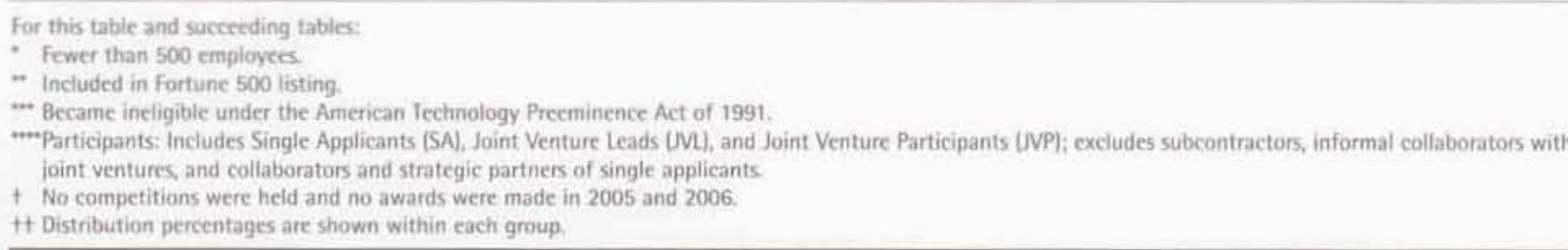 } \\
\hline
\end{tabular}




\begin{tabular}{|c|c|c|c|c|c|c|c|c|c|c|c|c|c|c|c|c|}
\hline Number of Awards & TOIALS & 2004 & 2003 & 2002 & 2001 & 2000 & 1999 & 1998 & 1997 & 1996 & 1995 & 1994 & 1993 & 1992 & 1991 & 1990 \\
\hline Total \& of Awards & 768 & 59 & 67 & 61 & 59 & 54 & 37 & 79 & 64 & 8 & 103 & 88 & 29 & 21 & 28 & 11 \\
\hline Small & 508 & 47 & 55 & 51 & 50 & 41 & 26 & 53 & 48 & 6 & 40 & 40 & 16 & 12 & 16 & 7 \\
\hline Medium & 91 & 4 & 4 & 2 & 4 & 3 & 3 & 10 & 6 & 1 & 26 & 19 & 5 & 3 & 1 & 0 \\
\hline Lange & 130 & 7 & 5 & 8 & 2 & 10 & 7 & 14 & B & 1 & 26 & 23 & 7 & 5 & 5 & 2 \\
\hline Other & 39 & 1 & 3 & 0 & 3 & 0 & 1 & 2 & 2 & 0 & 11 & 6 & 1 & 1 & 6 & 2 \\
\hline Single Applicant & 550 & 48 & 55 & 51 & 46 & 39 & 26 & 52 & 49 & 6 & 62 & 50 & 24 & 18 & 18 & 6 \\
\hline Smati & 433 & 43 & 53 & 47 & 43 & 35 & 22 & 44 & 40 & 5 & 33 & 24 & 14 & 12 & 13 & 4 \\
\hline Medium & 57 & 2 & 1 & 0 & 2 & 1 & 2 & 6 & 5 & 0 & 16 & 14 & 4 & 3 & 1 & 0 \\
\hline Large & 58 & 3 & 1 & 4 & 1 & 3 & 2 & 2 & 4 & 0 & 13 & 12 & 6 & 3 & 2 & 2 \\
\hline Other: & 2 & 0 & 0 & 0 & 0 & 0 & 0 & 0 & 0 & 0 & 0 & 0 & 0 & 0 & 2 & 0 \\
\hline Joint Venture Lead & 218 & 11 & 12 & 10 & 13 & 15 & 11 & 27 & 15 & 2 & 41 & 38 & 5 & 3 & 10 & 5 \\
\hline Small & 75 & 4 & 2 & 4 & 7 & 6 & 4 & 9 & B. & 0 & 7 & 15 & 2 & 0 & 3 & 3 \\
\hline Medium & 34 & 2 & 3 & 2 & 2 & 2 & 1 & 4 & 1 & 1 & 10 & 5 & 1 & 0 & 0 & 0 \\
\hline Large & 72 & 4 & 4 & 4 & 1 & 7 & 5 & 12 & 4 & 1 & 13 & 11 & 1 & 2 & 3 & 0 \\
\hline Other & 37 & 1 & 3 & 0 & 3 & 0 & 1 & 2 & 2. & 0 & 11 & 6 & 1 & 1 & 4 & 2 \\
\hline \multicolumn{17}{|l|}{ Number of Participants } \\
\hline Total of of Participants & 1.511 & 78 & 104 & 79 & 88 & 95 & 57 & 168 & 101 & 12 & 318 & 211 & 50 & 32 & 83 & 35 \\
\hline Small & 739 & 54 & 67 & 5I & 63 & 56 & 29 & 74 & 67 & 9 & 101 & 73 & 24 & 17 & 31 & 13 \\
\hline Medium & 295 & B & 13 & 4 & 7 & 11 & 8 & 39 & 18 & 2 & 97 & 60 & $\pi$ & 6 & 8 & 3 \\
\hline Large & 333 & 13 & 15 & 12 & 9 & 22 & 17 & 40 & 12 & 1 & 8) & 54 & 14 & 5 & 24 & 13 \\
\hline Other & 144 & 3 & 9 & 2 & 9 & 6 & 3 & 15 & 4 & 0 & 39 & 24 & I. & 3 & 20 & 6 \\
\hline Singie Applicant & 550 & 48 & 55 & 51 & 46 & 39 & 26 & 52 & 49 & 6 & 62 & 50 & 24 & 18 & 18 & 6 \\
\hline Total $N(N L+N V P)$ & 961 & 30 & 49 & 28 & 42 & 56 & 31 & 116 & 52 & 6 & 256 & 161 & 26 & 14 & 65 & 29 \\
\hline Jaint Venture Lead & 218 & 11 & 12 & 10 & 13 & 15 & 11 & 27 & 15 & 2 & 41 & 38 & 5 & 3 & 10 & 5 \\
\hline Joint Venture Participants & 743 & 19 & 37 & 18 & 29 & 41 & 20 & 89 & 37 & 4 & 215 & 123 & 21 & 11 & 55 & 24 \\
\hline Small & 231 & 7 & 12 & 10 & 13 & 15 & 3 & 21 & 19 & 3 & 61 & 33 & 8 & 5 & 15 & 6 \\
\hline Medrum & 204 & 4 & 9 & 2 & 3 & 8 & 5 & 29 & 12 & 1 & 71 & 41 & 6 & 3 & 7 & 3 \\
\hline Large & 203 & 6 & 10 & 4 & 7 & 12 & 10 & 26 & 4 & 0 & 55 & 31 & 7 & 1 & 19 & 11 \\
\hline Other & 105 & 2 & 6 & 2 & 6 & 6 & 2 & 13 & 2 & 0 & 28 & 18 & 0 & 2 & 14 & 4 \\
\hline \multicolumn{17}{|l|}{ Percent of Distribution } \\
\hline Total \& of Awards & 100 & 100 & 100 & 100 & 100 & 100 & 100 & 100 & 100 & 100 & 100 & 100 & 100 & 100 & 100 & 100 \\
\hline Smali & 66 & 80 & 82 & 84 & 85 & $7 E$ & 70 & ह7) & 75 & 75 & 39 & 45 & 55 & 57 & 57 & 64 \\
\hline Medium & 12 & 7 & 6 & 3 & 7 & 6 & 8 & 13 & 9 & 13 & 25 & 22 & 17 & 14 & 4 & 0 \\
\hline Large & 17 & 12 & 7 & 13 & 3 & 19 & 19 & 18 & 13 & 13 & 25 & 26 & 24 & 24 & 18 & 18 \\
\hline Other & 5 & 2 & 4 & 0 & 5 & 0 & 3. & 3 & 3 & 0 & 11 & 7 & 3 & 5 & 21 & 18 \\
\hline Single Applicant & 72 & 81 & 82 & 84 & 78 & 72 & 70 & 66 & 77 & 75 & 60 & 57 & 83 & 86 & 64 & 55 \\
\hline Small & 79 & 90 & 96 & 92. & 93 & 90 & 85 & 85 & 82 & 100 & 53 & 48 & 58 & 67 & 72 & 67 \\
\hline Medium & 10 & 4 & 2 & 0 & 4 & 3 & 8 & 12 & 10 & 0 & 26 & 28 & 17 & 17 & 6 & 0 \\
\hline Large & 11 & 6 & 2 & 8 & 2 & 8 & 8 & 4 & B & 0 & 21 & 24 & 25 & 17 & 11 & 33 \\
\hline Other: & 0 & 0 & 0 & 0 & 0 & 0 & D & 0 & 0 & 0 & 0 & 0 & 0 & 0 & 11 & 0 \\
\hline Joint Venture Lead & 28 & 19 & 18 & 16 & 22 & 28 & 30 & 34 & 23 & 25 & 40 & 43 & 17 & 14 & 36 & 45 \\
\hline Smail & 34 & 36 & 17 & 40 & 54 & 40 & 36 & 33 & 53 & 0 & 17 & 42 & 40 & 0 & 30 & 60 \\
\hline Medium & 16 & 18 & 25 & 20 & 15 & 13 & 9 & 15 & 7 & 50 & 24 & 13 & 20 & 0 & 0 & 0 \\
\hline Large & 33 & 36 & 33 & 40 & 8 & 47 & 45 & 44 & 27 & 50 & 32 & 29 & 20 & 67 & 30 & 0 \\
\hline Other & 17 & 9 & 25 & 0 & 23 & 0 & 9 & 7 & 13 & 0 & 27 & 16 & 20 & 33 & 40 & 40 \\
\hline \multicolumn{17}{|l|}{ Percent of Distribution } \\
\hline Total $/$ of Participants & 100 & 100 & 100 & 100 & 100 & 100 & 100 & 100 & 100 & 100 & 100 & 100 & 100 & 100 & 100 & 100 \\
\hline Small & 49 & 69 & 64 & 77 & 72 & 59 & 51 & 44 & $6 \overline{6}$ & 75 & 32 & 35 & 48 & 53 & 37 & 37 \\
\hline Medium & 20 & 10 & 13 & 5 & 8 & 12 & 14 & 23 & 18 & 17 & 31 & 28 & 22 & 19 & 10 & 9 \\
\hline Large & 22 & 17 & 14 & 15 & 10 & 23 & 30 & 24 & 12 & 8 & 25 & 26 & 28 & 19 & 29 & 37 \\
\hline Othet & 10 & 4 & 9 & 3 & 10 & 6 & 5 & 9 & 4 & 0 & 12 & 11 & 2 & 9 & 24 & 17 \\
\hline Single Applicant & 36 & 62 & 53 & 65 & 52 & 41 & 46 & 31 & 49 & 50 & 19 & 24 & 48 & 56 & 22 & 17 \\
\hline Total $N(J M L+N P)$ & 64 & 38 & 47 & 35 & 48 & 59 & 54 & 69 & 51 & 50 & B) & 76 & 52 & 44 & 78 & 83 \\
\hline Joint Venture Lead & 22 & 37 & 24 & 36 & 31 & 27 & 35 & 23 & 29 & 33 & 16 & 24 & 19 & 21 & 15 & 17 \\
\hline Joint Venture Participants & 77 & 63 & 76 & 64 & 69 & 73 & 65 & 77 & $\pi$ & 67 & B4 & 76 & 81 & 79 & 85 & 83 \\
\hline Smali & 31 & 37 & 32 & 56 & 45 & 37 & 15 & 24 & 51 & 75 & 28 & 27 & 38 & 45 & 27? & 25 \\
\hline Medium & 27 & 21 & 24 & 11 & 10 & 20 & 25 & 33 & 32 & 25 & 33 & 33 & 29 & 27 & 13 & 13 \\
\hline Large & 27 & 32 & 27 & 22 & 24 & 29 & 50 & 29 & 11 & 0 & 26 & 25 & 33 & 9 & 35 & 46 \\
\hline Other & 14 & 11 & 16 & 11 & 21 & 15 & 10 & 15 & 5 & 0 & 13 & 15 & 0 & 18 & 25 & 17 \\
\hline
\end{tabular}




\begin{tabular}{|c|c|c|c|c|c|c|c|c|c|c|c|c|c|c|c|c|}
\hline \multicolumn{17}{|c|}{ 4. ATP Awards (by technology area and project type) } \\
\hline Number of Awards & TOTALS & 2004 & 2003 & 2002 & 2001 & 2000 & 1999 & 1998 & 1997 & 1996 & 1995 & 1994 & 1993 & 1992 & 1991 & 1990 \\
\hline Total Awards & 768 & 59 & 67 & 61 & 59 & 54 & 37 & 79 & 64 & 8 & 103 & 88 & 29 & 21 & 28 & 11 \\
\hline Single Applicant & 550 & 48 & 55 & 51 & 46 & 39 & 26 & 52 & 49 & 6 & 62 & 50 & 24 & 18 & 18 & 6 \\
\hline Joint Venture Lead & 218 & 11 & 12 & 10 & 13 & 15 & $\pi$ & 27 & 15 & 2 & 41 & 38 & 5 & 3 & 10 & 5 \\
\hline Total Biotechnology Awards & 190 & 15 & 13 & 18 & 21 & 14 & 14 & 18 & 20 & 2 & 22 & 22 & 4 & 3 & 4 & 0 \\
\hline Single Applicant & 156 & 15 & 13 & 16 & 16 & 12 & 13 & 16 & 18 & 2 & 10 & 16 & 3 & 2 & 4 & 0 \\
\hline Joint Venture Lead & 34 & 0 & 0 & 2. & 5 & 2 & 1 & 2 & 2 & 0 & 12 & 6 & 1 & 1 & 0 & 0 \\
\hline Total Chemistry/Materiais Awards & 168 & 10 & 11 & 13 & 15 & 10 & 6 & 28 & 5 & 4 & 19 & 28 & 8 & 4 & 7 & 0 \\
\hline Single Applicant & 120 & 6 & 10 & 13 & 13 & 8 & 1 & 20 & 3 & 3 & 17 & 12 & 7 & 3 & 4 & 0 \\
\hline Joint Venture Lead & 48 & 4 & 1 & 0 & 2 & 2 & 5 & 8 & 2 & 1 & 2 & 16 & 1 & 1 & 3 & 0 \\
\hline Total Electronics/Photonics Awards & 167 & 16 & 19 & 16 & 9 & 18 & 7 & 22 & 7 & 2 & 10 & 7 & 11 & 7 & 8 & 8 \\
\hline Single Applicant & 100 & 12 & 14 & 10 & 5 & 12 & 5 & 8 & 2 & 1 & 5 & 3 & 9 & 7 & 4 & 3 \\
\hline Joint Venture Lead & 67 & 4 & 5 & 6 & 4 & 6 & 2 & 14 & 5 & 1 & 5 & 4 & 2 & 0 & 4 & 5 \\
\hline Total Information Technology Awards & 156 & 14 & 18 & 12 & 9 & 4 & 6 & 9 & 21 & 0 & 27 & 29 & 2 & 2 & 2 & 1 \\
\hline Single Applicant & 123 & 13 & 15 & $\pi$ & 8 & 4 & 4 & 7 & 18 & 0 & 18 & 18 & 2 & 2 & 2 & 1 \\
\hline Joint Venture Lead & 33 & 1 & 3 & 1 & 1 & 0 & 2 & 2 & 3 & 0 & 9 & 11 & 0 & 0 & 0 & 0 \\
\hline Total Manufacturing (Discrete) Awards & 87 & 4 & 6 & 2 & 5 & 8 & 4 & 2 & 11 & 0 & 25 & 2 & 4 & 5 & 7 & 2 \\
\hline Singie Applicant & 51 & 2 & 3 & 1 & 4 & 3 & 3 & 1 & 8 & 0 & 12 & 1 & 3 & 4 & 4 & 2 \\
\hline Joint Venture Lead & 36 & 2 & 3 & 1 & 1 & 5 & 1 & 1 & 3 & 0 & 13 & 1 & 1 & 1 & 3 & 0 \\
\hline \multicolumn{17}{|l|}{ Percent of Distribution } \\
\hline Total Awards & 100 & 100 & 100 & 100 & 100 & 100 & 100 & 100 & 100 & 100 & 100 & 100 & 100 & 100 & 100. & 100 \\
\hline Single Applicant & 72 & 81 & 82 & 84 & 78 & 72 & 70 & 66 & 77 & 75 & 60 & 57 & 83 & 86 & 64 & 55 \\
\hline Joint Venture Lead & 28 & 19 & 18 & 16 & 22 & 28 & 30 & 34 & 23 & 25 & 40 & 43 & 17 & 14 & 36 & 45 \\
\hline Total Biotechnology Awards & 25 & 25 & 19 & 30 & 36 & 26 & 38 & 23 & 31 & 25 & 21 & 25 & 14 & 14 & 14 & 0 \\
\hline Single Applicant & 82 & 100 & 100 & 89 & 76 & 86 & 93 & 89 & 90 & 100 & 45 & 73 & 75 & 67 & 100 & - \\
\hline Joint Venture Lead & 18 & 0 & 0 & 11 & 24 & 14 & 7 & 11 & 10. & 0 & 55 & 27 & 25 & 33 & 0 & - \\
\hline Total Chemistry/Materials Awards & 22 & 17 & 16 & 21 & 25 & 19 & 16 & 35 & 8 & 50 & 18 & 32 & 28 & 19 & 25 & 0 \\
\hline Single Applicant & 71 & 60 & 91 & 100 & 87 & 80 & 17 & 71 & 60 & 75 & 89 & 43 & 88 & 75 & 57 & - \\
\hline Joint Venture Lead & 29 & 40 & 9 & 0 & 13 & 20 & 83 & 29 & 40 & 25 & 11 & 57 & 13 & 25 & 43 & - \\
\hline Total Electronics/Photonics Awards & 22 & 27 & 28 & 26 & 15 & 33 & 19 & 28 & 11 & 25 & 10 & 8 & 38 & 33 & 29 & 73 \\
\hline Single Applicant & 60 & 75 & 74 & 63 & 56 & 67 & $\pi$ & 36 & 29 & 50 & 50 & 43 & 82 & 100 & 50 & 38 \\
\hline Joint Venture Lead & 40 & 25 & 26 & 38 & 44 & 33 & 29 & 64 & $\pi$ & 50 & 50 & 57 & 18 & 0 & 50 & 63 \\
\hline Total Information Technology Awards & 20 & 24 & 27 & 20 & 15 & 7 & 16 & 11 & 33 & 0 & 26 & 33 & 7 & 10 & 7 & 9 \\
\hline Single Applicant & 79 & 93 & 83 & 92 & 89 & 100 & 67 & 78 & 86 & - & 67 & 62 & 100 & 100 & 100 & 100 \\
\hline Joint Venture Lead & 21 & 7 & 17 & 8 & 11 & 0 & 33 & 22 & 14 & - & 33 & 38 & 0 & 0 & 0 & 0 \\
\hline Total Manufacturing (Discrete) Awards & 11 & 7 & 9 & 3 & 8 & 15 & 11 & 3 & 17 & 0 & 24 & 2 & 14 & 24 & 25 & 18 \\
\hline Single Applicant & 59 & 50 & 50 & 50 & 80 & 38 & 75 & 50 & 73 & - & 48 & 50 & 75 & 80 & 57 & 100 \\
\hline Joint Venture Lead & 41 & 50 & 50 & 50 & 20 & 63 & 25 & 50 & 27 & - & 52 & 50 & 25 & 20 & 43 & 0 \\
\hline
\end{tabular}




\begin{tabular}{|c|c|c|c|c|c|c|c|c|c|c|c|c|c|c|c|c|}
\hline Funding (\$Millions) & TOTALS & 2004 & 2003 & 2002 & 2001 & 2000 & 1999 & 1998 & 1997 & 1996 & 1995 & 1994 & 1993 & 1992. & 1991 & 1990 \\
\hline Total Funding & 2,269 & 155 & 154 & 156 & 164 & 144 & 110 & 235 & 162 & 19 & 414 & 309 & 60 & 48 & 93 & 46 \\
\hline Single Applicant & 1001 & 93 & 105 & 97 & 85 & 74 & 49 & 92 & 87 & 10 & 110 & 93 & 41 & 29 & 28 & 8 \\
\hline Joint Venture Lead & 1,268 & 62 & 49 & 59 & 79 & 70 & 61 & 143 & 75 & 9 & 304 & 216 & 19 & 19 & 65 & 38 \\
\hline Total Biotechnology Funding & 449 & 29 & 26 & 51 & 58 & 30 & 29 & 46 & 40 & 4 & 32 & 75 & 10 & 13 & 6 & 0 \\
\hline Single Applicant & 298 & 29 & 26 & 32 & 30 & 23 & 25 & 29 & 34 & 4 & 19 & 31 & 6 & 4 & 6 & 0 \\
\hline Joint Venture Lead & 151 & 0 & 0 & 19 & 28 & 7 & 4 & 17 & 6 & 0 & 13 & 44 & 4 & 9 & 0 & 0 \\
\hline Total Chemistry/Materials Funding & 488 & 33 & 22 & 26 & 32 & 23 & 32 & 62 & 21 & 7 & 96 & 92 & 15 & 11 & 16 & 0 \\
\hline Single Applicant & 215 & 12 & 19 & 26 & 24 & 16 & 2 & 35 & 5 & 4 & 29 & 19 & 13 & 5 & 6 & 0 \\
\hline Joint Venture Lead & 273 & 21 & 3 & 0 & B & 7 & 30 & 27 & 16 & 3 & 67 & 73 & 2 & 6 & 10 & 0 \\
\hline Total Electronics/Photonics Funding & 577 & 56 & 47 & 52 & 32 & 56 & 16 & 107 & 23 & 8 & 50 & 20 & 24 & 12 & 31 & 43 \\
\hline Single Applicant & 179 & 24 & 26 & 19 & 10 & 22 & B & 15 & 2 & 2 & 8 & 6 & 14 & 12 & 6 & 5 \\
\hline Joint Venture Lead & 398 & 32 & 21 & 33 & 22 & 34 & B & 92 & 21 & 6 & 42 & 14 & to & 0 & 25 & 38 \\
\hline Total Information Technology Funding & 504 & 30 & 40 & 21 & 24 & 8 & 23 & 16 & 54 & 0 & 162 & 115 & 3 & 3 & 4 & 1 \\
\hline Single Applicant & 224 & 24 & 28 & 18 & 15 & 8 & 8 & 12 & 32 & 0 & 33 & 35 & 3 & 3 & 4 & 1 \\
\hline Joint Venture Lead & 280 & 6 & 12 & 3 & 9 & 0 & 15 & 4 & 22 & 0 & 129 & $B O$ & 0 & 0 & 0 & 0 \\
\hline Total Manufacturing (Discrete) Funding & 251 & 7 & 19 & 6 & 18 & 27 & 10 & 4 & 24 & 0 & 74 & 7 & 8 & 9 & 36 & 2 \\
\hline Singie Applicant & 85 & 4 & 5 & 2 & 6 & 5 & 5 & 1 & 14 & 0 & 21 & 2 & 5 & 5 & 6 & 2 \\
\hline Joint Venture Lead & 166 & 3 & 13 & 4 & 12 & 22 & 4 & 3 & 10 & 0 & 53 & 5 & 3 & 4 & 30 & 0 \\
\hline \multicolumn{17}{|l|}{ Percent of Distribution } \\
\hline Total Funding & 100 & 100 & 100 & 100 & 100 & 100 & 100 & 100 & 100 & 100 & 100 & 100 & 100 & 100 & 100 & 100 \\
\hline Single Applicant & 44 & 60 & 68 & 62 & 52 & 51 & 45 & 39 & 54 & 53 & 27 & 30 & 68 & 60 & 30 & 17 \\
\hline Joint Venture Lead & 56 & 40 & 32 & 38 & 48 & 49 & 55 & 61 & 46 & 47 & 73 & 70 & 32 & 40 & 70 & B3 \\
\hline Total Biotechnology Funding & 20 & 19 & 17 & 33 & 35 & 21 & 26 & 20 & 25 & 21 & 8 & 24 & 17 & 27 & 6 & 0 \\
\hline Single Applicant & 66 & 100 & 100 & 63 & 52 & 77 & 86 & 63 & 85 & 100 & 59 & 41 & 60 & 31 & 100 & - \\
\hline Joint Venture Lead & 34 & 0 & 0 & 37 & 48. & 23 & 14 & 37 & 15 & 0 & 41 & 59 & 40 & 69 & 0 & - \\
\hline Total Chemistry/Materials Funding & 22 & 21 & 14 & 17 & 20 & 16 & 29 & 26 & 13 & 37 & 23 & 30 & 25 & 23 & 17 & 0 \\
\hline Single Applicant & 44 & 36 & 86 & 100 & 75 & 70 & 6 & 56 & 24 & 57 & 30 & 21 & 87 & 45 & 38 & - \\
\hline Joint Venture Lead & 56 & 64 & 14 & 0 & 25 & 30 & 94 & 44 & 75 & 43 & 70 & 79 & 13 & 55 & 63 & - \\
\hline Total Electronics/Photonics Funding & 25 & 36 & 31 & 33 & 20 & 39 & 15 & 46 & 14 & 42 & 12 & 6 & 40 & 25 & 33 & 93 \\
\hline Single Applicant & 31 & 43 & 55 & 37 & 31 & 39 & 50 & 14 & 9 & 25 & 16 & 30 & 58 & 100 & 19 & 12 \\
\hline Joint Venture Lead & 69 & 57 & 45 & 63 & 69 & 61 & 50 & 86 & 91 & 75 & 84 & 70 & 42 & 0 & 81 & 88 \\
\hline Total Information Technology Funding & 22 & 19 & 26 & 13 & 15 & 6 & 21 & 7 & 33 & 0 & 39 & 37 & 5 & 6 & 4 & 2 \\
\hline Single Applicant & 44 & 80 & 70 & 86 & 63 & 100 & 35 & 75 & 59 & - & 20 & 30 & 100 & 100 & 100 & 100 \\
\hline Joint Venture Lead & 56 & 20 & 30 & 14 & 38 & 0 & 65 & 25 & 41 & - & 80 & 70 & 0 & 0 & 0 & 0 \\
\hline Total Manufacturing (Discrete) Funding & 11 & 5 & 12 & 4 & 11 & 19 & 9 & 2 & 15 & 0 & 18 & 2 & 13 & 19 & 39 & 4 \\
\hline Single Apglicant & 34 & 57 & 32 & 33 & 33 & 19 & 60 & 25 & 58 & - & 28 & 29 & 63 & 56 & 17 & 100 \\
\hline Joint Venture Lead & 66 & 43 & 68 & 67 & 67 & 81 & 40 & 75 & 42 & - & 72 & 71 & 38 & 44 & 83 & 0 \\
\hline
\end{tabular}

\begin{tabular}{|c|c|c|c|c|c|c|c|c|c|c|c|}
\hline Region/State & Applications & $\begin{array}{c}\text { Total } \\
\text { Awards }\end{array}$ & Participants & Region/State & Applications & $\begin{array}{c}\text { Total } \\
\text { Awards }\end{array}$ & Participants & Region/State & Applications & $\begin{array}{c}\text { Total } \\
\text { Awardis }\end{array}$ & Participants \\
\hline New England & 742 & 104 & 183 & East North Central & 982 & 127 & 334 & Mountain & 456 & 45 & 77 \\
\hline Connecticut & 122 & 19 & 38 & Itlinois & 256 & 31 & 48 & Arizona & 83 & 6 & 15 \\
\hline Maine & 17 & 0 & 1 & Indiana & 61 & 3 & $B$ & Colorado & 155 & 17 & 31 \\
\hline Massachusetts & 520 & 76 & 130 & Michigan & 313 & 54 & 173 & Idaho & 24 & 2 & 2 \\
\hline New Hampshire & 49 & 4 & 8 & Ohio & 259 & 29 & 87 & Montana & 10 & 0 & 0 \\
\hline Rhode Island & 30 & 5 & 6 & Wisconsin & 93 & 10 & 18 & Nevada & 25 & 2 & 2 \\
\hline Vermont & 4 & 0 & 0 & West North Central & 285 & 31 & 67 & New Mexico & 57 & 9 & 13 \\
\hline Middle Atlantic & 1,043 & 114 & 223 & lowa & 26 & 3 & 4 & Utah & 99 & 9 & 14 \\
\hline New Jersey & 270 & 36 & 59 & Kansas & 38 & 1 & 1 & Wyoming & 3 & 0 & 0 \\
\hline New York & 452 & 51 & 100 & Minnesota & 141 & 22 & 43 & Pacific & 1,773 & 202 & 334 \\
\hline Pennsylvania & 321 & 27 & 64 & Missouri & 58 & 4 & 14 & Alaska & 1 & 0 & 0 \\
\hline South Atlantic & 1,097 & 102 & 171 & Nebraska: & 16 & 1 & 5 & California & 1,558 & 184 & 302 \\
\hline Delaware & 56 & 8 & 16 & North Dakota & 3 & 0 & 0 & Hawaii & 21 & 2 & 3 \\
\hline District of Columbia & 17 & 1 & 4 & South Dakota & 3 & 0 & 0 & Dregon & 77 & 10 & 18 \\
\hline Florida & 161 & 14 & 21 & West South Central & 417 & 38 & 101 & Washington & 116 & 5 & $\pi$ \\
\hline Georgia & 125 & 8 & 16 & Arkansas & 14 & 0 & 1 & U.S. Territories & 2 & 0 & 0 \\
\hline Maryland & 338 & 28 & 42 & touisiana & 32 & 2 & 3 & Puerto Rico & 1 & 0 & 0 \\
\hline North Carolina & 121 & 14 & 25 & Oklahoma & 29 & 3 & 7 & Virgin islands & 1 & 0 & 0 \\
\hline South Carolina & 41 & 5 & 6 & Texas & 342 & 33 & 90 & Foreign Country & 7 & 0 & 0 \\
\hline Virginia & 223 & 24 & 40 & & & & & & & & \\
\hline West Virginia & 15 & 0 & 1 & & & & & & & & \\
\hline East South Central & 120 & 5 & 21 & & & & & & & & \\
\hline Alabama & 32 & 1 & 8 & & & & & & & & \\
\hline Kentucky & 18 & 1 & 3 & & & & & & & & \\
\hline Mississippi & 17 & 1 & 2 & & & & & & & & \\
\hline Tennessee & 53 & 2 & 8 & & & & & & & & \\
\hline
\end{tabular}




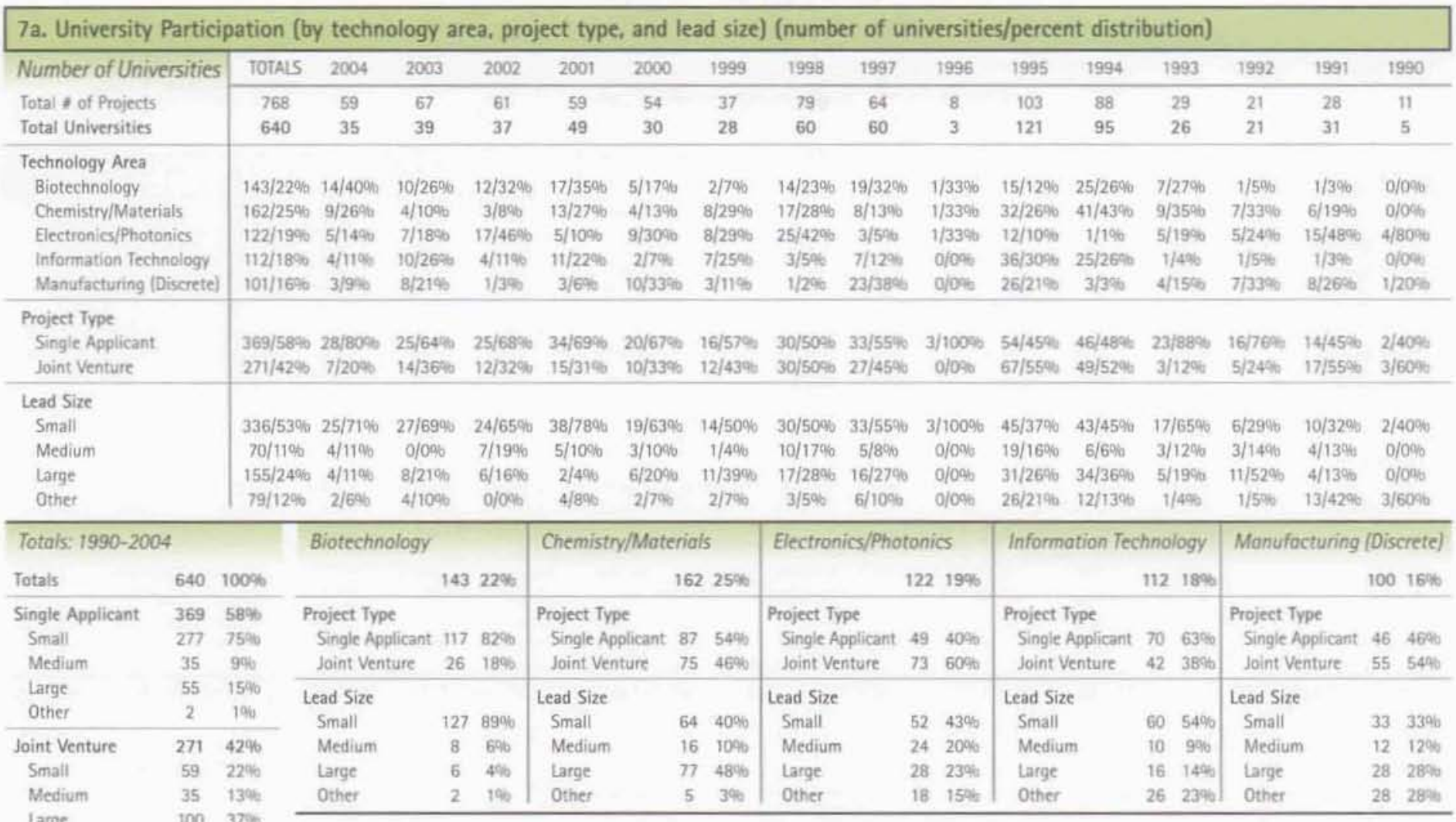

\begin{tabular}{|c|c|c|c|c|c|c|c|c|c|c|c|c|c|c|c|c|c|c|c|c|c|c|}
\hline \multirow{3}{*}{\multicolumn{2}{|c|}{$\begin{array}{l}\text { Number of Projects } \\
\text { Total } \text { of Projects } \\
\text { Total Projects w/Univ. Part. }\end{array}$}} & TOTALS & 2004 & \multicolumn{2}{|c|}{2003} & 2002 & 2001 & \multicolumn{2}{|l|}{2000} & 1999 & 1998 & 1997 & & 1996 & 1995 & 1994 & & 993 & 1992 & 1991 & \multicolumn{2}{|c|}{1990} \\
\hline & & \multirow{2}{*}{$\begin{array}{c}768 \\
372 / 489\end{array}$} & 59 & \multicolumn{2}{|l|}{67} & 61 & 59 & \multicolumn{2}{|l|}{54} & 37 & 79 & 64 & & 8 & 103 & 88 & & 29 & 21 & 28 & \multicolumn{2}{|r|}{11} \\
\hline & & & $23 / 39 \%$ & \multicolumn{2}{|c|}{$26 / 3996$} & $26 / 437 \%$ & $29 / 4996$ & \multicolumn{2}{|c|}{$21 / 3906$} & $19 / 5196$ & $39 / 49 \%$ & $28 / 44 \%$ & & $3 / 3896$ & $60 / 58 \% 6$ & $45 / 5196$ & 17) & $599 \%$ & $16 / 7696$ & $17 / 61 \%$ & \multicolumn{2}{|c|}{$3 / 2706$} \\
\hline \multicolumn{23}{|l|}{ Technology Area } \\
\hline Biotechnology & & $79 / 21 \%$ & $7 / 3098$ & \multicolumn{2}{|c|}{$6 \longdiv { 2 3 9 6 }$} & $10 / 38=$ & $10 / 34 \%$ & \multicolumn{2}{|c|}{$4 / 1946$} & $2 / 1100$ & $8 / 21 \%$ & $8 / 290$ & & $1 / 33 \% 6$ & $6 / 1090$ & $12 / 2746$ & \multicolumn{2}{|c|}{$3 / 1890$} & $1 / 6 \% 6$ & $1 / 6 \mathrm{es}$ & \multicolumn{2}{|c|}{$0 / 0 \mathrm{se}$} \\
\hline Chemistry/Mate: & & $93 / 250 \%$ & $6 / 2676$ & \multicolumn{2}{|c|}{$3 / 1290$} & $3 / 12 \%$ & $9 / 31 \%$ & \multicolumn{2}{|c|}{$3 / 1470$} & $4 / 2196$ & $14 / 360$ & $3 / 1196$ & & $1 / 3396$ & $16 / 2746$ & $18 / 40 \%$ & \multicolumn{2}{|c|}{$4 / 2456$} & $4 / 2500$ & $5 / 29 \%$ & \multicolumn{2}{|c|}{$0 / 0=16$} \\
\hline Electronics/Phot & nics & $70 / 199 \%$ & $4 / 1796$ & $5 / 199$ & & $8 / 31 \% 6$ & $2 / 7 \%$ & \multicolumn{2}{|c|}{$7 / 3396$} & $5 / 2696$ & $13 / 3396$ & $2 / 786$ & & $1 / 33 \%$ & $4 / 796$ & $1 / 2 \%$ & \multicolumn{2}{|c|}{$5 / 2900$} & $5 / 3+6$ & $6 / 35 \mathrm{Alt}$ & \multicolumn{2}{|c|}{$2 / 6796$} \\
\hline Information Teci & hology & $69 / 1996$ & $4 / 1746$ & $7 / 27$ & & $4 / 15 \%$ & $7 / 24 \%$ & $1 / 5 \%$ & & $5 / 2696$ & $3 / 89$ & $5 / 18 \%$ & & 0/046 & $18 / 3096$ & $12 / 27 \%$ & & $6 \% 6$ & $1 / 690$ & $1 / 600$ & & 1096 \\
\hline Manufacturing & iscrete) & $61 / 16 \%$ & $2 / 9 \%$ & $5 / 19^{\circ}$ & & $1 / 490$ & $1 / 396$ & $6 / 29 \%$ & & $3 / 169 \%$ & $1 / 3 \%$ & $10 / 3696$ & & $0 / 096$ & $16 / 27 \%$ & $2 / 4 \%$ & & $24 \%$ & $5 / 3190$ & $4 / 249 \%$ & & $33 \%$ \\
\hline Project Type & & & & & & & & & & & & & & & & & & & & & & \\
\hline Single Applicant & & $247 / 66 \%$ & 6. $17 / 74 \%$ & $17 / 65$ & & $22 / 850 \mathrm{~b}$ & $22 / 76 \%$ & $14 / 670$ & & $12 / 63 \%$ & $22 / 56 \%$ & $19 / 68 \%$ & & $/ 10096$ & $36 / 60 \%$ & $23 / 5146$ & $15 /:$ & 8890 & $13 / 81 \%$ & $10 / 59 \%$ & & 6790 \\
\hline Joint Venture & & $125 / 3440$ & $6 / 2696$ & $9 / 35^{\circ}$ & & $4 / 15 \%$ & $7 / 2490$ & $7 / 339$ & & $7 / 37 \%$ & $17 / 44 \%$ & $9 / 32 \%$ & & $0 / 096$ & $24 / 40 \%$ & $22 / 49 \%$ & & 1296 & $3 / 1906$ & $7 / 41 \%$ & & $33 \%$ \\
\hline Lead Size & & & & & & & & & & & & & & & & & & & & & & \\
\hline Small & & $215 / 5890$ & b. $16 / 7040$ & $18 / 69$ & & $21 / 81 \%$ & $23 / 7946$ & $14 / 670$ & & $11 / 5806$ & $22 / 5640$ & $19 / 6896$ & & $/ 10096$ & $25 / 4290$ & $17 / 3806$ & & $65 \%$ & $6 / 38 \%$ & $7 / 4146$ & & 6740 \\
\hline Medium & & $38 / 1096$ & $2 / 999$ & $0 / 00$ & & $1 / 4 \% 6$ & $3 / 1096$ & $2 / 100$ & & $1 / 506$ & $5 / 13 \%$ & $3 / 1106$ & & $0 / 090$ & $10 / 1706$ & $5 / 11 \% 6$ & & 160 & $3 / 19 / 6$ & $2 / 1296$ & & $10 \%$ \\
\hline Large & & $85 / 23 \%$ & $4 / 1746$ & $5 / 194$ & & $4 / 1596$ & $1 / 3+6$ & $4 / 19 \%$ & & $6 / 32 \%$ & $10 / 2646$ & $4 / 1440$ & & 0/096 & $16 / 27 \%$ & $18 / 4056$ & & $24 \% 0$ & $6 / 38 \mathrm{~s}$ & $3 / 18 \%$ & & $10 \%$ \\
\hline Other & & $34 / 90 \mathrm{~b}$ & $1 / 406$ & $3 / 120$ & & o/oss & $2 / 740$ & $1 / 5 \%$ & & $1 / 590$ & $2 / 590$ & $2 / 796$ & & $0 / 095$ & $9 / 1596$ & $5 / 1100$ & & 690 & $1 / 6 \%$ & $5 / 29 \%$ & & 3390 \\
\hline Totals: $1990-200$ & & & Biotechne & ology & & & Chemistr & $y /$ Mote & eriais & & Electron: & ies/Phot & tonic & & Informo & ation Tecl & hnoll & $\log y$ & Manufo & cturing & isc & crete) \\
\hline Totals & 372 & $100 \%$ & & & 79 & $12 \%$ & & & 93 & $15 \%$ & & & 70 & $11 \%$ & & & 69 & $11 \%$ & & & 61 & $10 \%$ \\
\hline Single Applicant & 247 & $66 \%$ & Project Type & & & & Project Typ & & & & Project Ty & & & & Project T & Type & & & Project 1 & Type & & \\
\hline Small & 186 & $75 \%$ & Single App & plicant & 66 & $84 \%$ & Single Ap & pplicant & 56 & $60 \%$ & Single Ap & pplicant & 37 & $53 \%$ & Single f & Applicant & 52 & $75 \%$ & Single & Applicant & 36 & 5996 \\
\hline Medium & 24 & 1096 & Joint Vent & ture & 13 & 1696 & Joint Ven & nture & 37 & $40 \%$ & Joint Ver & nture & 33 & 4740 & Joint V & lenture & 17 & $25 \%$ & Joint $V$ & enture & 25 & 4196 \\
\hline Large & 35 & 1496 & Lead Size & & & & Lead Size & & & & Lead Size & & & & Lead Size & & & & Lead Sirt & & & \\
\hline Other & 2 & 146 & Small & & 68 & $86 \%$ & Small & & 39 & 4240 & Small & & 39 & 5640 & Small & & 43 & $62 \%$ & Smail & & 26 & $43 \%$ \\
\hline Joint Venture & 125 & $34 \%$ & Medium & & 4 & 590 & Medium & & 9 & 109 & Medium & & 10 & 1496 & Mediun & & 8 & $12 \%$ & Mediur & & 7 & 1180 \\
\hline Small & 29 & $23 \%$ & Large & & 5 & 690 & Large & & 4) & $44 \%$ & Large & & 15 & $21 \%$ & Large & & 10 & 1490 & Large & & 14 & $23 \% 0$ \\
\hline Medium & 14 & 1145 & Other & & 2 & $3 \%$ & Other & & 4 & $4 \%$ & Other & & 6 & 906 & Other & & 8 & 1296 & Other & & 14 & $23 \%$ \\
\hline
\end{tabular}


8. Publications (by technology area, project type, and lead size)

\begin{tabular}{|c|c|c|c|c|c|c|c|c|c|c|c|c|c|}
\hline & TOTALS & 2004 & 2003 & 2002 & 2001 & 2000 & 1999 & 1998 & 1997 & 1996 & 1995 & 1994 & 1993 \\
\hline Total of Projects: & 768 & 59 & 67 & 61 & 59 & 54 & 37 & 79 & 64 & 8 & 103 & 88 & 29 \\
\hline Total Patents & 1701 & 18 & 32 & 50 & 96 & 167 & 90 & 117 & 234 & 39 & 419 & 252 & 187 \\
\hline \multicolumn{14}{|l|}{ Technology Area } \\
\hline Biotechnology & $462 / 2706$ & $7 / 39 \%$ & $1 / 346$ & $17 / 34 \%$ & $25 / 267$ & $24 / 1446$ & $22 / 2496$ & $19 / 10 \%$ & $120 / 51 \%$ & $22 / 56 / 6$ & $41 / 1046$ & $85 / 3446$ & $79 / 4240$ \\
\hline ChemistryfMaterials & $363 / 2186$ & $1 / 600$ & $0 / 096$ & $3 / 676$ & $22 / 239 \mathrm{k}$ & $23 / 1405$ & $23 / 2690$ & $17 / 1500$ & $3 / 18$ & $3 / 8 \%$ & $182 / 43 \%$ & $52 / 21 \%$ & $34 / 1896$ \\
\hline Electronics/Photonics & $207 / 12 \%$ & $8 / 4476$ & $16 / 5096$ & $13 / 2676$ & $25 / 2646$ & $0 / 096$ & $7 / 806$ & $81 / 69 \%$ & $11 / 5 \% \mathrm{t}$ & $14 / 360 \%$ & $1 / 0 \%$ & $31 / 1264$ & $0 / 0 \%$ \\
\hline Information Technology & $418 / 25 \%$ & $2 / 1106$ & $10 / 31 \%$ & $13 / 26 \%$ & $10 / 10 \%$ & $48 / 29 \%$ & $24 / 27 \%$ & $0 / 040$ & $36 / 15 \%$ & $0 / 0 \%$ & $139 / 3396$ & $83 / 33 \%$ & $53 / 28 \%$ \\
\hline Manufacturing (Discrete) & $251 / 1596$ & $0 / 0 \%$ & $5 / 16 \%$ & $4 / 896$ & $14 / 15 \%$ & $72 / 4396$ & $14 / 16 \%$ & $0 / 09 \%$ & $64 / 2790$ & $0 / 09 \%$ & $56 / 1340$ & $1 / 090$ & $21 / 1190$ \\
\hline \multicolumn{14}{|l|}{ Lead Type } \\
\hline Single Applicant & $852 / 50 \%$ & $10 / 560 \%$ & $24 / 75 \%$ & $37 / 7400$ & $25 / 2690$ & $48 / 2996$ & $44 / 4976$ & $52 / 4490$ & $200 / 85 \%$ & $34 / 87 \%$ & $161 / 3845$ & $78 / 31 \%$ & $139 / 74 \%$ \\
\hline Joint Venture & $849 / 50 \%$ & $8 / 4490$ & $8 / 2506$ & $13 / 2606$ & $71 / 7496$ & $119 / 7196$ & $46 / 5146$ & $65 / 56 \%$ & $34 / 1596$ & $5 / 13 \%$ & $258 / 62 \%$ & $174 / 69 \%$ & $48 / 269 \%$ \\
\hline \multicolumn{14}{|l|}{ Lead Size } \\
\hline Smail & $981 / 58 \%$ & $17 / 9416$ & $25 / 7846$ & $37 / 7476$ & $47 / 4996$ & $99 / 5946$ & $49 / 5446$ & $55 / 4770$ & $201 / 86$ th & $34 / 876$ & $178 / 42 \%$ & $120 / 4896$ & $119 / 644$ \\
\hline Medium & $9 4 \longdiv { 6 9 4 }$ & $0 / 095$ & $3 / 906$ & $2 / 4=6$ & $21 / 22 \%$ & $0 / 096$ & $4 / 4 \% 6$ & $1 / 196$ & $9 / 4 \%$ & $0 / 00 \%$ & $38 / 90:$ & $8 / 39$ & $8 / 406$ \\
\hline Large & $371 / 2240$ & $1 / 696$ & $4 / 1396$ & $11 / 220 \%$ & $6 / 6 \%$ & $33 / 2005$ & $25 / 2806$ & $48 / 4136$ & $10 / 490$ & $5 / 1390$ & $143 / 34 \%$ & $41 / 16 \%$ & $44 / 2496$ \\
\hline Other & $255 / 1540$ & $0 / 090$ & $0 / 0 \%$ & $0 / 0 \%$ & $22 / 23 \%$ & $35 / 21 \%$ & $12 / 1396$ & $13 / 11 \%$ & $14 / 696$ & $0 / 0 \%$ & $60 / 140 \%$ & $83 / 33 \%$ & $16 / 990$ \\
\hline
\end{tabular}

\begin{tabular}{|c|c|c|c|c|c|c|c|c|c|c|c|c|c|c|c|c|c|}
\hline \multicolumn{3}{|c|}{ Totals: $1990-2004$} & \multicolumn{3}{|l|}{ Biotechnology } & \multicolumn{3}{|c|}{ Chemistry/Materials } & \multicolumn{3}{|c|}{ Electronics/Photonics } & \multicolumn{3}{|c|}{ Information Technology } & \multicolumn{3}{|c|}{ Manufacturing (Discrete) } \\
\hline Totals & 1701 & $100 \%$ & & 462 & $27 \%$ & & 363 & $21 \%$ & & 308 & $18 \%$ & & 317 & $19 \%$ & & 251 & $15 \%$ \\
\hline \multirow{5}{*}{$\begin{array}{l}\text { Single Applieant } \\
\text { Small } \\
\text { Medium } \\
\text { Large } \\
\text { Other }\end{array}$} & 852 & $50 \%$ & \multirow{3}{*}{$\begin{array}{l}\text { Project Type } \\
\text { Single Applicant } \\
\text { Joint Venture }\end{array}$} & \multirow{3}{*}{$\begin{array}{l}364 \\
98\end{array}$} & \multirow{3}{*}{$\begin{array}{l}7996 \\
21 \%\end{array}$} & Project Type & \multirow[b]{2}{*}{148} & \multirow{3}{*}{$\begin{array}{l}4196 \\
59 \%\end{array}$} & \multirow{2}{*}{\multicolumn{2}{|c|}{ Project Type }} & \multirow{3}{*}{$\begin{array}{l}37 \% \\
63 \%\end{array}$} & \multirow{3}{*}{$\begin{array}{l}\text { Project Type } \\
\text { Single Applicant } \\
\text { Joint Venture }\end{array}$} & \multirow{3}{*}{$\begin{array}{l}135 \\
182\end{array}$} & \multirow{3}{*}{$\begin{array}{l}43 \% 6 \\
5796\end{array}$} & \multicolumn{3}{|l|}{ Project Type } \\
\hline & 735 & $86 \%$ & & & & Single Applicant & & & & \multirow{2}{*}{$\begin{array}{l}13 \\
95\end{array}$} & & & & & Single Applicant & 92 & 3700 \\
\hline & 29 & 390 & & & & Joint Venture & 215 & & Joint Venture & & & & & & Joint Venture & 159 & $63 \%$ \\
\hline & 88 & 1006 & Lead Size & & & Lead Size & & & Lead Size & & & Lead Size & & & Lead Size & & \\
\hline & 0 & 040 & Small & 427 & 9290 & Small & 136 & 3700 & Smali & 160 & $52 \%$ & Small & 126 & 4005 & Small & 132 & 5306 \\
\hline Joint Venture & 849 & $50 \%$ & Medium & 12 & 390 & Medium & 51 & 1490 & Medium & 15 & $5 \%$ & Medium & 13 & $4 \mathrm{te}$ & Medium & 3 & 196 \\
\hline Smail & 246 & 2990 & Large & 20 & 496 & Large & 147 & $40 \%$ & Large & 93 & $30 \%$ & large & 76 & $24 \%$ & Large & 35 & 1490 \\
\hline Medium & 65 & $8 \%$ & Other & 3 & $19 \%$ & Other & 29 & $8 \%$ & Other & 40 & $13 \%$ & Other & 102 & 3290 & Other & 81 & $32 \%$ \\
\hline
\end{tabular}

\begin{tabular}{|c|c|c|c|c|c|c|c|c|c|c|c|c|c|c|c|c|}
\hline & TOTAIS & 2004 & 2003 & 2002 & 2001 & 2000 & 1999 & 1998 & 1997 & 1996 & 1995 & 1994 & 1993 & 1992 & 1991 & 1990 \\
\hline Total I of Projects: & 768 & 59 & 67 & 61 & 59 & 54 & 37 & 79 & 64 & 8 & 103. & 88 & 29 & 21 & 28 & 11 \\
\hline Total Patents & 1418 & 3 & 21 & 18 & 63 & 50 & 67 & 93 & 117 & 33 & 371 & 345 & 94 & 46 & 60 & 37 \\
\hline \multicolumn{17}{|l|}{ Technology Area } \\
\hline Biotechnology & $346 / 24 \%$ & $0 / 0 \%$ & $0 / 090$ & $7 / 39 \%$ & $2 / 396$ & $1 / 2 \%$ & $1 / 1 \%$ & $28 / 30 \%$ & $25 / 21 \%$ & $7 / 21 \%$ & $39 / 11 \%$ & $208 / 60 \%$ & $19 / 20 \%$ & $8 / 17 \%$ & $1 / 290$ & $0 / 0 \% 0$ \\
\hline Chemistry/Materials & $362 / 26 \%$ & $3 / 1009$ & $0 / 096$ & $7 / 3996$ & $8 / 13 \%$ & $3 / 6 \%$ & $63 / 9490$ & $29 / 31 \%$ & $39 / 3300$ & $7 / 21 \%$ & $79 / 2106$ & $61 / 18 \%$ & $27 / 2990$ & $1 / 290$ & $35 / 589 \mathrm{q}$ & $0 / 096$ \\
\hline Electronics/Photonics & $337 / 249$ & O/096 & $16 / 7646$ & $4 / 2296$ & $22 / 3540$ & $18 / 36 \%$ & $3 / 4 \%$ & $17 / 18 \%$ & $33 / 2846$ & $19 / 58 \%$ & $34 / 946$ & $51 / 1546$ & $41 / 44 \%$ & $23 / 5004$ & $19 / 32 \%$ & $37 / 100 \%$ \\
\hline Information Technology & $246 / 1746$ & $0 / 09 \mathrm{~s}$ & $5 / 240 \%$ & $0 / 0 \%$ & $9 / 1400$ & $25 / 5096$ & $0 / 0 \%$ & $18 / 194 \mathrm{~h}$ & $15 / 1340$ & $0 / 0 \% 6$ & $146 / 39 \%$ & $24 / 746$ & $4 / 496$ & $0 / 0 \%$ & $0 / 096$ & o/04t \\
\hline Manufacturing (Discrete) & $127 / 9 \%$ & $0 / 00$ & opose & $0 / 096$ & $22 / 3506$ & $3 / 696$ & $0 / 045$ & $1 / 180$ & $5 / 47 \%$ & $0 / 090$ & $73 / 2095$ & $1 / 00 \%$ & $3 / 390$ & $14 / 3090$ & $5 / 8 \%$ & $0 / 000$ \\
\hline \multicolumn{17}{|l|}{ Project Type } \\
\hline Single Applicant & $685 / 4896$ & $3 / 1004 \mathrm{t}$ & $14 / 67 \%$ & $14 / 78 \% 6$ & $18 / 29 \%$ & $42 / 8490$ & $1 / 140$ & $40 / 43 \%$ & $43 / 37 \% 6$ & $27 / 62 \%$ & $133 / 3602$ & $222 / 64 \%$ & $84 / 8976$ & $31 / 6760$ & $13 / 22 \%$ & o/0es \\
\hline Joint Venture & $733 / 52 \%$ & $0 / 0 \%$ & $7 / 3396$ & $4 / 2296$ & $45 / 7100$ & $8 / 16 \%$ & $66 / 9990$ & $53 / 57 \%$ & $74 / 63 \%$ & $6 / 1800$ & $238 / 6496$ & $123 / 3600$ & $10 / 110 \%$ & $15 / 3396$ & $47 / 789$ & $37 / 10096$ \\
\hline \multicolumn{17}{|l|}{ Lead Size } \\
\hline Small & $627 / 4490$ & $0 / 0 \%$ & $12 / 5796$ & $14 / 78 \%$ & $39 / 62 \%$ & $20 / 4090$ & $37 / 55 \%$ & $41 / 44 \% 6$ & $51 / 4490$ & $27 / 82 \%$ & $92 / 25 \%$ & $193 / 5696$ & $41 / 4490$ & $24 / 52 \%$ & $12 / 20 \%$ & $24 / 65 \%$ \\
\hline Medium & $259 / 18 \%$ & $0 / 0 \%$ & $7 / 33 \%$ & $1 / 6 \%$ & $2 / 3 \%$ & $0 / 0 \%$ & $0 j 0 \%$ & $15 / 1696$ & $3 / 396$ & $0 / 094$ & $129 / 3500$ & $69 / 20 \%$ & $19 / 200 \%$ & $1 / 2 \%$ & $13 / 22 \%$ & $0 / 0 \%$ \\
\hline Large & $445 / 31 \%$ & $3 / 10040$ & $2 / 10 \%$ & $3 / 1790$ & $5 / 8 \%$ & $30 / 60 \%$ & $30 / 45 \%$ & $36 / 39 \%$ & $44 / 3896$ & $6 / 18 \%$ & $134 / 36 \%$ & $70 / 20 \%$ & $32 / 3496$ & $15 / 33 \%$ & $35 / 58 \% 6$ & $0 / 096$ \\
\hline Other & $87 / 69 \%$ & $0 / 096$ & $0 / 096$ & $0 / 0 \%$ & $17 / 27 \%$ & $0 / 0 \%$ & $0 / 095$ & $1 / 19 \mathrm{~b}$ & $19 / 16 \%$ & $0 / 0 \% 6$ & $16 / 495$ & $13 / 490$ & $2 / 2 \%$ & $6 / 1346$ & $0 / 09 \%$ & $13 / 3596$ \\
\hline
\end{tabular}

\begin{tabular}{|c|c|c|c|c|c|c|c|c|c|c|c|c|c|c|c|c|c|}
\hline \multicolumn{3}{|c|}{ Totols: 1990-2004 } & \multicolumn{3}{|l|}{ Biotechnology } & \multicolumn{3}{|c|}{ Chemistry/Moterials } & \multicolumn{3}{|c|}{ Electronics/Photonics } & \multicolumn{3}{|c|}{ Information Technology } & \multicolumn{3}{|c|}{ Manufacturing (Discrete) } \\
\hline Totals & 1418 & 10096 & & 346 & $24 \%$ & & 362 & $26 \%$ & & 337 & $24 \% 6$ & & 246 & $17 \%$ & & 127 & $9 \%$ \\
\hline Single Applicant & 685 & $48 \%$ & Project Type & & & Project Type & & & Project Type & & & Project Type & & & Project Type & & \\
\hline Small & 388 & 5796 & Single Applicant & 265 & 7746 & Single Applicant & 123 & $34 \%$ & Single Applicant & 145 & $43 \mathrm{~b}$ & Single Applicant & 92 & 3725 & Single Applicant & 60 & $47 \%$ \\
\hline Medium & 120 & $18 \%$ & Joint Venture & 81 & 2396 & Joint Venture & 239 & $66 \%$ & Joint Venture & 192 & 5796 & Joint Venture & 154 & $63 \% 6$ & Joint Venture & 67 & 5396 \\
\hline Large & 177 & 2696 & Lead Size & & & Lead Size & & & Lead Size & & & Lead Size & & & Lead Size & & \\
\hline Other & 0 & $0 \%$ & Small & 237 & $68 \%$ & Small & 90 & $25 \%$ & Small & 197 & $58 \%$ & Small & 50 & $20 \% 0$ & Small & 53 & $42 \%$ \\
\hline Joint Venture & 733 & $52 \%$ & Medium & 87 & 2506 & Medium & 28 & 800 & Medium & 27 & 840 & Medium & 108 & 4496 & Medium & 9 & $7 \%$ \\
\hline Small & 239 & $33 \%$ & Large & 16 & 540 & Large & 233 & 6406 & Large & 60 & $18 \% 6$ & Large & 80 & 3396 & Large & 56 & 4496 \\
\hline Medium & 139 & 1996 & Other & 6 & 296 & Other & 11 & $3+4$ & Other & 53 & $16 \%$ & Other & 8 & 396 & Other & 9 & 796 \\
\hline
\end{tabular}




\begin{tabular}{|c|c|c|c|c|c|c|c|c|c|c|c|c|c|c|c|c|}
\hline & TOTALS & 2004 & 2003 & 2002 & 2001 & 2000 & 1999 & 1998 & 1997 & 1996 & 1995 & 1994 & 1993 & 1992 & 1991 & 1990 \\
\hline Total o of Projects & 768 & 59 & 67 & 61 & 59 & 54 & 37 & 79 & 64 & B & 103 & 88 & 29 & 21 & 28 & 11 \\
\hline Total Projects w/Comm. & 367 & 3 & 17 & 17 & 13 & 27 & 12 & 55 & 47 & 6 & 79 & 66 & 25 & & & \\
\hline Technology Area & & & & & & & & & & & & & & & & \\
\hline Biotechnology & $67 / 18 \%$ & 0,096 & $2 / 12 \%$ & $6 / 35 \% 6$ & $5 / 3840$ & 3/11\% & $1 / 870$ & $9 / 16 \%$ & $12 / 26 \%$ & $2 / 3390$ & $8 / 1070$ & $16 / 2400$ & $3 / 1246$ & & & \\
\hline Chemistry/Materials & $91 / 2595$ & $0 / 0 \%$ & $4 / 2496$ & 2/1206 & $2 / 159 \%$ & $6 / 2206$ & $3 / 25 \% \mathrm{~b}$ & $21 / 3896$ & $2 / 406$ & $2 / 3390$ & $21 / 2700$ & $21 / 3240$ & $7 / 2695$ & & & \\
\hline Electronies/Photonics & $75 / 2096$ & $1 / 3396$ & $5 / 2940$ & $3 / 1806$ & $3 / 2340$ & $10 / 37 \%$ & $5 / 42 \%$ & $19 / 35 \%$ & 6/1396 & $2 / 3396$ & $6 / 896$ & $5 / 8 \%$ & $10 / 4046$ & \multirow{6}{*}{\multicolumn{3}{|c|}{$\begin{array}{l}\text { No dato availoble } \\
\text { (1990-1992): } \\
\text { Business } \\
\text { Reporting System } \\
\text { implemented } \\
\text { in } 1993\end{array}$}} \\
\hline Information Technology & $89 / 2440$ & $2 / 6790$ & $3 / 1890$ & $4 / 240 \%$ & $2 / 1590$ & $2 / 79 \%$ & $3 / 25 \%$ & $5 / 996$ & $18 / 3846$ & $0 / 0 \%$ & $26 / 3340$ & 22/33내 & $2 / 890$ & & & \\
\hline Manufacturing (Discrete) & $45 / 1240$ & $0 / 0 \%$ & $3 / 1896$ & $2 / 1200$ & 1/8\% & $5 / 2296$ & $0 / 0 \%$ & $1 / 296$ & 9/1996 & $0 / 04 \%$ & $18 / 2396$ & $2 / 3$ क & $3 / 1296$ & & & \\
\hline Project Type & & & & & & & & & & & & & & & & \\
\hline Single Applicant & $228 / 6290$ & $3 / 10096$ & $13 / 7606$ & $12 / 7190$ & $7 / 54460$ & $17 / 63^{40}$ & $5 / 4290$ & $33 / 6046$ & $35 / 7400$ & $5 / 83 \%$ & $44 / 569 \mathrm{~b}$ & $34 / 5290$ & $20 / 8040$ & & & \\
\hline Joint Venture & 139/38\% & $0 / 096$ & $4 / 2496$ & $5 / 2996$ & $6 / 46=30$ & $10 / 37 \%$ & $7 / 58 \%$ & $22 / 40 \% 6$ & $12 / 26 \%$ & $1 / 17 \% 0$ & $35 / 44 \%$ & $32 / 48 \%$ & $5 / 2000$ & & & \\
\hline \multicolumn{17}{|l|}{ Lead Size } \\
\hline Small & $22 \mathrm{~B} / 62 \mathrm{6}$ & $3 / 100 \%$ & $14 / 3206$ & $14 / 8296$ & $8 / 62 \%$ & $22 / 818$ & 7/5806: & $35 / 5494$ & $36 / 77 \%$ & $5 / 8390$ & $34 / 4370$ & $35 / 5306$ & $15 / 60=4$ & & & \\
\hline Medium & $37 / 1080$ & $\mathrm{OFOH}$ & $0 / 0 \%$ & $1 / 606$ & $1 / 800$ & $2 / 7 \pi$ & $0,00 \%$ & $9 / 16 \times 6$. & $3 / 6 \%$ & $0 / 096$ & $12 / 15 \div$ & $6 / 90$ & $3 / 126$ & & & \\
\hline Large & $74 / 2096$ & $0 / 00 \%$ & 271295 & $2 / 1200$ & $2 / 1590$ & $2 / 790$ & $4 / 3306$ & 9/1606 & $6 / 1396$ & $1 / 1798$ & $2 \pi / 2706$ & $19 / 290$ & $6 / 2446$ & & & \\
\hline Other & $28 / 8=6$ & $0 / 070$ & $1 / 6 \%$ & 0,096 & $2 / 15 \%$ & $1 / 498$ & $1 / 896$ & $2 / 4 \%$ & $2 / 406$ & O/OFh & $12 / 1516$ & $6 / 900$ & $1 / 490$ & & & \\
\hline
\end{tabular}

\begin{tabular}{|c|c|c|c|c|c|c|c|c|c|c|c|c|c|c|c|c|c|}
\hline \multicolumn{3}{|l|}{ Totais: $1990-2004$} & \multicolumn{3}{|l|}{ Biotechnology } & \multicolumn{3}{|c|}{ Chemistry/Materials } & \multicolumn{3}{|c|}{ Electronics/Photonics } & \multicolumn{3}{|c|}{ Information Technology } & \multicolumn{3}{|c|}{ Monufocturing (Discrete) } \\
\hline Totals & 367 & 1009 & & 67 & $18 \%$ & & 91 & $25 \%$ & & 75 & 2096 & & 89 & $24 \%$ & & 45 & $12 \%$ \\
\hline Single Applicant & 228 & $62 \%$ & Project Type & & & Project Type & & & Project Type & & & Project Type & & & Project Type & & \\
\hline Small & 182 & 8090 & Single Applicant & 50 & 7540 & Single Applicant & 54 & $59 \%$ & Single Applicant & 36 & 4870 & Single Applicant & का & $75 \%$ & Single Applicant & 21 & 4700 \\
\hline Medium & 21 & $9=6$ & Joint Venture & 17 & 2506 & Joint Venture & 37 & 413 & Joint Venture & 39 & 5294 & Joint Venture & 22 & $25 \% 6$ & Joint Ventute & 24 & 5300 \\
\hline Large & 25 & $111 \%$ & Lead Size & & & Lead Size & & & Lead Size & & & Lead Size & & & Lead Size & & \\
\hline Other & 0 & $0 \%$ & Small & 58 & $87 \%$ & Small & 46 & 516 & Smail & 46 & 6190 & Small & 57 & 6490 & Small & 21 & 470 \\
\hline Joint Venture & 139 & 3896 & Medium & 6 & $9 \%$ & Medium & 11 & $12 \%$ & Medium & 10 & 1390 & Medium & 9 & $10 \%$ & Merfium & 1 & 20 \\
\hline Small & 46 & 3390 & Large & 2 & 340 & Large & 30 & $33 \%$ & Large & 15 & 2096 & targe & 15 & 1740 & Large: & 12 & 2740 \\
\hline Medium & 13 & 1296 & Other & t & 140 & Other & 4. & 446 & Other & 4 & $5 \%$ & Other & B & 996 & Other & 10 & 2200 \\
\hline
\end{tabular}

Other $\quad 28 \quad 2096$

\section{Post-Award Attraction of External Funding ${ }^{*}$ (by area and lead size)}

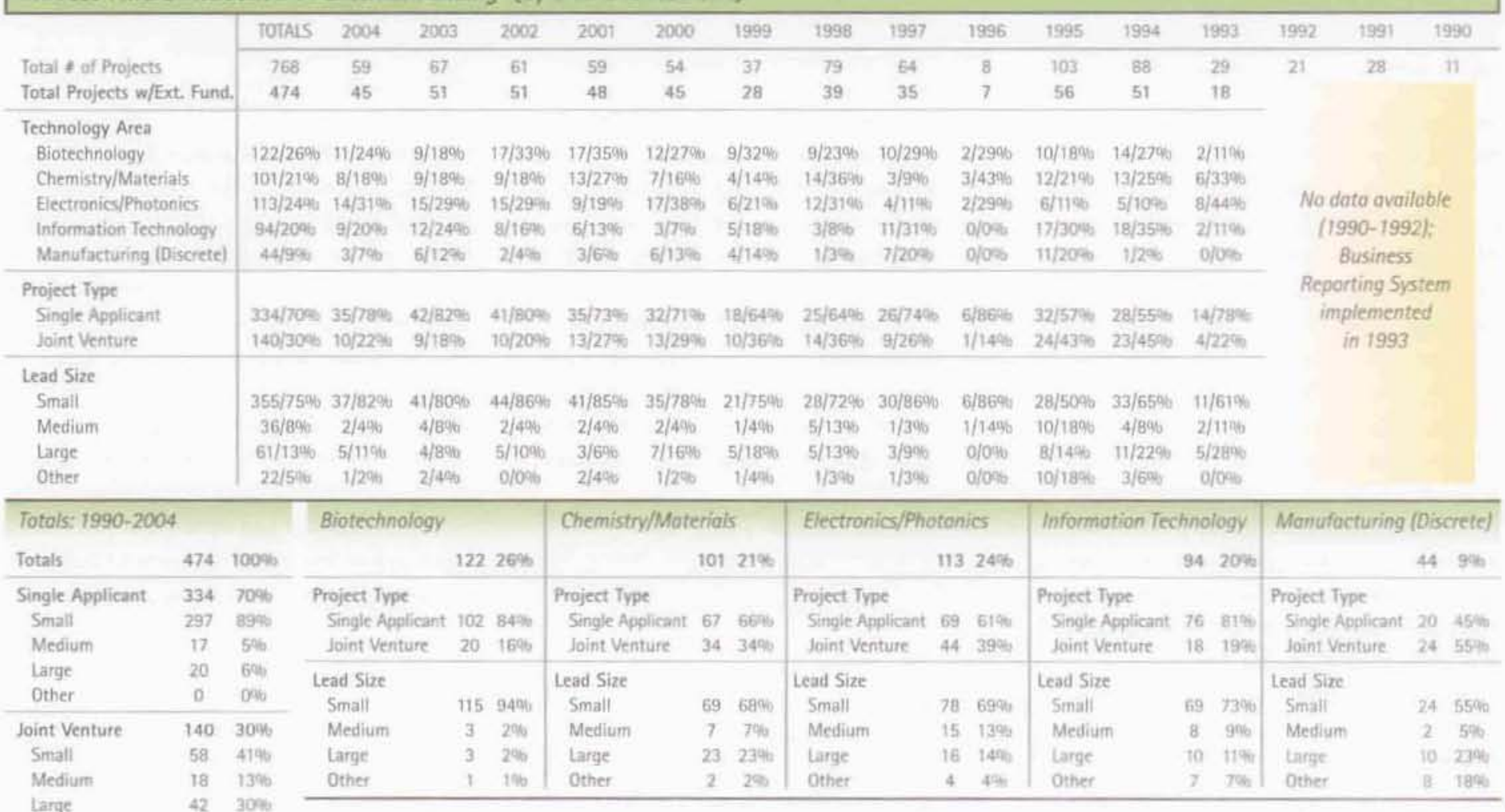

Oiner

- External funding includes funding from poblic and grivate sources received anytime after the award announcement. 


\section{Appendix B \\ Significant Recent Studies}

The ATP Economic Assessment Office measures the success of the Advanced Technology Program through a variety of evaluation studies, aided by leading experts. All the recent studies described in this appendix can be found at www.atp.nist.gov/eao/eao_pubs.htm.

\section{Economic Studies}

ATP and the U.S. Innovation System: A Methodology for Identifying Enabling R\&D Spillover Networks. Spillovers serve a central role in justifying public support for R\&D, but are difficult to identify and to measure. Research systems or networks are the patterns of interaction and communication among firms, universities, and other laboratories, and reveal the generation and exchange of scientific and technological knowledge. This study sets forth a novel methodology that draws on past research of identifying and quantifying knowiedge spillovers using patent citations. The methodology uses systems analysis and fuzzy logic to analyze R\&D spillovers within networks of R\&D organizations, and identifies spillover patterns across organizations, technological areas, geographic regions, and industries. The methodology is illustrated by the mapping of two research networks, one underlying micromechanical systems (MEMs), and the second underlying short wavelength sources for optical recording.

NIST GCR 06-895 (Economic Study). October 2006. Michael S. Fogorty. Amit K. Sinho, and Adam B. Jaffe

Identifying Technology Flows and Spillovers Through NAICS Coding of ATP Project Participants. The primary method for classifying industries is the North American Industry Classification System (NAICS). developed by an Office of Management and Budget interagency working group. This report describes a methodology that uses NAICS codes to refine industry classification data used by ATP's online Business Reporting System (BRS) project database. Six-digit NAICS codes are assigned to each ATP project participant's own-industry and use-industry of any commetcial applications reported by project participants for projects funded between January 1999 and July 2003. The results of the study demonstrate that ATP projects exhibit certain factors that suggest high spillover potential, such as muiti-use innovation, infrastructural technology, and licensing the technology inter-industry. Another finding was that a majority of the ATP participant's industries are characterized as primary technology generators, while approximately one-third of the use-industries are characterized as either primary or secondary technology generators. This suggests that AIP project selection enables technology to be developed in a more sophisticated technology sector, which may then flow to less sophisticated technology sectors. NISTR 7280 [Economic Study). April 2006. John Nail and Hayden Brown.

\section{Measuring Behavior Additionality in ATP Joint} Venture Projects: Findings from the Advanced Technology Program. This paper examines descriptive results from the Survey of ATP Joint Ventures, which shows that companies form an ATP joint venture to benefit from complementary R\&D expertise, to pool resources with other firms, and to address a technical problem that is common to their industry. One clear behavioral effect evidenced was that the formation of a joint venture project fosters trust and cooperation among partners. Partners in fact show goodwill and trust each other to a high extent, and a regression analysis confirmed that ATP involvement was an explanatory factor, along with effective governance procedures and the size of the joint venture. A postproject survey showed persistent collaborative links with 46 percent continuing with their partners on non-AIP technology subcontractors Over half of the participants continued in R\&D because of their positive ATP experience. For ATP, the concept of behavior additionality provides another dimension for evaluating outcomes from ATP-funded projects and broadens the concept of success to include both the direct and indirect effects of government funding of high-risk projects.

Alper prepored for the OECO Working Group on Behavior. Additionality (Economic Study). April 2006 . Stephonic Shipp. Andrew Wang, Stephen Compbell, and Lorel Wisniewsti (NIST). and Kerry Levin and Jennifer O'Brien (Westot).
The Role of the U.S. National Innovation System in the Development of the PEM Stationary Fuel Cell. The authors participated in a multi-country study of national innovation systems and their impact on new technology development, sponsored by the Organization for Economic Cooperation and Development. In particular, they looked at the impact of the U.S. national innovation system on the commercial deveiopment of proton exchange membrane (PEM) fuel cells for residential power applications. Their findings include that private industry conducts significant amounts of basic research in fuel cells, partially driven by the importance of the automotive, energy, and electronics industries in the participating countries. Energy security is considered another driver. Although industry receives the majority of new fuel cell patents issued, national laboratories and universities continue to publish the majority of the papers. Their findings support the value of public-private partnerships, especially projects that link private industry with universities or national laboratories.

MISTR 716 (Economic Study). February 2005. John Nail, Gary Anderson, Gerald Ceasor, and Christopher Hansen.

Evaluation of ATP's Intramural Research Awards Program. From fiscal year 1992 through fiscal year 2000 , AIP funded 1,052 intramurai projects with $\$ 99$ million allocated to researchers within NIST'S Measurement and Standards Laboratories. ATP statute allows the program to allocate up to 10 percent of its annual appropriations internally for standards development and technical activities in support of ATP's mission. Results are presented using survey, case study, and benchmarking approaches. Four case studies are presented, and the social rate of return of the funded research is approximated. The four ease studies inciude Wavelength References for Optical Fiber Communications (SRM 2517a); Injectable 


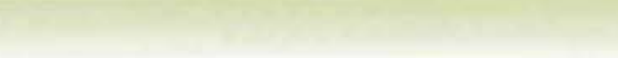

Composite Bone Grafts; Internet Commerce for Manufacturing; and Polymer Composite Dielectrics for Integrated Thin-Film Capacitors. Findings include the following:

- ATP funding assists NIST laboratories in initiating new research directions, thereby expanding the scope of laboratory research.

- Two publications, on average, resulted from every three intramural projects, and each publication was cited in the literature about 1.75 times.

- Fifty-four percent of the projects would not have been undertaken in the absence of ATP support; the principal investigators believe that the remaining 46 percent would have taken longer to complete, been less technically challenging, and generated fewer technical outputs without ATP funding.

NIST GCR 04-866 (Economic Study). December 2004. Albert N. Link and John T. Scott:

\section{Closing the Competitive Gap: A Retrospective} Analysis of the ATP $2 \mathrm{~mm}$ Project. ATP's twomillimeter project ( $2 \mathrm{~mm}$ project), which ran from 1992 through 1995, was an effort to improve the product quality, competitiveness, and market share of U.S. motor vehicle producers relative to their Japanese and European counterparts. The consortium of auto manufacturers, equipment suppliers, and universities teamed to improve the quality of domestically produced automobiles and light trucks and increase manufacturers' understanding of scientific approaches to reduce variation and thereby improve quality and lower cost while shortening the new product launch time. A typical auto body has approximately 100 critical dimensions that control the quality of closure panel fits, which can cause various quality problems such as wind noise, water leaks, rattles, squeaks, and a general appearance of low quality in the gaps between the body and doors, hood, and deck lid. In Japan, best practices in the early 1990 s resulted in total variation of critical body dimensions of no more than 2 millimeters; European automakers had a variation of about 3 millimeters: U.S. counterparts had a variation of 4 millimeters or more. This report details several outcomes:

- The variation of critical body dimensions toward meeting the $2 \mathrm{~mm}$ objective (with $+1-1 \mathrm{~mm}$ variance was reduced.

- The project was the key driving force in changing the manufacturing quality control technology used to improve quality, reduce cost, and shorten time to market by domestically owned vehicle manufacturers.

- Domestic producers were able to slow the loss of market share to offshore and transplant manufacturers.

- Approximately 1,400 new jobs were created.

- By conservative estimate, the project generated an increase of almost \$190 million in GDP (measured over a 10-year period following the start of the ATP project). These gains were achieved without any significant wage or price inflation and without any distorting subsidies or changes in trade policy.

Findings presented in this report are based on information gathered through case study interviews conducted in 2000 and 2001, model development and estimation using a database conducted for the research, and a macroeconomic model capable of handling multiple production processes for the motor vehicle manufacturing industry.

NIST GCR 03-856 (Economic Study). July 2004. Karen R. Polenske (MI), Nicolas O. Rockler (Regional Economic Consuitant), and Other Member of the Research Team.
Technology Adoption Indicators Applied to the Flow-Control Machining Project. An idea from the 1995 ATP competition produced a new automobile finishing process called Flow-Control Machining (FCM), which increases the precision of cast-metal parts for interior fluid flows. This economic study develops a set of technology adoption indicators (TAls) capable of selecting and analyzing possible spillover applications for FCM technology. When applied to engine manufacturers for lawnmowers and airplanes, TAls revealed that the lawnmower industry is more likely to adopt this new technology. due in part to new EPA regulations, with significant projected savings in GDP.

NISTRR 6888 (Economic Study). Moy 2003. Hayden Brown (NIST) and Mark Ehlen (Sandia Notional Lobs).

Inter-Industry Diffusion of Technology That Results from ATP Projects. This report describes the inter-industry diffusion of technology that might result if ATP-funded projects used US. input-autput (1-0) tables to identify the fit of those projects within the U.S. industrial structure. These tables can also track the most direct path of benefits flowing to other industries. In industries represented by an ATP participant, the intensity of purchase activities by similar companies in that industry could provide a useful indicator of the likelihood of spillovers; such an indicator could be quantified by $1-0$ tables. Rankings can be derived from 1998 1-0 tables for 36 ATP projects that were funded from 1992-1996 and resuited in commercialization.

NIST GCR 03-848 (Economic Study). April 2003. Joei Popkin [JPCEconomic Consultants]. 


\section{Economic Studies (cont.)}

Measuring the Impact of ATP-Funded Research Consortia on Research Productivity of Participating Firms: A Framework Using Both U.S. and Japanese Data. This study uses empirical methods to evaluate the effects of participation in ATP-funded consortia on the research productivity of consortia members. The authors developed a data set for one group of firms that participated in ATP-funded research consortia, and for a second control group that was never involved, Innovative output was measured using patent data. The findings revealed a positive relationship between the firms' intensity of participation in research consortia and their overall research productivity-participation in one additional ATP-funded consortium per vear would increase a firm's patenting that year by as much as 8 percent. Japanese data included in the study validated the fact that consortia have a positive impact on research productivity.

NIST GCR 02-830 (Economic Study) Deceniber 2002 Mariko Sakakibarn (UCLAV and lee Branstetter (Columbia Business School).

Program Design and Firm Success in the Advanced Technology Program: Project Structure and Innovation Outcomes. In evaluating ATP, the increased innovation of participant firms serves as an important indicator of program success. This study measures innovation outcomes by the number of patents granted and by a statistical analysis of firms before and after ATP project participation. The study showed that ATP has a positive effect on innovation in firms, and participation in the program increases firms' patenting, relative to their patenting prior to the ATP award. The study also showed that joint venture participation and university collaboration have positive impacts on innovation, as measured by increased firm patenting activity.

NISTIR 6943 (Economic Study). December 2002. Lynne G. Zucker and Michael R. Darby (UCLA), and Andrew L. Wang (NIST/AIP).
Universities as Research Partners. This study seeks to gain a better understanding of the performance of university-industry research partnerships by surveying a sample of pre-commercial research projects funded by AIP. Although results must be interpreted cautiously because of the small sample size, the study finds that projects with university involvement tend to be in areas involving "new" science, and therefore the projects may experience more difficulty and delay-but also are more likely to end in success. This finding implies that universities are contributing to basic research awareness and insight amang the partners in ATP-funded projects; therefore universities are important to U.S. innovation.

NIST GCR 02-829 (Economic Study. June 2002. Bronwnn H. Hall (UC/B), Albent N. Link UUNC/G), and John I. Scott (Dortmouth)

Winning an Award from the Advanced Technology Program: Pursuing R\&D Strategies in the Public Interest and Benefiting From a Halo Effect.

This study addresses two questions: (1) how a firm's R\&D strategy relates to the goals of ATP and affects the chances of winning an award from the program: and (2) how winning an award affects a firm's success in raising additional funds for a proposed research project. Data from a 1999 survey show that award winners are more likely to behave in ways that enhance the transfer of knowledge to-and the reception of technology by-other firms. Awardwinning companies are better networked than nonwinning applicants and exhibit a greater willingness to share research findings. Award-winning companies are also more likely to form partnerships to open up new innovation pathways. The study finds that award-winning firms have greater success in attracting additional funding for their ATP projects from other sources.

NISTRR 65 I] (Economic Study). March 2001, Maryann P. Feldman (Johns Hookins) and Marvelien R. Kelley (NIST/ATP)

\section{Policy Analysis Studies}

Can Policy Influence University Entrepreneurship?

This study presents a framework that links four strands of literature analyzing innovative activity at the level of the firm, region, and individual, and associated public policy, to explain why public policy might influence university scientists to decide to start a new firm and enter into entrepreneurship. Because no large-scale data set exists that explicitly links public policy to decision making of university scientists who become entrepreneurs, a case study methodology is adopted. Interviews are conducted with a broad spectrum of scientists who have become entrepreneurs, and with program officials involved with devising and implementing regional entrepreneurship policies. The main conclusion is that there is significant evidence that the public policy impact on innovation extends beyond the firm. Public policy can influence how university scientists and other knowledge workers reach the decision to commercialize their research by starting a new firm and entering into entrepreneurship. This suggests that public policies like public-private partnership programs, including the Advanced Technology Program and Small Business Investment Research program, can heip enhance and augment the entrepreneurship capital of regions.

NIST GCR 06-890 /Palicy Studyl. David B. Audretsch ane Doje Koyalar-Erdem, November 2006.

Understanding Private-Sector Decision Making for Early-Stage Technology Development, A "Between Invention and Innovation Project" Report. Financial market failures create obstacles to the commercialization of science-based innovations originating from inventors and technology entrepreneurs. Studies of this topic have tended to focus on the particular challenges associated with bringing new ideas to market through the creation of a new firm. Start-up firms are particularly appropriate vehicles for more radical innovations. But what about radical innovations that fall within the business strategy of larger firms?

Large firms have real difficulty creating radical innovations outside their core areas of business. This report shows that large firms may experience similar failures when trying to exploit high-technology innovations directly in their core area-called "in-core" innovations. Research indicates the following:

- Obstacles to radical in-core innovations are not market failures, but institutional ones. 
- Barriers to radical business innovations may include incompatibility of the new product with existing production processes, the need for a radical change in the business model, lack of familiarity with key technical knowledge by the product development teams, and concern about killing off existing products made obsolete by the radical, in-core innovation.

- Despite obstacles, corporate support for early-stage technology development (ESTD) is estimated to be as much as $\$ 13.2$ billion or 7.3 percent of $\$ 180.4$ billion invested in R\&D by U.S. industrial firms in 2000.

- ESTD investments are essential to sustaining longterm economic growth, and corporate funds may represent the most significant source of funding for U.S. ESTD activities.

The report is based on research and analysis performed by Booz Allen Hamilton, which conducted 39 detailed interviews with senior executives and investors from 31 large corporations across 8 industry sectors, and 8 venture capital firms.

NIST GCR 02-841A. September 2005. Philip E. Auerswald, Lewis M. Branscomb. Nicholos Demos, and Brian K. Min.

Evaluation Best Practices and Results: The Advanced Technology Program. ATP's evaluation efforts were instituted to meet external requests for ATP program results; to use evaluation as a management tool to meet program goals and improve program effectiveness; to understand ATP'S contributions to the U.S. innovation system; and to develop innovative methodologies to measure impact of the public R\&D investment. The program's economists track progress of ATP projects throughout project life and post-project using a variety of tools including surveys, data compilation, statistical analyses, economic studies, and studies by outside consultants and research economists. The authors describe the evolution of ATP's evaluation activities, its evaluation best practices based on ATP's experience since 1990, and findings from ATP studies. NISTRR 7174 (Policy Analysis Studies). May 2005, Stephanie Shipp. Connie Chang, and Lorel Wisniewsit.

\section{Understanding Private-Sector Decision Making} for Early-Stage Technology Development. This report examines trends in management of corporate R\&D and how new market realities affect the ways that corporations manage and support early-stage technology development (ESTD) activities. It is based on interviews with senior executives and investors from corporations across eight industry sectors and eight venture capital firms. Of $\$ 181$ billion invested in R\&D activities by U.S. firms in 2000 , onty
$\$ 13$ billion funded the types of ESTD activities that target delivery of radical innovations to market. Variations found across industries are shaped by forces such as the increasing sophistication required to develop new technological innovations, the increasing pressure on corporate R\&D divisions to demonstrate $\mathrm{ROI}$, and the importance of the lifecycle position of specific industries and individual companies.

NIST GCR-02-841B (Special Issues Study). September 2003. Nicholas Demos (Booz Alien Hamilton), Philip E. Auerswaid, Lewis M. Branscomb, and Brian K. Min (Harvord University).

Bridging From Project Case Study to Portfolio Analysis in a Public R\&D Program: A Framework for Evaluation and Introduction to a Composite Performance Rating System. This paper presents a framework for evaluating both individual projects and a portfolio of projects in the "mid term"-3-5 years after project completion. It introduces a prototype evaluation tool, the Composite Performance Rating System (CPRS), designed for ATP but adaptable to other programs. CPRS uses uniformly collected indicator metrics to rate each of ATP's completed projects in what was added to the national scientific and technical knowledge base, the knowledge it disseminated, and the technology commercialized into new products or processes. The indicator metrics compute star ratings (0 to 4 stars) to provide a quantitative assessment of the first 50 completed projects in the ATP portfolio: 16 percent received 4 stars; 26 percent received 3 stars; 34 percent received 2 stars; and 24 percent received 0 or 1 star. NIST-GCR 03-851 (Special lssues Study). August 2003. Rosulie Ruegg (TIA Consulting, Inc).

\section{A Toolkit for Evaluating Public R\&D Investment:} Models, Methods, and Findings from ATP's First Decade. This comprehensive report uses the large body of evaluation techniques and 45 selected studies developed by ATP during its first decade to provide an evaluation framework-a directory of methods, tools, techniques, principles, explanatory information, and best practices. These tools and techniques develop the body of knowledge about the behavior of participating companies, the degree of collaboration, spillover effects, interfaces with state and international technology programs, ATP's performance at large, and knowledge about evaluation itself. A cross-cutting look at study findings confirmed results from individual studies indicating that ATP is achieving its overarching objectives, leading to broadly distributed economic benefits:

- Findings on private firms' effects, drawn from 13 studies, indicate that ATP substantially expanded and enhanced the R\&D activities of the companies examined and that the ATP funds complemented private R\&D funds.
- A recurring finding from 10 studies showed high rates of collaboration within ATP projects, including joint ventures and single company projects. Of the first 50 completed projects, 84 percent showed a broad range of collaborative activities.

- Findings from 10 studies provided evidence that ATP projects generated outputs-in the forms of publications, patents, patent citations, collaborative linkages, and products-that will potentially lead to knowledge and market spillovers.

- Thirteen studies collectively attributed to ATP more than $\$ 15$ billion in expected present value of social benefits from just a few projects, much greater than the total amount spent to date by the program.

NiST GCR 03-857 (Special Issues 5tudy). July 2003, Rosalie Ruegg (TIA Consulting, inc) and irwin Felier (AAAS and Atennsylvania State University).

Between Invention and Innovation: An Analysis of Funding for Early-Stage Technology Development. This study addresses the distribution of funding for early-stage technology development across different institutional categories and compares government programs with private sources in terms of magnitude. The study also looks at the difficulties that firms face when attempting to find funding for early-stage, high-risk R\&D projects. To arrive at a reasonable estimate of the national investment in early-stage technology development, the authors relied on the observations of practitioners that were gathered during a series of workshops held in the United States. They afso collected data available on early-stage technology development investments from other studies and from public statistical sources. Findings include:

- Most funding for technology development in the phase between invention and innovation heralds from individual angel investors, corporations, and the federal government-not from venture capitalists.

- Markets for allocating risk capital to early-stage ventures are not efficient. According to the authors, federal technology development funds complement. rather than substitute for, private funds.

NIST GCR 02-84) (Special lssues Study). November 2002. Lewis.M. Branscomb and Philip E. Auerswaid (Harvand University). 


\section{Case Studies}

Benefit-Cost Analysis of a Cluster of ATP-Funded

Green Technologies. Preliminary results from a study of a cluster of ATP-funded green technology projects show substantial energy savings and considerable progress in overcoming barriers to technology development and successful commercialization. These projects are among approximately 40 ATP projects directed toward conservation of fossil energy resources through reduced use of fossil energy in buildings, industrial production, and transportation. with a total ATP investment of more than $\$ 110$ million. In-depth case studies quantify economic benefits and assess sustainability benefits from two ATP-funded green technology projects that have progressed to commercialization:

- The Renewable Resource-Based Plastics Manufacturing project, which developed an innovative process technology that uses U.S. grown corn as feedstock for polylactic acid in plastics manufacturing, replacing the use of petroleum-based feedstock.

- The High-Speed Identification and Sorting of Nonferrous Metal Scrap project, which increased recycling rates for valuable nonferrous alloy scrap (titanium, superalloys, and aluminum), and thereby decreased the cost of producing these nonferrous metal alloys.

Quantifiable economic benefits (both realized and projected) to U.S. industry and end users are estimated at more than $\$ 10$ for every $\$ 1$ of AIP's investment for both of these green technology projects.

NIST GCR 06-897. January 2007. Thomas M. Pelsoci [Deita Research Companyl.

Benefit-Cost Analysis of a Cluster of ATP-Funded DNA Chip Technologies. From 1994 through 2001. ATP's funding of Tools for DNA Diagnostics provided nearly $\$ 140$ million in cost-shared funds to 42 projects for R\&D to biotechnology firms that could not otherwise secure funding for their high-risk technology ventures. Most were start-up companies. These firms developed much of the technology infrastructure for the genomics revolution. The ATP funding supported a broad platform of knowledge with which to study genetic variations among people, different disease effects on individuals, and the most effective course of treatment for a patient based on personal genetic makeup. In-depth case studies by RTI International of two ATP-funded projects involving DNA-chip technologies and qualitative studies of three related projects aim to quantify early impacts of ATP funding on the genomic revolution for a subset of ATP-funded projects. Preliminary results indicate the following significant areas of impact:

- ATP advanced the state of the art of DNA chips. DNA chips now enable medical research that previously would have taken months or years, or possibly would not have occurred at all.

- ATP accelerated completion of the Human Genome Project. ATP-funded technology was instrumental in producing 30 percent of the finished Human Genome Project, saving federal tax dollars, and helping deliver the final draft of the human genome two years ahead of schedule.

- ATP advanced the analysis of human genetic variation. Analysis of single nucleotide polymorphisms (SNPs)-small variations in the sequence of bases that make up the human genome-allows researchers to understand how genetic differences among people relate to their susceptibility to ailments and the efficacy of potential treatments. ATP-funded technology enabled significant decreases in SNP analysis costs,

- ATP-supported projects deepened scientific knowledge of molecular diagnostic tools and broadened their availability.

NIST GCR 06-898 (Case Study). December 2006. RTI Intemational.

\section{Direct and Spillover Effects of ATP-Funded}

Photonics Technologies. In order to evaluate whether ATP's benefits outweigh costs, a relevant factor to examine is ATP's impact compared to what would have happened without ATP's presence. This study presents a research methodology that uses a quasi-control group of projects not fundied by ATP that made it to the final selection round in the same technology area, paired to a set of projects funded by ATP in the same technology area. Through a cluster of four case studies in photonics, the two awardees. from 1991 and 1994, are compared with the two ATP proposal semifinalists from the same competition years. The authors estimate ATP's incremental impact by exploring the following seven factors: 1) determining whether ATP projects advanced scientific and technical knowledge; 2) determining whether they increased the economic and competitive performance of U.S. companies; 3) determining whether they generated net spillover benefits to the broader economy; 4) determining whether ATP succeeded in identifying high-spillover projects in the context of the need for ATP; 5) examining how to improve case-study methods to better capture both market and knowledige spillovers; 6) identifying the principal market spillover mechanisms and the market and technological factors that promote larger spillovers; and 7) examining how to improve the methodologies for estimating the value of displaced technologies. Findings from the study include the following:

- Although ATP awards are small in funding amount, the federal public policy portfolio combined has succeeded in increasing U.S, national competitiveness and market share in microdisplays.

- ATP awardees have significantly higher publication and citation rates than nonawardees.

- Patents are a noisy, weak indicator of actual knowledge spillovers, while corporate publication citations provide a cleaner measure of true information flows.

NIST GCR 06-893 (Cose Study). October 2006 Todd A. Watkins and Theodore W. Schlie.

Performance of Second 50 Completed ATP Projects, Status Report No. 3. and Performance of Third 50 Completed ATP Projects, Status Report

No. 4. These reports assess the second 50 and third 50 ATP completed projects. The performance metrics show how each of the individual projects performed in terms of new technical knowledge created and disseminated, direct commercialization of new technologies, and overall project effectiveness. These reports comprise one element of ATP's evaluation program, providing a systematic and comprehensive look at a large group of AIP projects, and shedding light on the performance of the program at large. At each report's core are 50 mini-case studies covering the completed projects and investigating the performance of the projects several years after completion. In addition, an overview provides aggregate descriptive statistics showing knowledge creation/dissemination and progress toward commercial goals. These components are used to construct a composite performance score to indicate overall project effectiveness. The result is a four-star system of ratings, with scores ranging from zero to four stars. For a group of top-rated, four-star projects, the overview examines estimates of partial net benefits and considers their implications for the overall success of ATP to date. It aiso provides summary examples of strong three-star projects. Because technology development and commercialization take time and are characterized by unexpected breakthroughs and failures, future updates of these projects may aiter the findings reported here. NIST SP 950-3 (Cose Study), January 2006. Advanced Technology Program. NIST SP 950-4 (Case Study). September 2006. Advanced Technology Program. 
Toward a Standard Benefit-Cost Methodology for Publicly Funded Science and Technology Programs. The ATP's Economic Assessment Office seeks to develop a standard methodology for undertaking benefit-cost studies of science and technology projects for purposes of quantifying federal program impacts. A key objective is to facilitate the comparability and aggregation among benefit-cost studies of individual projects. This report examines the similarities and differences among ATP's benefitcost studies performed to date in order to identify methodological steps that can be taken to facilitate consistency and comparability across studies and aggregation of results of studies performed at different times.

Analysis of the published studies of approximately 30 projects revealed a great many similarities; for example, use of cash-flow analysis techniques consistent with public finance literature and good practice in both public and private investment analysis, computation of the same basic metrics (net present value, benefit-cost ratio, and internal rate of return), and consistency with the guidelines published in OMB Circular A-94.

The analysis identified and explored four sources of inconsistency in past ATP studies that impede the use of study results, especially for aggregation purposes. These include the following: the timing of the studies relative to the timing of ATP funding and the project life cycle, identification of the specific counterfactual to the AIP funding and the relative attribution to ATP in cases where there are multiple sources of funding. the choice of metrics to use (social return metrics or just the public return on ATP's investment), and the problem of different base years and different constant dollar years.

NISIRR 7319 (Cose Study). June 2006 . Jeanne Powell.
Bridging from Project Case Study to Portfolio Analysis in a Public R\&D Program: A Framework for Evaluation and Introduction to a Composite Performance Rating System. This paper presents a framework, rooted in case-study method, for evaluating both individual projects and a portfolio of projects. A prototype evaluation tool is introduced that offers new capabilities for the evaluation of public research and development programs in the intermediate period before long-run effects can be measured. The prototype evaluation tool, the Composite Performance Rating System (CPRS). designed for ATP, is also adaptable to other programs. CPRS uses uniformly collected output and outcome data to compute overall performance ratings for each of ATP's completed projects, using a four-star system. The distribution of ratings provides an easy-to-grasp measure of the overall portfolio's performance. This evaluation framework can be used by program administrators taking a top-down approach, project managers taking a bottom-up approach, and policymakers and other stakeholders interested in program results.

NIST GCR 06-891 (Cose Study). April 2006. Rosalic Rueg9?

Photonics Technologies: Applications in Petroleum Refining, Building Controls, Emergency Medicine, and Industrial Materials Analysis. ATP has provided cost-shared funding to more than 120 photonics projects since 1991. To assess the economic benefits from a portion of these projects, the author adopted a cluster study approach to combine the methodological advantages of detailed case studies and of higher-level overview studies. The following five projects were selected for analysis: Capillary Optics for X-Ray focusing and Collimating: MEMS-Based Infrared Micro-Sensor for Gas Detection; Infrared Cavity Ring-Down Spectroscopy: Optical Maximum Entropy Verification; and Integrated Micro-Optical Systems. Findings from the study indicate the following:

- U.S. industry, consumers, and the nation will enjoy at least $\$ 33$ of benefits for every dollar of ATP's $\$ 7.47$ million investment in the cluster of five projects.

- To date, $\$ 1.90$ of benefits have been realized for every dollar of ATP's investment in the five projects.

NIST GCR 05-879 (Case Study). September 2005. Thomas M Pelsoci.
Composites Manufacturing Technologies: Applications in Automotive, Petroleum, and Civil Infrastructure Industries, Economic Study of a Cluster of ATP-Funded Projects. Composite materials are strong, lightweight, and corrosion resistant, as well as expensive to manufacture and not widely used in large-scale industrial applications. In 1994, AIP undertook a program focused on composites manufacturing in order to trigger the creation of high-performance manufacturing infrastructure for commercial composite parts. From 1994 to 2000, ATP invested \$43 million, along with industry partners who invested \$39 million, in 22 high-risk projects. To assess the economic and societal benefits from ATP-funded projects for composites manufacturing, a cluster-study approach was used to combine the methodological advantages of detailed case studies and higher-level overview studies. Five projects were selected for analysis, spanning automotive, offshore oil production, and civil infrastructure applications. Within the cluster of five projects, two projects with the best near-term prospects for commercial deployment were selected for detailed case studies. The cluster study estimates exceptional returns on ATP's investment in five composites manufacturing projects:

- Benefit-to-cost ratios on ATP's investment ranging from $83: 1$ to $92: 1$.

- Net present value of ATP's investment ranging from $\$ 892$ to $\$ 994$ million.

- Public rates of return on ATP's investment ranging from 44 to 46 percent.

These measures reflect the estimated benefits to industry users and the general public relative to the ATP investment. Estimated benefits to direct recipients of ATP funding are excluded. Additional qualitative benefits are reported, including automotive quality improvements, energy production benefits, reduced harmful environmental emissions, and lower levels of traffic congestion in metropolitan areas. ATP's industry partners would not have developed high-risk, low-cost composites manufacturing technologies without ATP support and facilitation of broad-based industrial joint ventures. NisT GCR 04-863 (Cose Study). June 2004. Thomos M. Petsoei (Delto Research Company). 


\section{Case Studies (cont.)}

Economic Impact of the Advanced Technology Program's HDTV Joint Venture. ATP cost-shared a high-definition television (HDTV) joint venture project in 1995. Led by the Sarnoff Corporation, a research and development firm with broad experience in television technology, the nine-firm joint venture team investigated new approaches to creating and operating digital studios. Technical innovations from the project reduced the cost of conversion to digital television broadcasting for most TV stations and hastened the introduction of new digital studio technologies. Innovations included a system for processing compressed digital television signals and a new technology that enables more efficient operation of digital television transmitters. The technologies were commercialized by the joint venture members, and are used by TV stations around the country. Two key outcomes include the AgileVision system and integrated video server and compressed bit-stream switcher for broadcast operations; and digital adaptive precorrection (DAP). which prevents digital broadcast signals from bleeding over into adjacent channeis. Results of the combined public and private investment include the following:

- Net present value (NPV) of the net benefits (1995 as base year and real 2002 dollars): $\$ 126$ million to $\$ 205$ million.

- Social rate of return: 24.9 to 28.6

- Benefit-to-cost ratio: 3.5 to 5.0 .

NIST GCR 03-859 (Cose Study), January 2004. William L. White and Alan O'Connor (RT).
Low-Cost Manufacturing Process Technology for Amorphous Silicon Detectors: Applications in Digital Mammography and Radiography. This case study examines the 1995-2000 ATP-supported joint venture involving General Electric Global Research and PerkinElmer, Inc., to develop a low-cost manufacturing process for fabricating amorphous silicon detector paneis used in digital mammography and digital radiography systems. The GE Medical Systems Senographe* 2000 D system resulted from the ATP-funded project. This unit has proven to issue 20 percent fewer false positive results and therefore requires fewer patient recalls than conventional systems. Each unit is associated with $\$ 63,360$ in medical savings per year, and the original $\$ 1.575$ million ATP investment has resulted in technology estimated to be worth \$219-\$339 million. (2002) dollars in benefits to health care industry users and patients.

NIST GCR 03-944 (Cose Study). Fetruary 2003. Thomos M. Atsisoci (Deita Research Compony).

\section{Benefits and Costs of ATP Investments in} Component-8ased Software. From 1994 to 2000 , ATP provided $\$ 42$ million to support 24 projects under its focused program in Component-Based Software for building large software systems by assembling readily available components. This study assesses the impact of the ATP-supported projects using quantitative and qualitative analyses. Results show that two-thirds of the funded projects achieved their technical objectives. Viewed as an investment portfolio, the 24 projects delivered social returns exceeding reasonable benchmarks for public or private investment. The authors calculate a net present value of $\$ 840$ million and benefit-to-cost ratio of 10.5, suggesting that the expenditure of public funds was worthwhile.

GCR 02-834 (Cose Study). November 2002. William White and Michoel P. Golliaher (RTII.
Determinants of Success in ATP-Funded R\&D Joint Ventures: A Preliminary Analysis Based on 18 Automobile Manufacturing Projects. This study explores the growing importance of collaborative ventures to the nation's economic strength, the factors that make them work, and the role of government in fostering collaboration. The focus is on 18 ATP-funded automotive industry joint ventures initiated between 1991 and 1997 . Factors in success include trust, information sharing, an optimal number of participants, companies with complementary skills, personnel stability, cost containment, and a high level of company commitment. Findings suggest that ATP provides funding at eritical stages, accelerates research, improves outcomes, and encourages partners to take on higher risk and longer-term research. ATP also helps joint ventures to overcome batriers to collaboration and helps projects run more smoothity, albeit with some loss of flexibility on the part of the companies.

NIST 6CR 00-8003 (Cose StudyL. December 2001. Jeffrey H. Dyer (BYU) and Benjamin C. Powell (University of Pennsyivanial.

Closed-Cycle Air Refrigeration Technology for Cross-Cutting Applications in Food Processing, Volatile Organic Compound Recovery, and Liquid Natural Gas Industries. ATP co-funded a 1995 joint venture to design, fabricate, and pilot test closedcycle air refrigeration (CCAR), a new industrial technology that uses environmentally benign air as the working fluid. Market analyses showed the U.S. food processing industry to be a promising end market, where ultra-cold temperatures $\left(-70^{\circ} \mathrm{F}\right.$ to $\left.-150^{\circ} \mathrm{F}\right)$ help to improve food safety and reduce weight loss, dehydration from evaporation, and environmental emissions, Against a \$2.1 million ATP investment and $\$ 2.2$ million in corporate funds, the project has a net present value of $\$ 459-\$ 585$ million (2001 dollars), an internal rate of return of 83-90 percent, and a benefit-to-cost ratio of 220:1 to 280:1. The study concludes that CCAR technology would not have been developed without ATP funding. NIST GCR 01-819 (Case Study). December 2001. Thamas Peisoci [Data Research Company]. 


\section{Working Papers}

Factors Affecting U.S. Production Decisions: Why are There No Volume Lithium-lon Battery

Manufacturers in the United States? In the area of advanced rechargeable batteries and other areas as well, ATP has funded projects that were technically successful, but where the outiook for U.S, companies becoming major commercial players in high-volume applications is not promising at present. This study uses the case of lithium-ion batteries to seek a better understanding of industry factors that affect the introduction of new rechargeable batteries and similar types of technologies into the marketplace. Some findings from the report include the following:

- U.S. battery companies "opted out" of volume manufacturing of lithium-ion batteries, primarily because of a low return on investment compared with existina business, the significant time and investment required from conception through commercialization, and the time and expense required to establish a sales organization in Japan to access product design opportunities and take advantage of them

- Structural differences of the Japanese electronics products industry compared to its U.S. counterpart create barriers for U.S. firms seeking to market rechargeable batteries or battery materials in Japan. In markets for rechargeabie batteries. customers are large, high-technology electronics companies with their own battery manufacturing capability.

- The tendency could be for technological deveiopment to follow manufacturing to East Asia, as a natural consequence of developing manufacturing expertise.

ATP Working Poper Series. Working Paper 05-01. June 2005. Rolph 1. Brodd,
Catalyzing the Genomics Revolution: ATP's Tools for DNA Diagnostics Focused Program. The Human Genome Project began in 1990 as a multi-agency effort in the federal government that sought to determine the complete sequence of the DNA in the human genome by 2006. ATP participated in this effort with its Tools for DNA Diagnostics Focused Program, with competitions in 1994, 1995, and 1998; it also funded DNA tools projects in general/open competitions. Through 2002, ATP had committed more than $\$ 138$ million to cooperatively fund 42 R\&D projects on DNA tools. This working paper summarizes ATP's contributions to the field of DNA research, which include many innovative technologies along with the intellectual property portfolios of ATP-participating companies that have benefited an emerging industrial sector: ATP Working Popers Series 04-0t. July 2004.

A Study of the Management of Intellectual Property in ATP-Awarded Firms. Based on six case studies developed from interviews of ATP project participants, this paper examines the behavior of firms proposing research projects to ATP and whether such firms select research that minimizes the likelihood that other firms might benefit from resulting intellectual property. The six case studies represent two technology areas, and include single company projects and joint ventures. The findings suggest that intellectual property concerns do not affect the research that singie-company applicants propose but do affect a company's decision to apply as a singlecompany applicant or joint venture. The findings also show that when firms apply as joint ventures, they may pursue strategies for maintaining control of their intellectual property so that diffusion is minimized. ATP Working Pupers Series 00-01. August 2003. Julia Porter Liebeskind (University of Southern Colifornia).

\section{Brochures}

A Profile of ATP Manufacturing Investments, Inspiring Innovations in Industry. There are risks to pursuing early-stage manufacturing technology development, although a body of evidence suggests that in terms of innovation in manufacturing, the returns to the nation far exceed the costs. This brochure highlights a few recent manufacturing projects that received ATP awards.

Brochure. February 2005.

Beyond Measure, A Profile of ATP Health Care Investments. One-fourth of ATP's investments are in health care, and some of the era's most important health advances-DNA diagnostic tools, telemedicine. and tissue engineering, among others-trace their origins to young companies that opened frontiers with ATP funding. These breakthroughs and others are illustrated in projects described in this brochure. Brochure. Auqust 2003

Powering Our High-Speed Economy, A Profile of ATP Energy Investments. At a time when people are using more cell phones, PDAs, digital cameras, and laptop computers, ATP has supported new ways in which the United States can utilize electricity and communicate, by developing breakthrough technologies for fuels cells, solar cells, and batteries. ATP was the first, large government program to fund blackout-free distributed-generation technologies, such as fuel cells, that can power residences and businesses and provide improved backup power for telecommunications. Several projects that are described in the brochure tell of these energy accomplishments.

Brochure August 2003 


\section{Survey Data Results}

\section{Determinants of Success in R\&D Alliances.}

Innovation is often the consequence of bridging ideas from different knowledge reaims, and firms increasingly enter into R\&D alliances with other firms to combine complementary knowledge in the pursuit of innovative technologies. This study examines the determinants of success in R\&D alliances by looking at alliance structure characteristics (such as the number and type of partners), and firm-level attributes (such as prior alliance experience and existing $R \& D$ capabilities). These factors are thought to influence the alliance partners' ability to exchange knowledge and collaborate in R\&D, in turn influencing their ability to produce innovations. This study uses a unique survey dataset that includes 397 firms in 142 R\&D alliances that received funding from ATP. Empirical analysis produced some of the following conclusions:

- Alliance designers are largely successful in choosing the optimal structure in terms of number and type of alliance partners.

- Effective contractual provisions and governance arrangements for alliance management have a positive effect on alliance success in terms of delivering overall value and generating patent applications.

- Frequency of communication has a strong positive effect on three measures of R\&D alliance performance-the perceptual measure of overall value, the patent application measure, and the financial value from commercialization.

NISTIR 7323 (Survey Dato Resuits). August 2006. Jeffrey H. Dyer, Benjamin C. Powell, Mariko Sokakibaru, and Andrew Wang.
Findings from the Advanced Technology Program's Survey of Joint Ventures. The ATP conducted a survey of all joint ventures that received an ATP award between 1991 and 2001. The ATP funds both single-applicant companies and joint ventures, which must have at least two for-profit companies, but can also include universities, other companies, and nonprofit research organizations. The survey was conducted to understand the motivations and impacts of joint-venture collaborations. The findings reveal the following:

- The most important motivation for participants to form a joint venture was to benefit from the complementary R\&D expertise of their partners.

- Most joint ventures would not have been formed without the ATP award.

- The majority of respondents indicated that the joint venture undertook research that represented a new direction for both the company and the industry.

- ATP joint ventures are more ambitious than other research in their industry and more technically challenging than typical company projects.

- About one-third of all joint-venture participants reported that their ATP projects are based on university research, with more than half of the largest joint-venture participants (in terms of number of partners) reporting that their research is based on university research.

- The joint-venture partners reported that the exchange of technical know-how was critical in achieving research success.

NIST GCR 06-889 (Survey Dato Resuits). Juiy 2006. Jennifet O'Brien, Andrew Wang, Stephanie Shipp, and Kathieen McTigue.

Survey of ATP Applicants, 2002. (Note: The survey includes 6 fact sheets on customer satisfaction and time and cost for proposal preparation; 10 fact sheets on Funding Sources for Innovative R\&D, What Happens to Nonfunded Projects?, ATP Helps Companies Work With Universities, and 7 other topics)

This survey was administered to all applicants in the 2002 competition year in order to compare the company and project characteristics of awardee and nonawardee companies soon after the awards were announced. It addresses the counterfactual questionwhat happens when a project does not receive ATP funding? The survey results found that 39 percent of those projects were not pursued, and 44 were pursued on a smaller scale. Of those pursued on a smaller scale, more than four out of five reported that their project scope was reduced to below 40 percent of the proposed ATP project. Proposed ATP projects for both awardees and nonawardees are higher risk and have a longer time horizon than their typical R\&D projects. ATP awardees reported a greater contrast between their proposed ATP projects and typical R\&D projects, compared to nonawardees. A key finding is that ATP awardees attracted additional funding after submitting their ATP proposal. This phenomenon is referred to as the "halo effect:" Survey responses were obtained from 587 companies, including 129 participants who were awarded funding and 458 participants who did not receive funding. Survey findings are consistent with results from the 2000 survey and confirm the significant impact of ATP.

NIST GCR-05-876 (Survey Data Results). June 2005.

Customer Satisfaction Findings from the Advanced Technology Program's Survey of ATP Applicants 2002. ATP supports innovation in the United States through competitively awarded funding to companies pursuing early-stage, high-risk R\&D. The authors analyzed the characteristics of proposed projects submitted to ATP and the applicant companies, as well as factors that explain award selection, and subsequent funding outcomes of companies. Utilizing several regression methods, their analysis covered proposals submitted for the 2002 competition and for pooled data from 2000 and 2002 competitions based on information collected by the Survey of ATP Applicants 2000 and the Survey of Applicants 2002. Overall, respondents viewed ATP's review and decision process as fair; found ATP processes, information, tools, and materials to be useful; and were satisfied with ATP staff, In general, awardees rated ATP higher on customer satisfaction questions than did nonawardees, although most nonawardees offered favorable ratings as well. Responses to customer satisfaction questions given by both 2000 and 2002 applicants were very similar.

NIST GCR 05-873 (Survey Data Results). February 2005 Jeffrey Kerwin, Andrew Wang, and Stephen Campbell. 